\title{
Stable Silicon Isotopes Uncover a Mineralogical Control on the Benthic Silicon Cycle in the Arctic Barents Sea (EarthArXiv PREPRINT)
}

This manuscript has been submitted for publication in Geochimica et Cosmochimica Acta. Please note that this manuscript has been revised but has yet to be formally accepted for publication. Subsequent versions of this manuscript may have slightly different content. If accepted, the final version of this manuscript will be available via the 'Peer-reviewed Publication DOI' link on the right-hand side of this webpage. It is understood that all persons copying this information will adhere to the terms and constraints invoked by each author's copyright. This work may not be reposted without explicit permission of the copyright owner. Please feel free to contact the corresponding author, we welcome any feedback.

Author for correspondence: James Ward, School of Earth Sciences, University of Bristol (JamesPJ.Ward@bristol.ac.uk) 


\title{
EarthArXiv PREPRINT: Stable Silicon Isotopes Uncover a Mineralogical Control on the Benthic Silicon Cycle in the Arctic Barents Sea
}

\author{
James P. J. Ward ${ }^{1, *}$, Katharine R. Hendry ${ }^{1}$, Sandra Arndt ${ }^{2}$, Johan C. Faust ${ }^{3,7}$, Felipe S. \\ Freitas $^{1}$, Sian F. Henley ${ }^{4}$, Jeffrey W. Krause ${ }^{5,6}$, Christian März ${ }^{7}$, Hong Chin Ng${ }^{1}$, Rebecca \\ A. Pickering ${ }^{8}$, Allyson C. Tessin ${ }^{7}$ \\ ${ }^{1}$ School of Earth Sciences, University of Bristol, Bristol, BS8 1QE, UK \\ ${ }^{2}$ BGeosys, Department of Geosciences, Université libre de Bruxelles, Brussels, CP160/03 1050, Belgium \\ ${ }^{3}$ MARUM - Center for Marine Environmental Sciences, University of Bremen, Bremen, 28359, Germany \\ ${ }^{4}$ School of GeoSciences, The University of Edinburgh, Edinburgh, EH9 3FE, UK \\ ${ }^{5}$ Dauphin Island Sea Lab, Dauphin Island, AL, USA \\ ${ }^{6}$ School of Marine and Environmental Sciences, University of South Alabama, Mobile, AL, USA \\ ${ }^{7}$ School of Earth and Environment, University of Leeds, Leeds, LS2 9JT, UK \\ ${ }^{8}$ Department of Geology, Lund University, Sölvegatan 12223 62, Lund, Sweden \\ Author for correspondence: JamesPJ.Ward@bristol.ac.uk ${ }^{*}$
}

\begin{abstract}
Biogeochemical cycling of silicon ( $\mathrm{Si}$ ) in the Barents Sea is under considerable pressure from physical and chemical changes, including dramatic warming and sea ice retreat, together with a decline in dissolved silicic acid (DSi) concentrations of Atlantic inflow waters since 1990. Moreover, further expansion of the Atlantic realm (termed 'Atlantification') is expected to shift phytoplankton community compositions away from diatom-dominated spring blooms in favour of Atlantic flagellate species. The changes in pelagic primary production will alter the composition of the material comprising the depositional flux, which will subsequently influence the recycling processes at and within the seafloor. In this study we assess the predominant controls on the early diagenetic cycling of $\mathrm{Si}$, a key nutrient in marine ecosystems, by combining stable isotopic analysis $\left(\delta^{30} \mathrm{Si}\right)$ of pore water DSi and of operationally defined reactive pools of the solid phase. We show that low biogenic silica (BSi) contents (0.26-0.52 $\mathrm{wt} \%$ or $92-185 \mu \mathrm{mol} \mathrm{g}$ dry $\mathrm{wt}^{-1}$ ) drive correspondingly low asymptotic concentrations of
\end{abstract}


pore water DSi of $\sim 100 \mu \mathrm{M}$, relative to biosiliceous sediments (>20 wt\% BSi) wherein DSi can reach $\sim 900 \mu \mathrm{M}$. While Barents Sea surface sediments appear almost devoid of BSi, we present evidence for the rapid recycling of bloom derived BSi that generates striking transient peaks in sediment pore water [DSi] of up to $300 \mu \mathrm{M}$, which is a feature that is subject to future shifts in phytoplankton community compositions. Using a simple isotopic mass balance calculation we show that at two of three stations the pore water DSi pool at 0.5 $\mathrm{cm}$ below the seafloor $(+0.96$ to $+1.36 \%)$ is sourced from the mixing of core top waters $(+1.46$ to $+1.69 \%)$ with the dissolution of $\mathrm{BSi}(+0.82$ to $+1.50 \%$ ), supplemented with a lithogenic Si source (LSi) $\left(-0.89 \pm 0.16 \%\right.$ ). Further, our sediment pore water $\delta^{30} \mathrm{Si}$ profiles uncover a coupling of the Si cycle with the redox cycling of isotopically light metal oxides $(-2.88 \pm 0.17 \%$ o $)$. We suggest that a high LSi:BSi ratio and apparent metal oxide influence could lead to a degree of stability in the annual background benthic flux of DSi despite the pressures on pelagic phytoplankton communities. Coupled with supporting isotopic evidence for the precipitation of authigenic clays in Barents Sea sediment cores, our observations have implications for the regional Si budget.

Keywords: Silicon Isotopes, Benthic Flux, Pore Water, Reactive Pools, Sediment Nutrient Cycling

\section{Introduction}

The Barents Sea represents a highly productive gateway that joins the Atlantic and Arctic Oceans. This shelf sea accounts for $\sim 40 \%$ of the total Arctic Ocean primary production, despite occupying just 10\% of the areal extent (Smedsrud et al. (2013); Oziel et al. (2016) and references therein). However, the Barents Sea is at present subject to considerable climatedriven perturbations, including the highest rates of winter sea ice loss (47\% in March from 1979-2018) (Årthun et al., 2012; Smedsrud et al., 2013; Docquier et al., 2020) and surface water warming (Lind et al., 2018) observed across the Arctic Ocean. Much of this sea ice melt and surface water warming is driven by an expansion of the southern Atlantic Water (AW) realm ('Atlantification'), which is separated from the Arctic Water mass (ArW) of the northern Barents Sea by the oceanic polar front (PF) (Årthun, 2011; Oziel et al., 2016) (Fig. 
1). The consequences of these changes are predicted to have significant implications for $\mathrm{CO}_{2}$ uptake in the surface ocean, long term carbon sequestration, deep water formation, nutrient cycling in the pelagic and benthic realms, as well as the balance of marine ecosystems and primary production in the Barents Sea (Oziel et al., 2016; Freitas et al., 2020; Haug et al., 2017; Faust et al., 2021; Lind et al., 2018).

At present, phytoplankton spring blooms of the Arctic Ocean are a cornerstone event that make up a significant proportion of annual primary productivity across the region (Krause et al., 2018). The community composition of spring and early summer blooms is typically dominated by diatoms, a photosynthesising microalgae that uses dissolved silicic acid (DSi) to build frustules of biogenic silica (BSi), commonly termed 'opal' (Krause et al. (2019, 2018); Giesbrecht and Varela (2021); Downes et al. (2021) and references therein). Seawater is undersaturated with respect to the solubility of $\mathrm{BSi}$, which facilitates dissolution as diatoms and other silicifiers die and sink through the water column down to the seafloor following a bloom (Tréguer et al., 1995; Frings, 2017). Crucially, 30\% of this dissolution globally occurs at or just below the sediment-water interface (SWI) during early diagenesis, creating strong concentration gradients between the upper sediment pore and ocean bottom waters (Tréguer et al., 2021). This recycling process drives DSi fluxes back to the water column (Frings, 2017), which is a major component of the ocean Si nutrient cycle and thus has significant implications for the global carbon cycle by sustaining subsequent diatom blooms locally (e.g. shallow systems) or non-locally (through nutrients advected or mixed into the euphotic zone) (Loucaides et al., 2012; Dixit and Van Cappellen, 2003).

In addition to the recycling of diatom-derived BSi, other sources of DSi in marine sediment pore waters include the dissolution of siliceous sponge spicules ( $\mathrm{Ng}$ et al., 2020), radiolarian tests (Maldonado et al., 2019) and lithogenic minerals (LSi) (Geilert et al., 2020; Fabre et al., 2019; Ehlert et al., 2016b). The release of DSi from LSi phases has long been theorised in the North Atlantic to explain the magnitude of benthic recycling fluxes in sediments relatively devoid of BSi (Tréguer et al., 1995; Tréguer and De La Rocha, 2013). This dissolution is driven by North Atlantic bottom water DSi concentrations ([DSi]) ( 10-40 
$\mu \mathrm{M}$ ), which are well below that of many LSi mineral solubilities (Tréguer et al., 1995) (130 $\mu \mathrm{M}, 70 \mu \mathrm{M}$ and $100 \mu \mathrm{M}$ for montmorillonite, kaolinite and quartz in seawater respectively (Mackenzie et al., 1967; Lerman et al., 1975; Schink et al., 1975)). Furthermore, Ng et al. (2020) suggested that an increase in pore water [DSi] in cores of elevated [Fe] from the Greenland shelf was driven by both DSi desorption from Fe (oxyhydr)oxides as they reductively dissolve and through an increase in the solubility of $\mathrm{BSi}$ due to the removal of protective metal oxide coatings. This supports the hypothesis that redox reactions can regulate pore water DSi by influencing BSi dissolution kinetics (Aller, 2014; Ng et al., 2020).

The build-up of pore water DSi from BSi, LSi and metal oxide sources is often curbed by uptake through the precipitation of authigenic clays (AuSi) (Ehlert et al., 2016a; Geilert et al., 2020; Loucaides et al., 2010; Michalopoulos and Aller, 1995). The precipitation of AuSi can operate either through the dissolution of LSi and subsequent coprecipitation of DSi with the liberated dissolved $\mathrm{Al}$, or through a typical reverse weathering pathway whereby BSi reacts with $\mathrm{Al} / \mathrm{Fe}$ (oxyhydr)oxides and major cations present in pore waters (Ehlert et al. (2016a) and references therein). Reverse weathering therefore results in the formation of cation-rich AuSi minerals at the expense of reactive Si phases, such as BSi and degraded clays (equation 9) (Aller, 2014; Frings et al., 2016), representing a significant global ocean sink for elements such as K, Mg, Li, Ge and alkalinity (Sutton et al., 2018; Rahman et al., 2017). It is widely thought that AuSi minerals are common in continental shelf sediments, for example 'green clay' or glauconite, which is a product of BSi weathering (Ehlert et al., 2016a; Loucaides et al., 2010; Aller, 2014). The formation of AuSi represents an important early diagenetic pathway for BSi that can greatly enhance the efficiency of it's preservation (Aller, 2014; Frings et al., 2016; Rahman et al., 2017; Dale et al., 2021).

The balance of DSi release and uptake processes in marine sediments act to modulate the magnitude of benthic fluxes of DSi from Arctic shelf sediments (0.34 $\mathrm{Tmol} \mathrm{yr}^{-1}$ ), which are estimated to be as important for the regional Si budget as circum-Arctic rivers $(\sim 0.4 \mathrm{Tmol}$ $\mathrm{yr}^{-1}$ ) (März et al., 2015). Globally, rivers are estimated to contribute $\sim 55 \%$ of the total $\mathrm{Si}$ input (including dissolved and amorphous Si) to the ocean Si budget (Tréguer et al., 2021). 
However, a 20\% decrease in [DSi] has been observed in Barents Sea Atlantic inflow waters from 1990-2012 (Rey, 2012) and recent evidence suggests a kinetic limitation on diatom growth by surface water [DSi] in blooms off Svalbard (Krause et al., 2018), as well as in the Pacific and Canadian Arctic regions (Giesbrecht and Varela, 2021; Giesbrecht, 2019). This is compatible with the suggestion that a northward expansion of the AW realm will shift phytoplankton communities in favour of Atlantic flagellate species (e.g. Emiliania huxleyi and Phaeocystis), threatening to reduce the depositional flux of BSi to Arctic sediments (Neukermans et al., 2018; Orkney et al., 2020). It is therefore crucial to better understand how sensitive the benthic Si system is to further perturbations, given the pressures the Barents Sea and wider Arctic region face from anthropogenic warming and Atlantification. As a result, recent work has begun to develop a better mechanistic understanding of this subject through measurement of stable Si isotopes (Ehlert et al., 2016a; Geilert et al., 2020; Ng et al., 2020; Cassarino et al., 2020).

The aim of this work is to further develop our understanding of the early diagenetic cycling of $\mathrm{Si}$ in Arctic marine sediments through stable $\mathrm{Si}$ isotopic analysis on pore water DSi and its solid phase sources. We address specific research questions, including: 'What is the magnitude of the benthic DSi flux?', 'What are the sources of pore water DSi near the SWI?', 'Is there evidence of AuSi precipitation or a redox control on the benthic Si system?' and 'What are the key geographic and temporal variations?'.

\section{Materials and methods}

\subsection{Field methods}

During the Changing Arctic Ocean Seafloor (ChAOS) sampling campaign sediment cores were collected from the Barents Sea Opening (B03) and from five stations along a $30^{\circ} \mathrm{E}$ transect between 74 and $81^{\circ} \mathrm{N}$ in the central Barents Sea (B13-B17) over three consecutive years (2017-2019). This sampling was carried out to assess the temporal and spatial dynamics of the benthic Si system (Fig. 1, Table 1). Samples were collected between late June and early August aboard the RRS James Clark Ross (JR16006, JR17007 and JR18006), with 
Table 1: Sampling station information averaged across the three cruises.

\begin{tabular}{ccccc}
\hline Station & $\begin{array}{c}\text { Latitude } \\
\left({ }^{\circ} \mathrm{N}\right)\end{array}$ & $\begin{array}{c}\text { Longitude } \\
\left({ }^{\circ} \mathrm{E}\right)\end{array}$ & $\begin{array}{c}\text { Water } \\
\text { Depth }(\mathrm{m})\end{array}$ & $\begin{array}{c}\text { Bottom Water } \\
\text { Temp }\left({ }^{\circ} \mathrm{C}\right)\end{array}$ \\
\hline $\mathrm{B} 03$ & 72.6342 & 17.9224 & 367 & 3.9 \\
$\mathrm{~B} 13$ & 74.4331 & 29.9532 & 359 & 1.8 \\
$\mathrm{~B} 14$ & 76.5019 & 30.5012 & 295 & 1.9 \\
$\mathrm{~B} 15$ & 78.2192 & 29.9574 & 317 & -1.5 \\
$\mathrm{~B} 16$ & 80.0982 & 30.0257 & 286 & -1.5 \\
$\mathrm{~B} 17$ & 81.2825 & 29.6153 & 337 & 1.8 \\
\hline
\end{tabular}

sampling targeted at sites of similar water depth $(286-367 \mathrm{~m})$ (Table 1). Cruise reports are available, which include all accompanying details and complementary data (Hopkins, 2018; Solan, 2018; Barnes, 2019).

Sampling for sediment and pore water analysis was carried out with a Multicorer from UK National Marine Facilities. This device allowed for sampling of the upper $30-40 \mathrm{~cm}$ of sediment including the overlying core top water and intact SWI. For solid phase sampling, the core tubes were placed onto a manual core extruder and slices were taken with a Perspex plate (sampling resolution of $0.5 \mathrm{~cm}$ intervals from $0-2 \mathrm{~cm}$ below seafloor (cmbsf), $1 \mathrm{~cm}$ from 2 cmbsf), which were then stored at $-20^{\circ} \mathrm{C}$. For the dissolved phase, the overlying core top water was collected first, after which pore water samples were extracted with Rhizon filters attached to $30 \mathrm{~mL}$ plastic syringes, using spacers to create a vacuum (sampling resolution of $1 \mathrm{~cm}$ from $0.5-2.5 \mathrm{cmbsf}, 2 \mathrm{~cm}$ to $20.5 \mathrm{cmbsf}, 5 \mathrm{~cm}$ to $35.5 \mathrm{cmbsf})$. Pore water extractions were carried out at $4^{\circ} \mathrm{C}$ and were stored at the same temperature having been acidified with Romil UpA HCl. At stations B15 and B16 the in-situ temperature was $5.5^{\circ} \mathrm{C}$ colder than the sampling temperature, however pore water extractions were performed immediately after core recovery. Hendry et al. (2019) found that temperature change resulted in a deviation of measured sediment pore water [DSi] from original values, only when sediment cores had been standing at ambient temperature for more than 10 hours prior to pore water extraction. 
For sediment pore water element concentration analysis, pore waters were collected from three separate Multicorer deployments at each station and year (Fig. 2). One of the replicate deployments for each year at B13, B14 and B15 were also sampled for Si isotopic analysis (Fig. 3). These three stations span the three main hydrographic domains of the Barents Sea (AW, PF and ArW) (Fig. 1).

Sediment core incubations were carried out on-board in 2019 at a fixed temperature of $4^{\circ} \mathrm{C}$ to quantify benthic DSi fluxes. Shortly after retrieval, an air-tight cap was sealed over the top of a core tube containing an undisturbed sediment surface and overlying core top water. The cap incorporated a plastic tube where a $60 \mathrm{~mL}$ plastic syringe could be connected for sample collection and a magnetic stirrer attached to the base to gently homogenise the core top water (see Fig. S3 for a schematic). The incubations were run over a 24 hour period, with $50 \mathrm{~mL}$ samples extracted through an Acrodisc filter $(0.2 \mu \mathrm{m})$ at 3 hour intervals. Sediment core incubations are commonly used to measure DSi benthic flux magnitudes (Ragueneau et al., 2002; Hou et al., 2019; Gehlen et al., 1995; Berelson et al., 2003; Srithongouthai et al., 2003) and are considered a more practical solution to in-situ benthic flux chambers (Hammond et al., 2004). Experiments of this nature cannot replicate the in-situ physical conditions, such as bottom water currents, however they are thought to be a better representation of the DSi benthic flux than estimates based on concentration gradient calculations, as processes such as bioturbation and bioirrigation are typically better represented (Cermelj et al., 1997).

\subsection{DSi concentration analysis of pore waters and seawater}

[DSi] analysis of pore water samples, as well as the incubation samples from 2019 (see section 4.1) were carried out on-board using a Lachat QuikChem 8500 flow injection autoanalyser. Internationally certified reference materials for seawater nutrients (KANSO Ltd., Japan) were used to define the accuracy associated with this method, which averaged $2.8 \%$ across the three cruises (1.5-5\%).

\subsection{Solid phase extraction and DSi concentration analysis}

Operationally defined reactive pools of $\mathrm{Si}$ were extracted from the solid phase following Pickering et al. (2020). An additional study was also carried out here to assess the influence 
of oven drying and grinding sediment samples prior to isotopic analysis (see supp. section 2). In summary, oven drying and grinding can significantly alter the isotopic composition of the sediment leachates and measured BSi content. We therefore present data sourced from samples that were frozen after core recovery and gently thawed to room temperature prior to digestion.

This sequential digestion procedure separates $\mathrm{Si}$ into operational pools based on the conditions, kinetics (time dependent) and sequence of the reaction (Pickering et al., 2020; Rahman et al., 2016; Michalopoulos and Aller, 2004; DeMaster, 1981). Reagents were added to 50-70 mg of thawed (dry weight) or dried sediment in the following sequence: $36 \mathrm{~mL}$ $0.1 \mathrm{M} \mathrm{HCl}$ (in-house distilled) for 18 hours at room temperature (Si-HCl pool); $25 \mathrm{~mL} 0.1$ $\mathrm{M} \mathrm{Na}_{2} \mathrm{CO}_{3}$ (Sigma-Aldrich BioXtra) for 5 hours in an $85^{\circ} \mathrm{C}$ water bath (Si-Alk pool); 10 $\mathrm{mL} 4 \mathrm{M} \mathrm{NaOH}$ (Honeywell Fluka Trace SELECT) for 2 hours at $85^{\circ} \mathrm{C}$ ( $\mathrm{Si}-\mathrm{NaOH}$ pool). Predominantly, these sequential extractions are thought to remove authigenic metal oxide coatings, BSi and LSi phases respectively (Michalopoulos and Aller, 2004; Pickering et al., 2020). In addition to the digestion sequence applied by Pickering et al. (2020), here $5 \mathrm{~mL}$ of $10 \% \mathrm{H}_{2} \mathrm{O}_{2}$ (Fisher Chemical Extra Pure SLR) was added to the sediment samples for 30 minutes after the $0.1 \mathrm{M} \mathrm{HCl}$ leach to remove diluting organic phases (Mortlock and Froelich, 1989). After each digestion the supernatants were extracted after centrifugation and filtered through $0.22 \mu \mathrm{m}$ PES syringe filters (Pall Acrodisc). The residual sediment was rinsed in triplicate with Milli-Q water (18.2 $\mathrm{M} \Omega$ ) to remove any remaining reagent.

The use of $\mathrm{Na}_{2} \mathrm{CO}_{3}$ to remove $\mathrm{BSi}$ relies on the difference between rapid, nonlinear dissolution of BSi and the slower, linear dissolution of LSi (DeMaster, 1981). The traditional intercept method was employed for BSi concentration analysis, whereby aliquots of $\mathrm{Na}_{2} \mathrm{CO}_{3}$ are extracted at 2, 3 and $5 \mathrm{hr}$ intervals over the course of the digestion. The [DSi] of the aliquots were plotted as a function of time and the extrapolated intercept of a linear regression was taken as the sediment sample BSi content (DeMaster, 1981) (Fig. S4). It is known that the intercept method encapsulates some degree of contamination from LSi dissolution. For example, Barão et al. (2015) have shown that non-biogenic phases can be released into the 
$\mathrm{Na}_{2} \mathrm{CO}_{3}$ solution within the initial non-linear phase of the digestion. Ragueneau and Tréguer (1994) estimate that this interference represents $\sim 15 \%$ of the BSi content calculated from the intercept of the linear regression. In order to minimise LSi contamination for isotopic analysis of the BSi phase, digestion experiments were ceased at 20 minutes by neutralisation with in-house distilled $\mathrm{HCl}$ (Pickering et al., 2020). The [DSi] in the 20 minute $\mathrm{Na}_{2} \mathrm{CO}_{3}$ extractions were all found to be below the linear regression intercept, thus contamination from LSi is thought to be minimal (Fig. S4). Corrections for LSi interference following Kamatani and Oku (2000) and Ragueneau et al. (2005) were carried out to confirm this assumption (see supp. section 3). These calculations were found to depend strongly on the inferred $\mathrm{Si} / \mathrm{Al}$ ratio of the LSi phase, however the results suggest a low degree of LSi interference in the 20 minute extraction (1.5-8\%) (Table S1).

After neutralising and separating the 20 minute $\mathrm{Na}_{2} \mathrm{CO}_{3}$ supernatant from the sediment sample centrifuge tubes, $25 \mathrm{~mL}$ of fresh $\mathrm{Na}_{2} \mathrm{CO}_{3}$ was added and the digestion resumed for a further 5 hours according to the traditional approach (DeMaster, 1981), prior to the $\mathrm{NaOH}$ digestion (Pickering et al., 2020).

[DSi] in the leachate samples collected from the sequential digestion experiments were measured chlorometrically by molybdate blue spectrophotometry (Heteropoly Blue Method) (Strickland and Parsons, 1972) on a VWR V-1200 spectrophotometer at the University of Bristol. This method has an analytical precision of $2-3 \%$ (RSD), with a slightly higher average reproducibility of triplicate samples normalised to sediment dry weight of $5.5 \%$ (range 0.09 to $16.4 \%$ ). This external reproducibility is higher as it captures environmental factors, including spatial heterogeneity.

\subsection{Isotopic analysis}

\subsubsection{Sample preparation (DSi co-precipitation and column chemistry)}

Core top and pore water samples were pre-concentrated prior to isotopic analysis by the Mg-induced co-precipitation (MAGIC) method following Karl and Tien (1992) and De Souza et al. (2012). Sample preparation was carried out in a clean setting at the University of Bristol's, Bristol Isotope Group (BIG) laboratory. This method involves the adsorption of Si 
to brucite $\left(\mathrm{Mg}(\mathrm{OH})_{2}\right)$ as it precipitates from seawater, which concentrates the $\mathrm{Si}$ and reduces the cation and anion matrix by up to two orders of magnitude, allowing for the effective use of cation exchange resin columns (De Souza et al., 2012). Brucite precipitation is induced by the addition of $1 \mathrm{M} \mathrm{NaOH}$ (Titripur) to pH-neutral samples in two steps. After both 1 $\mathrm{M} \mathrm{NaOH}$ additions the samples were centrifuged and the supernatant removed. Precipitates were rinsed with $0.001 \mathrm{M} \mathrm{NaOH}$ solution to remove excess ions $\left(\mathrm{Na}^{+}, \mathrm{Cl}^{-}, \mathrm{SO}_{4}{ }^{2-}, \mathrm{Ca}^{2+}\right.$, $\mathrm{K}^{+}$) after the second precipitation cycle (Ng et al., 2020). Samples were dissolved for column chemistry by the addition of $60-200 \mu \mathrm{L}$ in-house distilled $\mathrm{HCl}$ (depending on sample size) and diluted with Milli-Q.

The pre-concentrated sea and pore water samples, solid phase leachates and reference standards were all passed through cation exchange columns, following Georg et al. (2006). Here, a resin (Bio-Rad AG50W-X12) was used for the chromatographic separation of Si from sea water matrix (De Souza et al., 2012). Each sample was loaded onto the columns and eluted with the required volume of Milli-Q to produce a $2 \mathrm{ppm}$ solution. This method retains ambient cations (e.g. $\mathrm{Na}^{+}, \mathrm{Mg}^{2+}, \mathrm{Fe}^{2+}$ ) and does not attract DSi as non-ionic orthosilicic acid $\left(\mathrm{H}_{4} \mathrm{SiO}_{4}\right)$ or the negatively charged species $\mathrm{H}_{3} \mathrm{SiO}_{4}{ }^{-}$, which are in equilibrium at $\mathrm{pH} 2-8$ (Georg et al., 2006). Samples were collected with acid-cleaned Nalgene LDPE bottles and the Si isotopic composition was analysed within 48 hours of column chemistry.

\subsubsection{Mass spectrometry}

Stable Si isotopic compositions were measured on a Finnigan Neptune Plus High Resolution MC-ICP-MS by Thermo Fisher Scientific in the BIG laboratory. Data acquisition was carried out through numerous sessions over two years. Si solutions were transferred from the autosampler via a PFA Savillex C-flow nebuliser $\left(100 \mu \mathrm{l} \mathrm{min}^{-1}\right)$ connected either to a PFA Teflon barrel spray chamber or an Apex IR Desolvating Nebulizer.

Most samples analysed for their $\mathrm{Si}$ isotopic composition were measured in duplicate or triplicate (80 of 123 pore and core top water samples and 39 of 45 sediment leachates) using a standard-sample bracketing technique (De La Rocha, 2002) and were blank corrected. The intensity of ${ }^{28} \mathrm{Si}$ in the $0.1 \mathrm{M} \mathrm{HCl}$ blank was $<1 \%$ of the sample intensity in every analytical 
session. Each standard and sample was doped with $\mathrm{Mg}$ (10 ppm Inorganic Ventures) to further address mass bias and instrumental drift through internal standard normalisation (Cardinal et al., 2003), as well as with $0.001 \mathrm{M} \mathrm{H}_{2} \mathrm{SO}_{4}$ (ROMIL-UpA) and $1 \mathrm{M} \mathrm{HCl}$ to counteract anionic matrix effects $\left(\mathrm{SO}_{4}{ }^{2-}\right.$ and $\mathrm{Cl}^{-}$) (Hughes et al., 2011; Van Den Boorn et al., 2009).

Stable Si isotopic compositions are reported in $\delta^{n} \mathrm{Si}$ notation in units of per mille (\%o) (equation 1), which represents a deviation of the ${ }^{30} \mathrm{Si} /{ }^{28} \mathrm{Si}$ or ${ }^{29} \mathrm{Si} /{ }^{28} \mathrm{Si}$ ratio of the sample relative to the international standard NBS-28.

$$
\delta^{n} S i=\left(\frac{\left({ }^{n} S i /{ }^{28} S i\right)_{\text {sample }}}{\left({ }^{n} S i /{ }^{28} S i\right)_{\text {standard }}}-1\right) \cdot 1000
$$

Data quality was assessed through the correlation between $\delta^{29} \mathrm{Si}$ and $\delta^{30} \mathrm{Si}\left(\mathrm{R}^{2}=0.997\right)$. Isotopic data presented here falls on a mass dependent fractionation line of gradient 0.5119 (Fig. S5), which is in between that expected of mass dependent kinetic (0.5092) and equilibrium (0.518) Si isotope fractionation (Reynolds et al., 2007; Cardinal et al., 2003). Regular analysis of reference standards was carried out in each analytical session to quantify the long-term external reproducibility of sample measurements to 2 standard deviations $(2 \sigma)$. The mean values of standards measured in this study (Diatomite $+1.24 \pm 0.14 \%$ o $(\mathrm{n}=116)$; LMG08 -3.47 $\pm 0.13 \%$ o $(\mathrm{n}=46) ; \mathrm{ALOHA}_{1000}+1.23 \pm 0.17 \%$ ( $\left.\left.\mathrm{n}=30\right)\right)$ agree well with published values (+1.26 $\pm 0.2 \%$ o (Reynolds et al., 2007); -3.43 $\pm 0.15 \%$ o (Hendry et al., 2011; Hendry and Robinson, 2012); $+1.24 \pm 0.2 \%$ (Grasse et al., 2017) respectively) (Fig. S6). Measurement replicate reproducibility $(2 \sigma)$ ranges from 0.01 to $0.30 \%$ or for pore waters, 0.10 to $0.19 \%$ for core top waters and 0.01 to $0.23 \%$ for sediment leachates, averaging $0.11 \%$.

\subsection{Metal concentrations}

The concentrations of a suite of metals $(\mathrm{Al}, \mathrm{Ti}, \mathrm{Fe}, \mathrm{Mn}, \mathrm{Mg}, \mathrm{V})$ were determined in the sediment extraction leachates $\left(0.1 \mathrm{M} \mathrm{HCl}, 0.1 \mathrm{M} \mathrm{Na}_{2} \mathrm{CO}_{3}, 4 \mathrm{M} \mathrm{NaOH}\right)$ by Inductively Coupled Plasma-Optical Emission Spectroscopy (ICP-OES) at the University of Bristol, using an Agilent Technologies 710 (Fig. S2). Analytical performance was assessed throughout the four sessions by periodic measurement of blanks and calibration standards. RSD $(1 \sigma)$ 
ranged from $0.25-12.75 \%$, averaging $2.70 \%$ across repeat standard measurements $(\mathrm{n}=22)$ and all elements analysed.

\subsection{Benthic flux calculations}

The core top water $[\mathrm{DSi}](\mu \mathrm{M})$ of each sample extraction from the incubation experiments was plotted as a function of the ratio of time:core top water height (day $\mathrm{m}^{-1}$ ) (Fig. 4). The gradient of the linear regression represents the flux magnitude $\left(\mathrm{mmol} \mathrm{m}{ }^{-2}\right.$ day $\left.^{-1}\right)$ and the total benthic flux $\left(\mathrm{J}_{t o t}\right)$, as it takes into account molecular diffusion, advection, bioturbation and bioirrigation. This method corrects the rate of DSi release over time for the influence of sample removal at each time interval following Hammond et al. (2004) and Ng et al. (2020). The flux magnitude uncertainties were obtained from the error on the gradient of the linear regression (Fig. 4).

Molecular diffusive fluxes $\left(\mathrm{J}_{\text {diff }}\right)$ were also calculated using Fick's first law of diffusion while assuming a linear [DSi] gradient across the SWI (equation 2-4). A linear gradient assumption uses the [DSi] at $\sim 0 \mathrm{cmbsf}$ (core top water) and the uppermost sediment porewater (0.5 cmbsf). Previous studies have also employed an exponential curve fitting methodology to determine DSi flux magnitudes (Frings, 2017; Ng et al., 2020; McManus et al., 1995). Both methods were compared here (Table 2) and it was deemed that the linear assumption was more appropriate for the Barents Sea stations (please see supp. section 4 for the discussion).

$$
\begin{gathered}
\theta=1-\ln \left(\phi^{2}\right) \\
D_{\text {sed }}=D_{s w} / \theta \\
J_{\text {diff }}=-\phi \cdot D_{\text {sed }} \cdot(d[D S i] / d z)
\end{gathered}
$$

, where $\theta$ represents sediment tortuosity, $\phi$ is porosity in the surface sediment, $D_{\text {sed }}$ is the is the diffusion coefficient of DSi in seawater $\left(D_{s w}\right)$ corrected for tortuosity (Boudreau, 1996) and $d[D S i] / d z$ is the [DSi] gradient across the SWI. $\mathrm{D}_{s w}$, which is dependent on temperature 
(T) and viscosity $(\eta)$, was determined based on an empirical relationship derived from an experimental study (Rebreanu et al., 2008) (equation 5), using bottom water temperatures measured at each station in 2017 (Table 1).

$$
D_{s w}=3.33 \times 10^{-12} \cdot(T / \eta)
$$

where $\mathrm{D}_{s w}$ is in $\mathrm{cm}^{2} \mathrm{~s}^{-1}, \mathrm{~T}$ in kelvin and $\eta$ in poises $\left(\mathrm{g} \mathrm{cm}^{-1} \mathrm{~s}^{-1}\right)$.

\section{Results}

\subsection{Pore water}

\subsubsection{DSi concentration profiles}

Overall, pore water asymptotic and quasi-asymptotic DSi concentrations of the Barents Sea are similar to those of the nearby Norwegian Sea $(\sim 100 \mu \mathrm{M})$ and North Atlantic Ocean (99-230 $\mu \mathrm{M})$ (Ragueneau et al., 2001; Rickert, 2000; Sayles et al., 1996; Schlüter and Sauter, 2000). In general the northern, ArW sites (B15, B16, B17) (Fig. 1) exhibit typical [DSi] asymptotic profiles and are more alike between both the coring events within one cruise and between the three cruise years when compared with the AW stations (B03, B13, B14) (Fig. 2). The AW stations present with quasi-asymptotic profiles, generally showing gradual

increases in [DSi] towards the base of the sediment cores, as well as greater variability in the surface sediment intervals relative to the northern stations. Station B15 exhibits a typical downcore exponential increase in DSi to an asymptotic value of approximately $100 \mu \mathrm{M}$ at 3 cmbsf (Fig. 3), while station B13 also displays a rapid increase in [DSi] in the upper pore waters to a similar concentration as B15, but continues to gradually increase with depth. Station B14 [DSi] profiles are more variable, presenting with striking peaks in 2017 and 2019 of up to $300 \mu \mathrm{M}$ at 2.5-3 cmbsf, also showing a gradual release of DSi towards the base of the sediment cores (Fig. 2 and 3).

\subsubsection{Benthic DSi flux magnitudes}

Diffusive flux $\left(\mathrm{J}_{\text {diff }}\right)$ magnitudes calculated using Fick's first law of diffusion (equation 4) with a two-point linear assumption of the concentration gradient at the SWI of B13, 
B14 and B15 across the cruise years range from +0.05 to $+0.44 \mathrm{mmol} \mathrm{m}^{-2}$ day $^{-1}$ (mean $+0.21 \pm 0.23 \mathrm{mmol} \mathrm{m}{ }^{-2}$ day $\left.^{-1}(2 \sigma, \mathrm{n}=27)\right)$. $\mathrm{J}_{\text {tot }}$ values derived from the 2019 on-board incubation experiments range from $+0.08 \pm 0.06$ to $+0.19 \pm 0.13 \mathrm{mmol} \mathrm{m}^{-2}$ day $^{-1}$ (Fig. 4, Table 2). However, the core incubation temperature $\left(4^{\circ} \mathrm{C}\right)$ differed slightly from that in-situ at most stations. For stations B13 and B14, incubations were $2^{\circ} \mathrm{C}$ too warm and $5.5^{\circ} \mathrm{C}$ too warm at B15 and B16. Temperature change over the course of an incubation can induce a shift in the calculated DSi benthic flux of $6.0 \%{ }^{\circ} \mathrm{C}^{-1}$ due to the additive effects of temperature on molecular diffusion rates and pore water DSi concentrations (Li and Gregory, 1974; Hammond et al., 2004). This observation indicates that core incubation-derived $\mathrm{J}_{\text {tot }}$ estimates could be between 12 and 30\% lower than those presented in Table 2 and Fig. 4.

Both the raw and temperature corrected $\mathrm{J}_{\text {tot }}$ values lie within uncertainty of equivalent Fick's first law derived $\mathrm{J}_{\text {diff }}$ magnitudes and within range of a pan-Arctic review of shelf sediment DSi fluxes $\left(\mathrm{J}_{\text {tot }}\right)\left(-0.03\right.$ to $+6.2 \mathrm{mmol} \mathrm{m}^{-2}$ day $^{-1}$, mean $+0.6 \pm 1.3 \mathrm{mmol} \mathrm{m}^{-2}$ day $^{-1}$, where a negative flux indicates DSi diffusion from bottom waters into the sediment) (Fig. S7) (Bourgeois et al., 2017).

\subsubsection{Isotopic composition of DSi}

$\delta^{30} \mathrm{Si}_{D S i-P W}$ values fall within range of those previously analysed in terrestrial (Opfergelt and Delmelle (2012); Sutton et al. (2018); Frings et al. (2016) and references therein) and marine (Ehlert et al., 2016a; Cassarino et al., 2020; Geilert et al., 2020; Ng et al., 2020) sediment pore waters, ranging from -0.51 to $+1.69( \pm 0.14 \% 02 \sigma)$. Station B13 $\delta^{30} \mathrm{Si}_{D S i-P W}$ ranges from +0.30 to $+1.36 \%$, B14 is the most variable ranging from -0.51 to $+1.69 \%$ o and B15 from +0.53 to $+1.63 \%$. Only two of nine cores were found to have a $\delta^{30} \mathrm{Si}_{D S i-P W}$ composition at the base within error of that at $0.5 \mathrm{cmbsf}$ (B14 and B15 2019), most tend towards isotopically lighter compositions with depth (Fig. 3). The composition of core top waters from $2017\left(\delta^{30} \mathrm{Si}_{D S i-C T}\right)$ are similar across the three sites $(\mathrm{B} 13+1.64 \pm 0.19 \%$ $(\mathrm{n}=5), \mathrm{B} 14+1.46 \pm 0.15 \%$ ( $\mathrm{n}=3), \mathrm{B} 15+1.69 \pm 0.18 \%$ o $(\mathrm{n}=6)) \cdot \delta^{30} \mathrm{Si}_{D S i-C T}$ at B13 is within long term reproducibility of the composition of North Atlantic Waters at 300-400 m depth $(+1.55 \%)$ and B15 presents with a similar composition to that of Arctic deep waters of 
Table 2: Parameters used to calculate the benthic fluxes of DSi through the two-point linear and exponential curve-fitting techniques. Please see supp. section 4 for a discussion on the curve fitting methodology. All values for the diffusive fluxes $\left(\mathrm{J}_{\text {diff }}\right)$ represent a mean of triplicate coring events for each station and cruise year. Porosity $(\phi)$ was determined in the surface interval for JR16 (2017) samples, which was then used as the assumed value for the following years. Uncertainty on $\mathrm{J}_{\text {diff }}$ represents $2 \sigma$ of the triplicate cores for each cruise year. For $\mathrm{J}_{\text {tot }}$ uncertainty is derived from the error on the gradient. ${ }^{*}$ due to a shortage of sample volume, $\mathrm{B} 15 \delta^{30} \mathrm{Si}_{D S i-I n c}$ values represent mixtures of the $0 / 6 \mathrm{hr}$ and $21 / 24 \mathrm{hr}$ extractions.

\begin{tabular}{|c|c|c|c|c|c|c|c|c|c|}
\hline Cruise & 2017 & & & 2018 & & & 2019 & & \\
\hline Station & B13 & B14 & B15 & B13 & B14 & B15 & B13 & B14 & B15 \\
\hline Sampling Date & $17 / 07$ & $30 / 07$ & $20 / 07$ & $14 / 07$ & $25 / 07$ & $17 / 07$ & $07 / 07$ & $13 / 07$ & $10 / 07$ \\
\hline \multicolumn{10}{|l|}{ Fick's First Law } \\
\hline$\phi$ & 0.90 & 0.91 & 0.92 & - & - & - & - & - & - \\
\hline$\theta^{2}$ & 1.21 & 1.19 & 1.17 & - & - & - & - & - & - \\
\hline $\mathrm{D}_{s w} \times 10^{2}\left(\mathrm{~m}^{2} \mathrm{yr}^{-1}\right)$ & 1.51 & 1.51 & 1.49 & - & - & - & - & - & - \\
\hline $\mathrm{D}_{\text {sed }} \times 10^{2}\left(\mathrm{~m}^{2} \mathrm{yr}^{-1}\right)$ & 1.25 & 1.27 & 1.28 & - & - & - & - & - & - \\
\hline \multicolumn{10}{|l|}{ Linear } \\
\hline$\frac{d[D S i]}{d z}\left(\mathrm{mmol} \mathrm{m}^{-3} \mathrm{~m}^{-1}\right)$ & 8400 & 12000 & 5100 & 4800 & 3900 & 3100 & 6900 & 11000 & 4300 \\
\hline$J_{\text {diff }}\left(\mathrm{mmol} \mathrm{m}{ }^{-2}\right.$ day $\left.^{-1}\right)$ & 0.26 & 0.37 & 0.16 & 0.15 & 0.12 & 0.10 & 0.21 & 0.33 & 0.14 \\
\hline $\pm 2 \sigma$ & 0.17 & 0.13 & 0.20 & 0.14 & 0.08 & 0.12 & 0.24 & 0.19 & 0.05 \\
\hline \multicolumn{10}{|l|}{ Exponential } \\
\hline $\mathrm{C}_{S W I}(\mu \mathrm{M})$ & 6.9 & 15.4 & 4.4 & 7.8 & 6.5 & 9.4 & 8.8 & 13.0 & 6.1 \\
\hline $\mathrm{C}_{\text {asymp }}(\mu \mathrm{M})$ & 92 & 123 & 98 & 90 & 102 & 91 & 101 & 162 & 103 \\
\hline$\beta\left(\mathrm{m}^{-1}\right)$ & 130 & 175 & 65 & 78 & 57 & 57 & 115 & 93 & 52 \\
\hline$\frac{d[D S i]}{d z}\left(\mathrm{mmol} \mathrm{m}{ }^{-3} \mathrm{~m}^{-1}\right)$ & 9600 & 17000 & 5700 & 6600 & 5400 & 4700 & 10000 & 14000 & 5100 \\
\hline$J_{\text {diff }}\left(\mathrm{mmol} \mathrm{m}^{-2}\right.$ day $\left.^{-1}\right)$ & 0.30 & 0.54 & 0.18 & 0.20 & 0.17 & 0.15 & 0.31 & 0.44 & 0.16 \\
\hline $\pm 2 \sigma$ & 0.17 & 0.09 & 0.20 & 0.21 & 0.11 & 0.13 & 0.35 & 0.23 & 0.06 \\
\hline \multicolumn{10}{|l|}{ Incubation $\left(\mathbf{J}_{t o t}\right)$} \\
\hline$\frac{d(\mu M D S i)}{d(t / h)}$ & - & - & - & - & - & - & 0.13 & 0.19 & 0.08 \\
\hline$\pm\left(\mathrm{mmol} \mathrm{m}^{-2} \mathrm{day}^{-1}\right)$ & - & - & - & - & - & - & 0.13 & 0.13 & 0.06 \\
\hline$\delta^{30} \mathrm{Si}_{D S i-I n c} 0 h r(\%)$ & - & - & - & - & - & - & 1.49 & 1.70 & - \\
\hline$\delta^{30} \mathrm{Si}_{D S i-I n c} 3 h r(\% 0)$ & - & - & - & - & - & - & 1.58 & 1.69 & $1.86^{*}$ \\
\hline$\delta^{30} \mathrm{Si}_{D S i-I n c} 24 h r(\% 0)$ & - & - & - & - & - & - & 1.71 & 1.89 & $1.88^{*}$ \\
\hline
\end{tabular}


the Beaufort shelf $(+1.84 \pm 0.10 \%$ at the halocline $(125-200 \mathrm{~m}))$ and Canada Basin $(+1.88$ $\pm 0.12 \%$ below $2000 \mathrm{~m}$ ) (De Souza et al., 2012; Varela et al., 2016).

\subsection{Solid phase}

\subsubsection{BSi content}

BSi contents were measured in three sediment depth intervals across the three sites for samples collected in 2019, which ranged from $0.26-0.52 \mathrm{wt} \%\left(92-185 \mu \mathrm{mol} \mathrm{g} \mathrm{dry} \mathrm{wt}^{-1}\right)$ in the surface interval (0-0.5 cmbsf), highest at B14 underneath the PF (Fig. 5A). However, these values appear to be highly susceptible to sample preparation technique, with sediment grinding found to artificially increase BSi content by more than one-third (see supp. section 2 for discussion). The BSi contents analysed here are low relative to the Southern Ocean $(\sim 40 \%)$, but consistent with the North Atlantic mean $(<1 \%)$ (Khalil et al., 2007) and neighbouring Kara $(<1 \mathrm{wt} \%)$ and Norwegian $(<2 \mathrm{wt} \%)$ Seas (Kulikov, 2004; Rickert, 2000). All three cores show a decrease in BSi content with depth to $\sim 0.20 \mathrm{wt} \%$ in the mid-core (Fig. 5A). Analyses have only been carried out on samples from 2019, but it is assumed that sediment composition does not vary considerably on an interannual scale due to the generally low sedimentation rates observed in the Barents Sea since the last glacial period (0.04-2.1 mm $\mathrm{yr}^{-1}$ ) (Faust et al., 2020).

\subsubsection{Isotopic composition of the operational pools}

The composition of the $0.1 \mathrm{M} \mathrm{HCl}$ leach ( $\mathrm{Si}-\mathrm{HCl}$ pool) was isotopically very light for the marine environment, averaging $-2.88 \pm 0.17 \%$ o $(n=20)$, almost identical to the mean value analysed in the same leach phase of Mississippi River plume sediments (-2.89 $\pm 0.45 \%$ ) (Pickering et al., 2020). These values were within long term reproducibility and so indistinguishable across the stations. The $0.1 \mathrm{M} \mathrm{Na}_{2} \mathrm{CO}_{3}$ leach (Si-Alk) composition $\left(\delta^{30} \mathrm{Si}_{S i-A l k}\right)$ was geographically distinct, presenting with values of $+1.43 \pm 0.14 \%$ o $(n=8)$ and $+1.50 \pm 0.19 \%$ $(\mathrm{n}=7)$ at B13 and B14 respectively, but $+0.82 \pm 0.16 \%$ ( $\mathrm{n}=14)$ under ArW conditions at B15 (Fig. 5B). ${ }^{30} \mathrm{Si}_{B S i}$ of suspended particulates collected from the Beaufort Shelf and Canada Basin are isotopically heavier than this and amongst the highest values recorded for surface 
pelagic diatoms $(+2.03$ to $+3.51 \pm 0.10 \%$ ), thought to be driven by the incorporation of sea-ice species into the assemblages (Varela et al., 2016). However, Varela et al. (2016) observed a decrease in $\delta^{30} \mathrm{Si}_{B S i}$ with water depth, with a value of $+1.51 \%$ o $(\mathrm{n}=1)$ measured at $800 \mathrm{~m}$. Furthermore, an average $\delta^{30} \mathrm{Si}_{B S i}$ of $+1.42 \pm 0.95 \%$ o $(\mathrm{n}=26)$ was analysed in samples collected from surface and intermediate water depths (50 to $500 \mathrm{~m}$ ) across the Central Arctic Ocean (CAO) by Liguori et al. (2020). These compositions are consistent with $\delta^{30} \mathrm{Si}_{S i-A l k}$ at stations B13 and B14.

The isotopic composition of surface sample $\mathrm{NaOH}$ leachates $\left(\delta^{30} \mathrm{Si}_{\mathrm{NaOH}}\right)$, a harsh alkaline digestion thought to activate the LSi pool (Pickering et al., 2020), was found to be within uncertainty across the three stations, averaging $-0.89 \pm 0.16 \%$ ( $\mathrm{n}=18)$ and did not vary with sample preparation techniques (supp. section 2). $\delta^{30} \mathrm{Si}_{\mathrm{NaOH}}$ in this study is lower than that measured by Pickering et al. (2020) in the same leachate of coastal Mississippi River plume sediments $(-0.54 \pm 0.15 \%$ o $)$ but is within range of the mean weathered continental crust and global average clay composition (-0.57 $\pm 0.6 \%$, Bayon et al. (2018)).

\section{Discussion}

\subsection{Quantifying the benthic flux of DSi in the Barents Sea}

A recent compilation estimated that the global benthic flux of DSi (comprising both $\mathrm{J}_{\text {diff }}$ calculations and $\mathrm{J}_{t o t}$ from incubation experiments) ranges from -0.03 to $+24.2 \mathrm{mmol}$ $\mathrm{m}^{-2}$ day $^{-1}$ (Ng et al., 2020). Benthic fluxes of DSi emanating from CAO basin sediments are within the lower end of this range $\left(+0.002\right.$ to $+0.035 \mathrm{mmol} \mathrm{m}^{-2}$ day $\left.^{-1}\right)$ (März et al., 2015) and an order of magnitude lower than $\mathrm{J}_{\text {tot }}$ measurements from Arctic shelf sediments (-0.03 to $+6.2 \mathrm{mmol} \mathrm{m}^{-2}$ day $^{-1}$ ) (Bourgeois et al., 2017), but are similar to flux magnitudes estimated for Norwegian Sea sediments $\left(+0.06 \mathrm{mmol} \mathrm{m}^{-2}\right.$ day $^{-1}$ (Rickert, 2000)) and the deep Northwest and Northeast Atlantic $\left(+0.057\right.$ and $+0.16 \mathrm{mmol} \mathrm{m}^{-2}$ day $^{-1}$ respectively $)$ (Sayles et al., 1996; Ragueneau et al., 2001). In this study of the Barents Sea, the $\mathrm{J}_{\text {diff }}$ $\left(+0.05\right.$ to $+0.44 \mathrm{mmol} \mathrm{m}^{-2}$ day $\left.^{-1}\right)$ and $\mathrm{J}_{\text {tot }}\left(+0.08 \pm 0.06\right.$ to $+0.19 \pm 0.13 \mathrm{mmol} \mathrm{m}^{-2}$ day $\left.^{-1}\right)$ approximations of the benthic DSi flux are consistent within uncertainty (Table 2) and are in 
the range of previously published values for pan-Arctic shelf and nearby Svalbard sediments (Bourgeois et al., 2017). Despite the importance of benthic remineralisation for water column nutrient replenishment, the spatial coverage of DSi flux magnitudes is particularly sparse in the European sector of the Arctic Ocean (Fig. S7) (Bourgeois et al., 2017), which is improved by our new estimates.

Previous studies have found no systematic relationship between DSi benthic flux magnitudes and seafloor depth, latitude or temperature, although significant differences were observed with sediment lithology (Frings, 2017; Bourgeois et al., 2017). While there are substantial spatial gaps in available observational data, $88 \%$ of the Arctic seafloor is estimated to be dominated by clay and siliceous mud (Fig. S8) (lithological data from Dutkiewicz et al. (2015)), including the Barents Sea. These lithological groups present with similar global DSi benthic flux magnitudes $\left(+0.36(+0.11\right.$ to +1.29$)$ and $+0.52(+0.08$ to +4.66$) \mathrm{mmol} \mathrm{m}^{-2}$ day $^{-1}$ respectively) (Frings, 2017). Therefore, following März et al. (2015), a multiplication of the calculated flux magnitude by total Arctic shelf area could be deemed a reasonable estimate for the regional contribution of Arctic shelf sediments to the DSi budget.

Our shelf sediment fluxes are an order of magnitude greater than those observed in CAO basins, consistent with the findings of März et al. (2015). If we assume a total Arctic shelf area of $5.03 \times 10^{6} \mathrm{~km}^{2}$ (Jakobsson et al., 2003) we can build upon previous estimates for the regional delivery of DSi from Arctic shelf sediments. With a conservative shelf flux of $+0.05 \mathrm{mmol} \mathrm{m}^{-2}$ day $^{-1}$, the lowest Barents Sea $\mathrm{J}_{\text {diff }}$ among the three stations, a regional

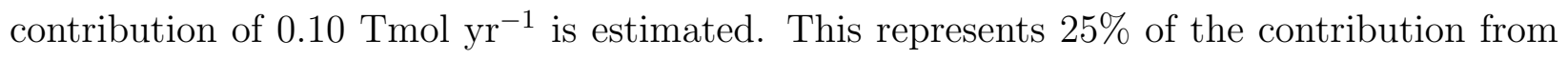
major Arctic rivers (0.4 Tmol $\mathrm{yr}^{-1}$ ) (Holmes et al., 2012). However, if we use the mean diffusive Barents Sea flux of $+0.21 \mathrm{mmol} \mathrm{m}^{-2}$ day $^{-1}$, we calculate a regional value of 0.38 Tmol $\mathrm{yr}^{-1}$. This is comparable to März et al. (2015) and represents $94 \%$ of the riverine DSi flux, potentially 108\% if the pan-Arctic riverine flux calculated by Hawkings et al. (2017) is used $\left(0.35 \mathrm{Tmol} \mathrm{yr}^{-1}\right)$, providing further support for the relative importance of the DSi flux from early diagenetic cycling in Arctic shelf sediments. Furthermore, this regional estimate errs on the side of caution, given that benthic fluxes an order of magnitude greater than 
those observed in this study can be found in the Canadian Archipelago and Beaufort Sea (Fig. S7) (Bourgeois et al., 2017; März et al., 2015).

\subsection{What are the sources of pore water DSi near the SWI?}

Isotopic analysis of incubation core top water samples $\left(\delta^{30} \mathrm{Si}_{D S i-I n c}\right)$ was carried out to determine the source material fuelling the measured fluxes (Fig. 4). Si has three stable isotopes $\left({ }^{28} \mathrm{Si},{ }^{29} \mathrm{Si},{ }^{30} \mathrm{Si}\right)$, which can undergo low temperature kinetic fractionation within the DSi pools of the water column and sediment pore water as $\mathrm{Si}$ is released or removed through biotic and abiotic processes. It is due to this fractionation that $\mathrm{Si}$ isotopes can be used as a tool to trace pathways of the Si cycle. The main process removing DSi from the water column is uptake by diatoms for the formation of $\mathrm{BSi}$, which discriminates against the heavier isotope $\left({ }^{30} \mathrm{Si}\right)$ (Varela et al., 2016), the degree to which is potentially species dependant (Sutton et al., 2013; De La Rocha et al., 1997; Milligan et al., 2004; Sun et al., 2014). However, dissolution of $\mathrm{BSi}$ is thought to either occur without isotopic fractionation, or invoke a slight enrichment in the lighter isotope in the dissolved phase (Demarest et al., 2009; Wetzel et al., 2014; Sun et al., 2014). AuSi forming through kinetic precipitation reactions and sorption of Si onto metal oxides (specifically $\mathrm{Fe}$ (oxyhydr)oxides) on the other hand preferentially uptake the lighter isotope to a similar degree, leaving the residual DSi relatively heavy in composition (Opfergelt and Delmelle, 2012; Hughes et al., 2013; Delstanche et al., 2009; Zheng et al., 2016). An enrichment in the heavier isotope was observed in surface sediments of the Peruvian margin, where reaction transport modelling revealed that DSi was reprecipitating with a fractionation factor $\left({ }^{30} \epsilon\right)$ of $-2 \%$, attributed to AuSi precipitation (Ehlert et al., 2016a).

At stations B13 and B14 we observe an increase in $\delta^{30} \mathrm{Si}_{D S i-I n c}$ between the initial $\left(\delta^{30} \mathrm{Si}_{D S i-I n c} 0 h r\right.$ of +1.49 and $+1.70 \pm 0.14 \%$ respectively $)$ and final $\left(\delta^{30} \mathrm{Si}_{\text {DSi-Inc } 24 h r}\right.$ of +1.71 and $+1.89 \pm 0.14 \%$ respectively) sample measurements, albeit just within long term reproducibility of Diatomite standard measurements $(2 \sigma \pm 0.14 \%$ o $(\mathrm{n}=116))$ (Fig. 4, Table 2 ). There is little change in $\delta^{30} \mathrm{Si}_{D S i-I n c}$ across the incubation at B15, although the two samples analysed are mixtures of $0 / 6 \mathrm{hr}$ and $21 / 24 \mathrm{hr}$ due to inadequate sample volume and so any variation over the time period could be suppressed (Fig. 4, Table 2). Isotopic variation 
over the course of the incubation should reflect the composition of the material dissolving into the pore waters and subsequently being released into the core top water. Therefore, as [DSi] increases, the composition of the core top water should tend closer to the average $\delta^{30} \mathrm{Si}_{D S i-P W}$ measured in the $0.5 \mathrm{cmbsf}$ interval $(1.16 \pm 0.3 \%)$, which likely reflects the isotopic composition of the benthic DSi flux. A simple mass balance calculation (equation 6) shows that the observed increases in $\delta^{30} \mathrm{Si}_{D S i-I n c}$ cannot solely be driven by the dissolution of BSi or LSi, which is supported by the composition of the solid phase reactive pools, as $\delta^{30} \mathrm{Si}_{D S i-I n c} 24 h r$ is higher than $\delta^{30} \mathrm{Si}_{S i-A l k}$ at all stations (Table 2; Table 3). This discrepancy is most apparent at B15 where the difference between $\delta^{30} \mathrm{Si}_{S i-A l k}$ and $\delta^{30} \mathrm{Si}_{D S i-I n c}$ is $>1.0$ $\%$.

$$
\delta^{30} S i_{24 h r}=\delta^{30} S i_{0 h r} \cdot f_{0 h r}+\delta^{30} S i_{B S i} \cdot\left(1-f_{0 h r}\right)
$$

where $f_{0 h r}$ represents the fraction of the initial incubation core top water $\left(\delta^{30} \mathrm{Si}_{0 h r}\right)$ present in the mixture at the end of the core incubation experiment $\left(\delta^{30} \mathrm{Si}_{24 h r}\right)$.

The observed increase in [DSi] across all incubations is not significant enough to have driven the concomitant increase in $\delta^{30} \mathrm{Si}_{D S i-I n c}$, without the presence of a $\mathrm{BSi}$ phase isotopically much heavier than $\delta^{30} \mathrm{Si}_{A l k}$ measured here. Assuming $\delta^{30} \mathrm{Si}_{D S i-I n c} 24 h r$ represents a mixture of $\delta^{30} \mathrm{Si}_{D S i-I n c}$ ohr and the dissolving BSi (or LSi) $\left(\delta^{30} \mathrm{Si}_{B S i}\right)$, we can use the increases in [DSi] across the incubation period to determine the theoretical composition of BSi (equation 6 ). We find that the dissolving phase would require a composition of $+4.5,+2.7$ and $+1.9 \%$ at B13, B14 and B15 respectively. These theoretical compositions are heavier than many $\delta^{30} \mathrm{Si}$ values previously measured in $\mathrm{BSi}(-0.75$ to $+3.0 \%$, mean $+1.11 \%$ (Frings et al., 2016; Sutton et al., 2018; Egan et al., 2012)) and $\delta^{30} \mathrm{Si}_{A l k}$ in this study (+0.82 to $+1.50 \%$ ).

Both $\mathrm{J}_{\text {diff }}$ and $\mathrm{J}_{\text {tot }}$ observed here are up to two orders of magnitude lower than those of Greenland margin incubation experiments $\left(+0.31\right.$ to $+3.1 \mathrm{mmol} \mathrm{m}^{-2}$ day $\left.^{-1}\right)(\mathrm{Ng}$ et al., 2020), therefore the relatively slow rate of DSi release from Barents Sea sediments could allow for the expression of uptake processes (precipitation or adsorption) within the core top water 
composition on short timescales through the incubation, rather than solely representing the composition of the dissolving phase(s). However, the gradual increase in DSi in the core top waters over the incubation period indicates that the release rate of DSi from dissolution exceeds that of the uptake processes, while the contemporaneous increase in $\delta^{30} \mathrm{Si}_{D S i-I n c}$ implies that the latter impose a stronger isotopic fractionation on the dissolved phase than the former.

Given the difficulties in determining the sources of the pore water DSi pool through isotopic analysis of the incubation experiment samples, an assessment into the complexity of the processes controlling the $\delta^{30} \mathrm{Si}$ of Barents Sea pore waters $\left(\delta^{30} \mathrm{Si}_{P W-D S i}\right)$ was carried out. If $\delta^{30} \mathrm{Si}_{P W-D S i}$ values are a consequence of a simple two endmember mixing system, whereby a fluid of core top water composition $(+1.46$ to $+1.69 \%$, $4-27 \mu \mathrm{M})$ mixes with a pure phase derived from the dissolution of BSi ( $900 \mu \mathrm{M}$ solubility (Loucaides et al., 2012; Van Cappellen and Qiu, 1997) and +0.82 to $+1.50 \%{ }^{30} \delta^{30} \mathrm{Silk}_{A l k}$ ), the data points should lie along a mixing line. The mixing line was calculated using equation 7 (Geilert et al., 2020), which assumes steady state

$$
\delta^{30} S i_{\text {mix }}=\frac{\left(\delta^{30} S i_{D S i-C T} \cdot[D S i]_{C T} \cdot f\right)+\left(\delta^{30} S i_{B S i} \cdot[D S i]_{B S i s o l} \cdot(1-f)\right)}{\left([D S i]_{C T} \cdot f\right)+\left([D S i]_{B S i s o l} \cdot(1-f)\right)}
$$

where CT refers to the core top water and $f$ represents the mixing fraction between the two phases. $\delta^{30} \mathrm{Si}_{m i x}$ was calculated across a range of $f$ values.

The pore water isotopic data do not fall on the calculated mixing lines plotted in Fig. 6, indicating that Si cycling within the Barents Sea seafloor is not conservative and is influenced by processes that fractionate $\delta^{30} \mathrm{Si}_{P W-D S i}$ to higher (heavier) and lower (lighter) values. To further elucidate the specific sources and sinks that combine to produce the observed [DSi] profiles, we can examine the downcore trends in [DSi] and $\delta^{30} \mathrm{Si}_{P W-D S i}$.

Barents Sea asymptotic and quasi-asymptotic sediment pore water DSi concentrations are much lower than the theoretical solubility of pure BSi in seawater $(600-1000 \mu \mathrm{M}$ at 0 $2^{\circ} \mathrm{C}, 1600-1900 \mu \mathrm{M}$ at $25^{\circ} \mathrm{C}$ (Rickert, 2000; Lawson et al., 1978; Hurd, 1983; Van Cappellen and Qiu, 1997; Dixit et al., 2001; Rickert et al., 2002)). Multiple hypotheses have been 
used to explain the magnitude of pore water DSi asymptotes, including a true equilbirium (Dixit et al. (2001) and references therein), however numerous studies have since shown that the apparent solubility of $\mathrm{BSi}$ is inversely correlated to the ratio of lithogenic to biogenic components. This ratio is widely accepted to be, or correlate with, the main factor controlling the accumulation of DSi in marine sediments (Loucaides et al., 2010; Rickert, 2000; Dixit et al., 2001; Gallinari et al., 2002; Van Cappellen and Qiu, 1997). The term apparent solubility is used as the value represents a weighted average of all the silicate phases present within the matrix (Rickert, 2000; Van Cappellen and Qiu, 1997). The apparent solubility tends to be very similar in magnitude to the measured in-situ pore water asymptotic DSi concentration, therefore solubility represents an important control on the pore water DSi pool (Rickert, 2000; Dixit et al., 2001; Gallinari et al., 2002; Van Cappellen and Qiu, 1997; Sarmiento and Gruber, 2006).

Stations B13, B14 and B15 have surface level (0-0.5 cmbsf interval) BSi contents of 0.39 $\pm 0.09(2 \sigma), 0.52 \pm 0.02$ and $0.26 \pm 0.07 \mathrm{wt} \%$ respectively (or $139 \pm 33,185 \pm 7,92 \pm 24 \mu \mathrm{mol}$ g dry $\mathrm{wt}^{-1}$ ) and an estimated LSi fraction of $96 \%$ (equation 8, Sayles et al. (2001)). This LSi fraction is similar to those of the Greenland and Norwegian Seas (37-98\%, mean 86\%) (Pirrung et al., 2008) and Kara Sea to the east (84-98\%, mean 88\%) (Fahl et al., 2003; Rickert, 2000). The presence of silicate minerals (LSi or AuSi) reduces the solubility of the bulk sediment as these minerals have a much lower solubility than fresh BSi (Rickert, 2000). However, the sediment detrital component also actively influences the BSi solubility in multiple ways. LSi dissolution releases $\mathrm{Al}$ into the pore water dissolved phase, which can be incorporated into BSi, thereby introducing interferences in the dissolution properties (Van Bennekom et al., 1991). Further, reverse weathering produces cation-rich aluminosilicates that directly replaces BSi with a less soluble clay phase (Dixit et al., 2001; Van Cappellen and Qiu, 1997) (equation 9), although this process can also occur at the expense of other reactive Si phases, such as degraded terrigenous clays (Frings et al., 2016; Aller, 2014).

$$
\% L S i=100-\%\left(B S i+\mathrm{CaCO}_{3}+T O C\right)
$$




$$
\text { ReactiveSi }+\mathrm{Al}(\mathrm{OH})_{4}^{-}+\text {cations }+\mathrm{HCO}_{3}^{-} \rightarrow \text { aluminosilicates }+\mathrm{H}_{2} \mathrm{O}+\mathrm{CO}_{2}
$$

The pore water asymptotic DSi concentration thus represents a dynamic balance between dissolution and reprecipitation of Si phases, that reflects the average solubility of each constituent phase in the assemblage. Given our estimate that clay rich Barents Sea surface sediments are composed of approximately $96 \%$ detrital content and very low surface BSi contents of just $0.26-0.52 \mathrm{wt} \%$, it is then not surprising that the asymptotic concentrations measured here are similar to the solubility of many silicate minerals. Indeed, a previous study of neighbouring Norwegian Sea sediments that are almost devoid of BSi $(<1$ wt\%) show low apparent solubilities $(140 \mu \mathrm{M})$ and corresponding asymptotic pore water DSi concentrations $(110 \mu \mathrm{M})$ (Rickert, 2000) not dissimilar to those observed here, as do sediments of the CAO (70-100 $\mu \mathrm{M})$ (März et al., 2015). These values are much lower than pore water [DSi] found in BSi rich sediments (>20 wt\%) of the subarctic North Pacific or Southern Ocean, which can present with asymptotic DSi concentrations of 500-900 $\mu \mathrm{M}$ (Dixit et al., 2001; King et al., 2000; Rabouille et al., 1997; Aller, 2014).

Relative to the respective core top waters, stations B13, B14 and B15 have isotopically lighter upper pore waters and higher [DSi], indicating an isotopically lighter phase is being released into the DSi pool (Fig. 3). Through a simple mass balance, akin to equation 6 , we calculate the theoretical isotopic composition of the $0.5 \mathrm{cmbsf}$ pore water interval, with the assumption that the increase in [DSi] between the core top water and this depth is driven solely by the dissolution of either the BSi or LSi phase (of $\delta^{30} \mathrm{Si}_{A l k}$ and $\delta^{30} \mathrm{Si}_{\mathrm{NaOH}}$ composition respectively). Below $0.5 \mathrm{cmbsf}$, the predicted $\delta^{30} \mathrm{Si}_{D S i-P W}$ is much lower than that analysed, likely reflecting the precipitation of $\mathrm{AuSi}$ as the pore water [DSi] surpasses the solubility concentration of the AuSi (see section 4.3.1). In summary, while the composition of the 0.5 cmbsf pore water intervals at B15 across the three cruises can be reproduced by the discrete dissolution of the BSi phase, at B13 and B14 neither phase is able to reproduce the analysed composition alone (Table 3). This finding points to the contemporaneous release of BSi and LSi into the pore water DSi pool, which has implications for the Barents Sea Si budget, as 
Table 3: Mean values of the parameters used in the upper pore water mass balance calculations (equation 6) for the three cruise years. $\delta^{30} \mathrm{Si}_{D S i-P W}$ at $0.5 \mathrm{cmbsf}$ was predicted based on two calculations simulating the sole dissolution of BSi and LSi respectively. The proportion of LSi dissolution contributing to the 0.5 cmbsf DSi pool was calculated assuming a known fraction of core top water $\left([\mathrm{DSi}]_{C T} /[\mathrm{DSi}]_{0.5 c m b s f}\right)$ and no influence of AuSi precipitation at this depth interval. For B15, calculations were only carried out for 2018 and 2019 as the $0.5 \mathrm{cmbsf} \delta^{30} \mathrm{Si}_{D S i-P W}$ value was not available. $\delta^{30} \mathrm{Si}_{D S i-C T}$ could only be determined for 2017 due to a lack of sufficient sample volume in subsequent years.

\begin{tabular}{lccc}
\hline Parameter & $\mathrm{B} 13$ & $\mathrm{~B} 14$ & $\mathrm{~B} 15$ \\
\hline$[D S i]_{C T}(\mu \mathrm{M})$ & 8.0 & 9.2 & 7.7 \\
$\delta^{30} \mathrm{Si}_{D S i-C T}(\%)$ & 1.64 & 1.46 & 1.69 \\
{$[D S i]_{0.5 c m b s f}(\mu \mathrm{M})$} & 49.6 & 60.6 & 22.8 \\
$\mathrm{f}_{C T}$ & 0.18 & 0.16 & 0.34 \\
$\delta^{30} \mathrm{Si}_{A l k}(\% 0)$ & 1.43 & 1.50 & 0.82 \\
$\delta^{30} \mathrm{Si}_{N a O H}(\%)$ & -0.89 & -0.89 & -0.89 \\
\hline$\delta^{30} \mathrm{Si}_{D S i-P W}$ predicted (BSi release) $(\% 0)$ & 1.47 & 1.49 & 1.12 \\
$\delta^{30} \mathrm{Si}_{D S i-P W}$ predicted (LSi release) $(\% 0)$ & -0.43 & -0.52 & 0.0 \\
$\delta^{30} \mathrm{Si}_{D S i-P W} 0.5$ cmbsf measured (\%o) & 1.15 & 1.17 & 1.15 \\
$\mathrm{LSi}^{\mathrm{L}}$ contribution to 0.5 cmbsf [DSi $(\%)$ & 14 & 13 & - \\
\hline
\end{tabular}

BSi dissolution represents a recycling of oceanic Si, while LSi constitutes a source of new $\mathrm{Si}$ discharging from the seafloor.

The importance of LSi as a DSi source for the pore water pool was inferred in a similar study of Guaymas basin sediment cores (Geilert et al., 2020), as well as for diagenetic products in Mississipi River plume sediment (Pickering et al., 2020). Furthermore, Tréguer et al. (1995) posited that LSi could be significant for Atlantic sediments, given that [DSi] in bottom waters is well below the solubility of many terrigenous minerals. These observations are consistent with the hypothesis that non-siliceous oceanic sediments (i.e. clays and calcareous sediment) contribute an estimated $64 \%$ of the global benthic Si flux (Frings, 2017) and with numerous experiments that demonstrate the release of Si from silicate minerals within days 
of being placed in low [DSi] seawater at ArW temperatures (Mackenzie and Garrels (1965); Mackenzie et al. (1967); Siever (1968); Fanning and Schink (1969); Lerman et al. (1975); Tréguer et al. (2021) and references therein). Additionally, LSi dissolution has been shown to represent a significant yet previously overlooked source of DSi to beach and ocean margin sediments (Jeandel et al., 2011; Fabre et al., 2019; Ehlert et al., 2016b).

Digestion experiments carried out in this study show that the Si-NaOH pool, associated with soluble LSi and residual, less reactive BSi (e.g. sponge spicules and radiolarians) (Pickering et al., 2020) is isotopically light and indistinguishable in composition across the three stations $\left(\delta^{30} \mathrm{Si}_{\mathrm{NaOH}}\right.$ of $-0.89 \pm 0.16 \%$ ). Thus, dissolution of the $\mathrm{Si}-\mathrm{NaOH}$ pool could account for the shift towards lower $\delta^{30} \mathrm{Si}_{P W-D S i}$ observed across the SWI at the three stations.

While the harsh alkaline extraction is able to activate recalcitrant $\mathrm{BSi}$, the $\delta^{30} \mathrm{Si}_{\mathrm{NaOH}}$ measured in this study is thought to be primarily representative of the Si isotopic composition of the soluble LSi phase. This conclusion is supported by the molar Al/Si ratios (0.57-0.67) analysed in the $\mathrm{NaOH}$ leachates of B13, B14 and B15 (Fig. S2). These values are higher than the $\mathrm{Al} / \mathrm{Si}$ of the continental crust (0.22-0.29 (Rahn (1976) and references therein)), but within range of common clay minerals (0.48-0.96 (Kim et al. (2004); Koning et al. (2002); Rahn (1976) and references therein). Indeed, the fine-grained sediments of the ChAOS sampling stations north of B13 are dominated by the clay and silt size fraction (Faust et al., 2020). Furthermore, an $\mathrm{Al} / \mathrm{Si}$ of 0.68 is much higher than that measured in $\mathrm{BSi}$ (diatom, sponge and radiolarian-derived) in sediment traps, marine sediments and laboratory studies, which ranges from $2.1 \times 10^{-5}$ to 0.165 (0.029 mean) (Middag et al. (2009); van Bennekom et al. (1989); Hendry and Andersen (2013); Ren et al. (2013) and references therein). These values are however consistent with the average $\mathrm{Al} / \mathrm{Si}$ measured in the $\mathrm{Na}_{2} \mathrm{CO}_{3}$ leachates (0.024) (Fig. S2), indicating that $\delta^{30} \mathrm{Si}_{A l k}$ reflects the true composition of the BSi pool.

In order to explain the regionally distinct $\delta^{30} \mathrm{Si}_{A l k}$ compositions, we simulate the uptake of DSi and production of BSi by diatoms following De La Rocha et al. (1997). With an initial surface water composition of $+2.0 \%$ (Varela et al., 2016; Liguori et al., 2020), a ${ }^{30} \epsilon$ of $-1.18 \%$ represents the minimum fractionation factor that is able to reproduce a $\delta^{30} \mathrm{Si}$ in the 
accumulated BSi pool of $+0.82 \%$ and therefore the fraction of DSi remaining in the surface water (f) is equal to 1 (Fig. S9). A ${ }^{30} \epsilon$ of $-1.18 \%$ is within range of previously measured values for the uptake of DSi by diatoms (-0.42 to $-2.21 \%$, averaging $-1.1 \pm 0.4 \%$ ) (Sutton et al., 2013; De La Rocha et al., 1997). If we then assume instead that the diatoms take up DSi with a more substantial ${ }^{30} \epsilon$ of $-2 \%$, the accumulating BSi pool has a composition of $+0.82 \%$ when $\mathrm{f}$ is equal to 0.4 . Under either modelled ${ }^{30} \epsilon$ scenario, a $\delta^{30} \mathrm{Si}$ of $+1.5 \%$ in the accumulated BSi can also be accounted for (f equal to 0.1-0.2), equivalent to the $\delta^{30} \mathrm{Si}_{\text {Alk }}$ measured at station B14 (Fig. S9). This observation illustrates that in a scenario wherein the diatom community composition of the spring blooms both north and south of the PF are identical, the discrepancy in $\delta^{30} \mathrm{Si}_{A l k}$ can be explained by a contrast in the stage of bloom development from which the sampled BSi phases were deposited. However, a range of diatom species have been identified across the three hydrographic domains of the Barents Sea (e.g. Chaetoceros/Thalassiosira at the PF/marginal ice zone (MIZ) and Fragilariopsis/Chaetoceros/Melosira arctica in the ArW region) (Oziel et al., 2017; Wassmann et al., 1999, 2006a) and ${ }^{30} \epsilon$ has been found to be species dependent (Sutton et al., 2013; De La Rocha et al., 1997). Therefore, the regionally distinct $\delta^{30} \mathrm{Si}_{A l k}$ values could also represent contrasts in the diatom species assemblage of spring blooms north and south of the PF.

To summarise, the benthic Si cycle of the Barents Sea cannot be characterised as a conservative system comprised of mixing between two endmember solutions, one of core top water composition and the other derived from the dissolution of BSi. We conclude there is strong evidence for the dissolution of both BSi and LSi, as well as the uptake of DSi by processes within the sediment cores. We also observe evidence for uptake processes active within the incubation experiments, potentially demonstrating that the uptake of DSi can occur on both shorter (daily) and longer (thousands of years) timescales.

\subsection{Is there evidence of AuSi precipitation or a redox control on the benthic Si system?}

\subsubsection{Evidence of AuSi precipitation}

The composition and trends of $\delta^{30} \mathrm{Si}_{D S i-P W}$ values in the upper $3 \mathrm{cmbsf}$ are similar at B14 and B15 and across the three cruises (Fig. 3), characterised by an enrichment in the 
heavier isotope below 0.5 cmbsf, which drives the $\delta^{30} \mathrm{Si}_{D S i-P W}$ back towards the core top water compositions. This shift is likely to be caused by the precipitation of AuSi in Barents Sea sediments, which preferentially removes the lighter isotope. At B13 we see a deviation towards a heavier composition at the same depth interval (Fig. 3) that is consistent with AuSi formation, although the shift is within analytical uncertainty. Similar shifts have been observed in $\delta^{30} \mathrm{Si}_{D S i-P W}$ profiles of previous studies of both temperate and high latitude systems (Geilert et al., 2020; Ehlert et al., 2016a; Ng et al., 2020). This increase in the $\delta^{30} \mathrm{Si}_{D S i-P W}$ is unlikely to be caused by the dissolution of a solid phase, as the $\delta^{30} \mathrm{Si}_{D S i-P W}$ at $3.5 \mathrm{cmbsf}$ at the three stations increases to higher values than that measured in the operational pools, especially at B15 (Fig. 5B). Additionally, dissolution would not resolve the relative shift from 0.5 cmbsf to 3.5 cmbsf observed at stations B14 and B15 (Fig. 3), which requires enrichment in the heavier isotope downcore.

Sediment pore water solutes are incorporated into authigenic clay minerals during reverse weathering, following a reaction scheme similar to equation 9 . Therefore, pore water elemental concentrations can be analysed alongside $\delta^{30} \mathrm{Si}_{D S i-P W}$ to provide a further indication as to whether AuSi precipitation is active within the sediments (Aller, 2014). Most pore water $\mathrm{Mg}$ concentration profiles measured in this study show a gradual negative trend downcore at stations B13, B14 and B15, potentially indicating their uptake into AuSi, although fewer of the $\mathrm{K}$ concentration profiles show a similar decline, with most presenting with little to no downcore change (Fig. S10). However, a lack of concomitant dissolved K uptake does not necessarily preclude the interpretation that reverse weathering is occuring within the seafloor. Ng et al. (2020) observed a similar decline in Mg with no decrease in K in sediments from the Greenland margin, which they interpret as reflecting the precipitation of an AuSi clay phase that has a different stoichiometry than might be expected under a typical reverse weathering regime. Geilert et al. (2020) determined that AuSi is precipitating within oxygen minimum zone sediments of the Guaymas Basin, which present with an increasing pore water dissolved K concentration downcore. Furthermore, our hypothesis that LSi is dissolving in Barents Sea sediments complicates the interpretation of pore water elemental 
indicators that are typically associated with reverse weathering. Dissolution of terrigenous clays from the LSi pool would release solutes into the pore water phase, potentially mitigating some of the K uptake that corresponds to AuSi precipitation.

Previous assumptions as to the solubility of AuSi minerals (220-330 $\mu \mathrm{M})$ would preclude precipitation of AuSi in Barents Sea and many North Atlantic sediments, as [DSi] remains undersaturated with respect to these minerals (Loucaides et al., 2010; Dixit et al., 2001; Ehlert et al., 2016a; Krissansen-Totton and Catling, 2020; Cassarino et al., 2020). However, dissolution experiments carried out over 8.5 years suggest that glauconite, an aluminosilicate and common weathering product of BSi (Odin and Fröhlich, 1988), has a solubility of $\sim 50$ $\mu \mathrm{M}$ in seawater (Lerman et al., 1975). In addition, Wollast (1974) calculated that sepiolite, an authigenic clay mineral found to form on BSi surfaces in deep ocean sediments (Hurd, 1973), could theoretically precipitate from seawater with a [DSi] as low as $30 \mu \mathrm{M}$. Subsurface formation of low solubility AuSi minerals such as these could explain why we see an initial decrease in $\delta^{30} \mathrm{Si}_{D S i-P W}$ as LSi dissolves, then an increase to the $3.5 \mathrm{cmbsf} \delta^{30} \mathrm{Si}_{D S i-P W}$ maxima, as DSi increases past the solubility of the precipitating phase. This hypothesis is consistent with previous work evidencing the precipitation of AuSi in LSi-dominated high latitude sediments (März et al., 2015). This is an important observation, as approximately one-third of the global seafloor is occupied by sediments relatively devoid of $\mathrm{BSi}(<1 \mathrm{wt} \%)$ (Tréguer and De La Rocha, 2013).

Coupling the evidence for benthic LSi dissolution near the SWI with that for AuSi precipitation has implications for the regional ocean Si budget. If LSi sourced from a terrestrial environment is dissolving in shallow seafloor sediments, contributing to the benthic DSi flux, these minerals represent a new source of ocean DSi. If this LSi-sourced DSi is subsequently reprecipitated as $\mathrm{AuSi}$, the $\mathrm{AuSi}$ term represents a true sink, as that benthic DSi can no longer interact with the bottom water DSi pool. It is for this reason that the early diagenetic conversion of BSi to AuSi is generally also considered a significant sink of ocean $\mathrm{Si}$ (Rahman et al., 2017, 2016; Laruelle et al., 2009). It has been argued that the BSi to AuSi reaction pathway does not represent a significant sink for ocean $\mathrm{Si}$, instead reflecting an early diage- 
netic conversion between solid phases at depth that enhances the preservation of BSi (Frings et al., 2016; DeMaster, 2019). However, here we have shown that both LSi and BSi are dissolving in the uppermost sediments of the Barents Sea and thus contribute to the benthic DSi flux. Therefore, AuSi precipitation likely represents a true sink of Si in the context of the shallow sediment cores studied here, as the exchange of sediment pore water DSi with the overlying bottom water is impeded by their precipitation.

\subsubsection{Evidence for a redox influence on the benthic Si cycle}

Below 3.5 cmbsf at B13 and B14 and below 10.5 cmbsf at B15, we see an enrichment in the lighter isotope downcore across all cruise years (Fig. 3) in addition to a general trend towards increased [DSi] towards the base of the cores at B13 and B14 (Fig. 2), albeit at a much slower rate than beneath the SWI. These observations point to the release of an isotopically light $\mathrm{Si}$ source. The downcore increase in $[\mathrm{DSi}]$ is unlikely to be driven by the dissolution of $\mathrm{BSi}$, given that corresponding $\mathrm{BSi}$ contents have reached or are approaching their minima of $\sim 0.2 \mathrm{wt} \%$ by the mid-core $(\sim 15 \mathrm{cmbsf})$ (Fig. $5 \mathrm{~A})$. Furthermore, we have presented evidence supporting the dissolution of LSi in the upper reaches of the sediment, below the SWI. However, below this depth the rate of LSi dissolution is likely to slow, given that pore water $[\mathrm{DSi}]$ at all Barents Sea stations approaches $\sim 100-150 \mu \mathrm{M}$ within the upper 5 cmbsf, which is similar to or above the apparent Si solubility of many silicate minerals (Mackenzie et al., 1967; Lerman et al., 1975) and low BSi bulk sediment in seawater at low temperatures (Jones et al., 2012; Fanning and Schink, 1969; Willey, 1978).

Potential sources for this isotopically light pool of $\mathrm{Si}$ at depth are: i) the desorption of $\mathrm{Si}$ adsorbed onto metal oxides, or ii) sponge derived $\mathrm{BSi}$ dissolution. The affinity of the lighter Si isotope for metal oxides, specifically Fe (oxyhydr)oxides, is well documented. Adsorption of DSi onto Fe (oxyhydr)oxides has a ${ }^{30} \epsilon$ of -1.1 to $-3.2 \%$, enriching the residual dissolved phase in the heavier isotope (Zheng et al., 2016; Delstanche et al., 2009). Following Pickering et al. (2020) we are able to demonstrate the presence of such a reactive pool in all three sediment cores. The $\delta^{30} \mathrm{Si}$ of the $\mathrm{Si}-\mathrm{HCl}$ pool $\left(\delta^{30} \mathrm{Si}_{H C l}\right)$, which is thought to remove metal oxide coatings from BSi (Pickering et al., 2020), averaged $-2.88 \pm 0.17 \%$ and 
was indistinguishable within long term reproducibility across the three sites. $\delta^{30} \mathrm{Si}_{H C l}$ did however appear susceptible to contrasting sample preparation techniques, presenting with much higher $\delta^{30} \mathrm{Si}_{\mathrm{HCl}}$ values in ground sediment samples $(-2.56 \pm 0.14 \%$ o), likely as a result of LSi contamination (see supp. Section 2 for discussion). The ubiquitous presence and desorption of $\mathrm{Si}$ from this metal oxide phase at the three stations could explain the ${ }^{28} \mathrm{Si}$ enrichment we observe across the oxic-anoxic boundaries, as well as the gradual increase in [DSi] observed below $\sim 3.5$ cmbsf most clearly at B13.

Examination of the $[\mathrm{Fe}]$ pore water profiles of the same sampling stations indicates that the light isotope enrichment occurs at a similar depth interval to where Fe appears and $\mathrm{NO}_{3}{ }^{-}$is diminishing in the pore water phase (Fig. 3). This observation is consistent with a change in redox state to anoxic conditions, which drives the reductive dissolution of solid Fe (oxyhdr)oxides. Furthermore, reaction-transport model output derived from baseline steady-state simulations of B13 and B15 (Freitas et al., 2020) indicate that the release of Fe into the dissolved phase across the redox boundaries is driven by a combination of organic matter degradation and the reoxidation of reduced species $\left(\mathrm{H}_{2} \mathrm{~S}\right)$ diffusing upwards towards the SWI (Fig. S11). The disparity in $\delta^{30} \mathrm{Si}_{D S i-P W}$ profiles between 3.5 and $10.5 \mathrm{cmbsf}$ at B13 and B15 (which reaches a peak at 8.5 cmbsf with B15 an average of $+0.96 \%$ higher), are consistent with the different depths of the redox boundaries found at the two sites, which is shallower at B13 than at B15 (Fig. 3).

In addition to the reductive dissolution of Fe (oxyhydr)oxides observed across Barents Sea sediment redox boundaries, reductive dissolution of Mn (oxyhydr)oxides is indicated by a decrease in the solid phase Mn content and concomitant increase in dissolved $\mathrm{Mn}$ across distinct depth intervals (Figs. S12 and S10). The cycling of Mn metal oxides could also influence $\delta^{30} \mathrm{Si}_{D S i-P W}$, however the release of dissolved Mn occurs at slightly shallower depth intervals than Fe. At station B15 for example, pore water Fe concentrations increase from 10.5 cmbsf compared with $4.5 \mathrm{cmbsf}$ for $\mathrm{Mn}$, the latter being approximately $5 \mathrm{~cm}$ shallower than where the shift in $\delta^{30} \mathrm{Si}_{D S i-P W}$ begins (Fig. 3). The interpretation that Fe (oxyhydr)oxides are driving the observed shifts in pore water $\delta^{30} \mathrm{Si}$ across the redox 
boundaries is therefore favourable, however both metal oxides could be contributing.

It has previously been suggested for sediments of the Greenland Shelf that the reductive dissolution of protective solid phase Fe coatings on BSi increased pore water DSi, by enhancing the reactivity of the $\mathrm{BSi}$, although there appeared to be no influence on $\delta^{30} \mathrm{Si}_{D S i-P W}$ (Ng et al., 2020). Higher ${ }^{30} \mathrm{Si}_{D S i-P W}$ values at one station in the Peruvian Upwelling Zone were interpreted to be due to the adsorption of Si onto reactive Fe (Ehlert et al., 2016a) and a heavy $\delta^{30} \mathrm{Si}_{D S i-P W}$ in pore fluids of elevated $[\mathrm{Fe}](190 \mu \mathrm{M})$ in the Guaymas Basin was interpreted to be driven by the precipitation of Fe-Si silicates (Geilert et al., 2020). Our finding supports this previous work by identifying a redox-driven shift in $\delta^{30} \mathrm{Si}_{D S i-P W}$ in marine sediment cores. It is likely that the low asymptotic and quasi-asymptotic [DSi] in the sediments studied here allows for the detection of this process, which is masked by a much larger DSi pool in other shelf seas.

Dissolution of sponge spicule derived $\mathrm{BSi}$, which has been observed in core incubation experiments of Greenland shelf sediments (Ng et al., 2020), is another potential DSi source enriched in the lighter isotope $\left(\delta^{30} \mathrm{Si}_{\text {sponge }}\right.$ values range from -5.72 to $+0.87 \%$, mean $-2.1 \%$ o (Sutton et al. (2018) and references therein)). While the release of DSi from sponge BSi cannot be ruled out for the Barents Sea stations, the corresponding depths of negative shifts in $\delta^{30} \mathrm{Si}_{D S i-P W}$ profiles with increasing (decreasing) pore water $[\mathrm{Fe}]\left(\left[\mathrm{NO}_{3}{ }^{-}\right]\right)$indicate a redox driven coupling between metal oxides and $\mathrm{Si}$. In addition, the $\delta^{30} \mathrm{Si}_{\mathrm{HCl}}$ values at all three stations provide strong evidence for the presence of an isotopically light metal oxide phase in the sediment, as this digestion is highly unlikely to dissolve sponge spicules and instead thought to predominantly remove authigenic metal oxide coatings from BSi (Pickering et al., 2020). As a result, desorption of $\mathrm{Si}$ from the metal oxide phase is thought to be the most likely cause of the observed downcore shift towards lighter compositions at the three Barents Sea stations (Fig. 3). Coupled with the observations supporting the release of LSi in the surface sediment layers, this evidence suggests that there is a ${ }^{28} \mathrm{Si}$ enriched, mineralogical control on the DSi released into Barents Sea cores below the SWI. 


\subsection{What are the key geographic and temporal variations?}

[DSi] profiles of the ArW stations (B15, B16, B17) (Fig. 1) show striking similarities both spatially (within sediment core replicates of one cruise) and temporally (between cruises) (Fig. 2). This characteristic is not as evident in the cores of the AW dominated region (B03, B13, B14), which is most apparent at B14 where there is evidence for non-steady state, transient dynamics in the upper 5 cmbsf. Here, we see strong peaks in [DSi] and consequently the benthic flux magnitudes in 2017 and 2019, which is in contrast to 2018, where the [DSi] profile presents with a more typical, asymptotic form (Fig. 3, Table 2).

Oceanic frontal zones are highly dynamic and the PF (B14, Fig. 1) of the Barents Sea is no exception, where the interleaving of multiple water masses enhances physical mixing (Barton et al. (2018) and references therein). Wassmann and Olli (2004) attributed this feature to the observed increase in particulate organic carbon export efficiency at depth underneath the Barents Sea PF, relative to stations on the adjacent sides.

In addition to the physical mixing, studying of sea ice conditions from the respective cruise years indicates that the MIZ was influencing B14 much later in 2017 and 2019 than prior to the 2018 cruise (Fig. 7). In 2018 the MIZ in the Barents Sea retreated more rapidly and earlier in the season, receding north of the polar front almost three months prior to sampling, unlike in 2017 and 2019 when the retreat was just six weeks prior to sediment coring. The most distinct phytoplankton blooms observed in the Barents Sea are found beneath the MIZ, supported by stratification of the nutrient rich photic zone in late spring and summer as sea ice melts (Wassmann et al., 2006b; Reigstad et al., 2002; Olli et al., 2002). Phytoplankton community compositions of Barents Sea MIZ blooms are initially dominated by diatoms (Olli et al., 2002) and observations from the Fram Strait indicate that BSi export fluxes increase with sea ice cover (Lalande et al., 2013). We therefore suggest that the sediment pore water [DSi] peaks at station B14 are transient features, sourced from the dissolution of fresher, more reactive $\mathrm{BSi}$ relative to the background material, which is deposited under MIZ bloom conditions and results in stronger [DSi] gradients across the SWI. The resulting enhanced rate of molecular diffusion would then begin to dissipate the peak. We suggest that the 
increased time under ice free conditions in 2018 prior to sampling relative to the other cruise years allowed for sufficient recovery of the DSi profile towards steady state conditions, such that the peak was not observed after pore water extraction.

The hypothesis that fresh, bloom derived BSi dissolution is driving the sediment pore water [DSi] peaks observed at B14 is also evidenced in a comparison of the $\delta^{30} \mathrm{Si}_{D S i-P W}$ values at 0.5 cmbsf across the cruise years. In 2017 and 2019 where the peaks in pore water DSi are observed, the $0.5 \mathrm{cmbsf}$ pore water samples have heavier isotopic compositions $(+1.22$ and $+1.33 \pm 0.14 \%$ respectively) than that sampled in $2018(+0.96 \pm 0.16 \%$ o. This disparity is likely to be a result of the dissolution of fresh $\mathrm{BSi}$ with a $\delta^{30} \mathrm{Si}$ similar to that measured in the Si-Alk reactive pool of the 2019 surface sediment interval $(+1.50 \pm 0.19 \%)$. In all three cruise years, the $\delta^{30} \mathrm{Si}_{D S i-P W}$ then increases to a maxima within the 1.5 and $2.5 \mathrm{cmbsf}$ depth intervals. The average $\delta^{30} \mathrm{Si}_{D S i-P W}$ within these two pore water intervals in 2018 was $+1.52 \%$ ( +1.34 to $+1.69 \%$ ) , indicating that the dissolution of fresh BSi in 2017 and 2019 would be indistinguishable from the $\delta^{30} \mathrm{Si}_{D S i-P W}$ background signal.

We estimate that the bloom derived fresh BSi contributes an additional $0.23 \mathrm{mmol} \mathrm{m} \mathrm{m}^{-2}$ $\mathrm{d}^{-1}$ to the B14 background (2018) DSi flux of $0.12 \mathrm{mmol} \mathrm{m}^{-2} \mathrm{~d}^{-1}\left(43.8 \mathrm{mmol} \mathrm{m} \mathrm{yr}^{-1}\right)$ (Table 2), representing an increase of $192 \%$. If we assume this elevated flux endures across the three months required to dissipate the DSi peak, which is likely an overestimation, this would equate to an additional $20.9 \mathrm{mmol} \mathrm{m}^{-2}$ to the total annual DSi flux at B14 of 64.7 mmol $\mathrm{m}^{-2}$ (background plus the contribution from the bloom material).

The superposition of non-steady state seasonal dynamics driven by tight benthic-pelagic coupling under bloom conditions onto a background steady state benthic Si system can also elucidate the intricate downcore structures observed in the DSi profiles at station B14 (Fig. 2). The gradual increase in DSi observed downcore from 10-15 cmbsf across the cruise years is consistent with the other AW stations (B03 and B13). Therefore the addition of a transient DSi peak onto the DSi profiles of stations B03 or B13 within the upper 5 cmbsf would result in a DSi profile not dissimilar to that observed at B14 in 2017 and 2019. The linear increases in DSi towards the base of the AW station sediment cores is unlikely to be 
driven by the dissolution of $\mathrm{BSi}$, given that measurements of the solid phase show that a $\mathrm{BSi}$ minima of $\sim 0.2 \mathrm{wt} \%$ is reached in the mid core (Fig. $5 \mathrm{~A}$ ). This increase could instead be fuelled by the continued dissolution of LSi or desorption of Si from metal oxides, consistent with $\delta^{30} \mathrm{Si}_{D S i-P W}$ observations that evidence the continued release of an isotopically light source of Si at depth (Fig. 3).

Previously it was thought that dissolution rates of $\mathrm{BSi}$ were very slow relative to the residence time of $\mathrm{BSi}$ in upper seafloor sediments, leading to the assumption that the benthos represented a stable repository, unaffected by seasonal variability in surface processes and the export efficiency of phytodetritus (Ragueneau et al., 2001). This stability was interpreted to be due to the fact that the residence time of BSi in surface sediments (decades to centuries) is much longer than that of seasonal and interannual variation in fluxes to the seafloor (Schlüter and Sauter, 2000; Sayles et al., 1996), which is in agreement with similar findings regarding the early diagenetic remineralisation of organic matter (Sayles et al., 1994; Martin and Bender, 1988). In direct contrast to these findings, research into the Si cycle of the Porcupine Abyssal Plain uncovered strong evidence for non-steady state, transient responses in the pore water DSi stock driven by deposition of fresh BSi phytodetritus on a seasonal timescale (Ragueneau et al., 2001). Ragueneau et al. (2001) noted an increase in the sediment pore water DSi inventory of $+19 \%$ from early spring to summer, resulting in an enhanced DSi benthic flux of $+54 \%$ across the same time interval. These increases were coeval with a significant rise in the deposition flux of BSi at the SWI. Typically these peaks in DSi inventory were found within the upper 5.5 cmbsf, however they were observed as deep as 10-20 cmbsf. Ragueneau et al. (2001) conclude that the delivery of fresh BSi to depth by megafaunal mixing allowed for the expression of seasonal dynamics well below the SWI.

Bioturbation coefficients were determined experimentally for stations B13, B14 and B15, which range from 2-6 $\mathrm{cm}^{2} \mathrm{yr}^{-1}$ to a maximum depth of $6.5 \mathrm{cmbsf}$ (Solan et al., 2020). These observations illustrate that fresh BSi deposited at the SWI could influence the sediment column at the depth intervals wherein we observe peaks in DSi (1.5-4.5 cmbsf), despite the low rates of sediment accumulation (Zaborska et al., 2008; Faust et al., 2020) that would 
preclude burial to such a depth on a seasonal timescale if advective processes were acting alone (Fig. 2).

As with organic matter (Sayles et al., 1994), in order for variations in BSi deposition fluxes to influence pore water DSi on a seasonal time frame, the mean lifetime of the deposited material must be less than one seasonal period (1 year) (Burdige, 2006). Therefore, BSi undergoing dissolution must a priori have a reactivity constant $\left(k_{d i s s}\right)$ of $>1 \mathrm{yr}^{-1}$, as the lifetime of material undergoing first-order dissolution is equivalent to $1 / k_{\text {diss }}$ (Burdige, 2006). $k_{\text {diss }}$ of fresh diatoms in the surface ocean range from 3 to $70 \mathrm{yr}^{-1}$ (Ragueneau et al., 2000). Typically, $k_{\text {diss }}$ values of this magnitude are not found in sediment cores, however a $k_{d i s s}$ of $1.38 \mathrm{yr}^{-1}$ (mean lifetime of 9 months) was measured as deep as $19 \mathrm{cmbsf}$ at $4850 \mathrm{~m}$ depth at the Porcupine Abyssal Plain, attributed to bioturbation by megafauna (Ragueneau et al., 2001). A bloom derived $\mathrm{BSi} k_{\text {diss }}$ of $1.38 \mathrm{yr}^{-1}$ corresponds to a half life of six months, implying that just $25 \%$ of the material would be preserved beyond one year. It is therefore plausible that the periodic deposition of fresh phytodetritus associated with the Arctic spring bloom in the much shallower Barents Sea $(\sim 300 \mathrm{~m})$ could readily influence sediment pore water chemistry, especially given the effect of frontal mixing on export efficiency observed in proximity to station B14 (Wassmann and Olli, 2004).

\subsection{Conclusions}

This work highlights the highly dynamic nature of the Arctic benthic Si system, which involves the cycling of Si from BSi, LSi and Si adsorbed onto metal oxides to the DSi phase, some of which is then taken up to form AuSi. These findings provide important implications for the Arctic Ocean Si budget, as the dissolution of LSi represents a source of new Si and the subsequent reprecipitation of DSi as AuSi constitutes a potentially important isotopically light sink.

We show that fresh BSi derived from pelagic phytoplankton blooms is rapidly recycled in the upper reaches of the Barents Sea seafloor. This recycling process presents as distinctive, transient increases in pore water [DSi] immediately beneath the SWI, consistent with lower latitude systems (e.g. the Porcupine Abyssal Plain (Ragueneau et al., 2001)). These [DSi] 
peaks appear to dissipate within six weeks to three months, as evidenced by the contrasting sea ice conditions relative to the sampling time across the three cruises.

This strong benthic-pelagic coupling for $\mathrm{Si}$ in the spring bloom period will probably be subject to change as the community composition of phytoplankton blooms tend towards that of the Atlantic system and the MIZ retreats northwards (Dybwad et al., 2021). The impacts of Atlantification and sea ice loss that bring about these changes in community composition are also amplified by the observed reduction in [DSi] across the subpolar North Atlantic Ocean (Hátún et al., 2017) and consequently in Barents Sea Atlantic inflow waters over the last three decades (Rey, 2012). These pressures will likely result in less favourable conditions for diatom growth, potentially exacerbating the Si-limitation observed in diatom blooms off Svalbard (Krause et al., 2018), which has also been detected across the Arctic Ocean and in the North Atlantic subpolar region (Giesbrecht and Varela, 2021; Giesbrecht, 2019; Krause et al., 2019).

These changes would significantly influence the transient dynamics observed in this study. At present, the magnitude of the benthic DSi fluxes driven by seasonal dynamics in primary productivity (2017 and 2019) at B14 represent an estimated 192\% increase relative to the apparent background flux magnitude (2018). The anticipated adjustment in the composition of pelagic primary producers that will be deposited at the SWI may hinder this recycling process in the future, thereby reducing the estimated contribution of the bloom derived material to the annual DSi benthic flux. However, here we have inferred a significant influence from mineral-derived Si (LSi and metal oxides) on the background Barents Sea benthic Si system, which is almost devoid of BSi. This mineralogical control may afford an element of stability to the magnitude of the annual benthic flux of DSi. Whether this benthic-derived DSi directly influences pelagic primary production in the Barents Sea photic zone or is transported off-shelf is unclear and is the subject of ongoing research.

\section{Acknowledgements}

This research is part of the Changing Arctic Ocean Seafloor project (ChAOS) of the Changing Arctic Ocean Programme, funded by the Natural Environment Research Council 
(NERC) (grant numbers NE/P005942/1, NE/P006108/1 and NE/P006493/1 2017-2022). Authors are grateful to all those involved in cruises JR16006, JR17007, JR18006 aboard the RRS James Clark Ross, as well as National Marine Facilities and the British Antarctic Survey for their logistical support. We also thank colleagues at the University of Bristol for technical support (Dr C. Coath, Dr L. Cassarino, Dr J. Hatton, Dr S. Bates, Ms R. Ward and Dr A. McAleer), as well as the reviewers and associate editor for their constructive comments to improve this manuscript.

\section{Appendix A: Supplementary Material}

Supplementary material has been prepared in support of this manuscript. This material includes a document comprising a detailed discussion of a series of sensitivity experiments carried out to determine the influence of solid phase sample preparation techniques on the isotopic composition of reactive pool leachates. We also present an explanation of the LSi correction calculations for the Si-Alk pool, as well as a description of the exponential curvefitting methodology used to determine the magnitude of benthic DSi fluxes, complimentary to the linear (two-point) and incubation techniques.

\section{Research Data}

Research data associated with this article are available in the UK Polar Data Centre (UK PDC), British Antarctic Survey and can be accessed with https://doi.org/10.5285/8933AF23E051-4166-B63E-2155330A21D8.

\section{References}

Aller, R. C., 2014. 8.11 - Sedimentary Diagenesis, Depositional Environments, and Benthic Fluxes. Treatise on Geochemistry (Second Edition) 8, 293-334.

Årthun, M., 2011. Ocean surface heat flux variability in the Barents Sea. J. Mar. Syst. 83 (1-2), 88-98. 
Årthun, M., Eldevik, T., Smedsrud, L. H., Skagseth, Ingvaldsen, R. B., 2012. Quantifying the influence of atlantic heat on barents sea ice variability and retreat. J. Clim. 25 (13), 4736-4743.

Barão, L., Vandevenne, F., Clymans, W., Frings, P., Ragueneau, O., Meire, P., Conley, D. J., Struyf, E., 2015. Alkaline-extractable silicon from land to ocean: A challenge for biogenic silicon determination. Limnol. Oceanogr.: Methods 13 (7), 329-344.

Barnes, D., 2019. Changing Arctic Ocean Seafloor JR18006 Cruise Report, RRS James Clark Ross. Tech. rep.

Barton, B. I., Lenn, Y. D., Lique, C., 2018. Observed atlantification of the Barents Sea causes the Polar Front to limit the expansion of winter sea ice. J. Phys. Oceanogr. 48 (8), $1849-1866$.

Bayon, G., Delvigne, C., Ponzevera, E., Borges, A. V., Darchambeau, F., De Deckker, P., Lambert, T., Monin, L., Toucanne, S., André, L., 2018. The silicon isotopic composition of fine-grained river sediments and its relation to climate and lithology. Geochim. Cosmochim. Acta 229, 147-161.

Berelson, W., McManus, J., Coale, K., Johnson, K., Burdige, D., Kilgore, T., Colodner, D., Chavez, F., Kudela, R., Boucher, J., 2003. A time series of benthic flux measurements from Monterey Bay, CA. Cont. Shelf Res. 23, 457-481.

Boudreau, B. P., 1996. The diffusive tortuosity of fine-grained unlithified sediments. Geochim. Cosmochim. Acta 60 (16), 3139-3142.

Bourgeois, S., Archambault, P., Witte, U., 2017. Organic matter remineralization in marine sediments: A Pan-Arctic synthesis. Global Biogeochem. Cycles 31 (1), 190-213.

Burdige, D., 2006. Geochemistry of Marine Sediments. Princeton University Press, Princeton, NJ. 
Cardinal, D., Alleman, L. Y., De Jong, J., Ziegler, K., André, L., 2003. Isotopic composition of silicon measured by multicollector plasma source mass spectrometry in dry plasma mode. J. Anal. At. Spectrom. 18, 213-218.

Cassarino, L., Hendry, K. R., Henley, S. F., MacDonald, E., Arndt, S., Freitas, F. S., Pike, J., Firing, Y. L., 2020. Sedimentary Nutrient Supply in Productive Hot Spots off the West Antarctic Peninsula Revealed by Silicon Isotopes. Global Biogeochem. Cycles 34 (12).

Cermelj, B., Bertuzzi, A., Faganeli, J., 1997. Modelling of pore water nutrient distribution and benthic fluxes in shallow coastal waters (Gulf of Trieste, Northern Adriatic). Water Air Soil Pollut. 99, 435-444.

Dale, A. W., Paul, K. M., Clemens, D., Scholz, F., Schroller-Lomnitz, U., Wallmann, K., Geilert, S., Hensen, C., Plass, A., Liebetrau, V., Grasse, P., Sommer, S., 2021. Recycling and Burial of Biogenic Silica in an Open Margin Oxygen Minimum Zone. Global Biogeochem. Cycles 35 (2).

De La Rocha, C. L., 2002. Measurement of silicon stable isotope natural abundances via multicollector inductively coupled plasma mass spectrometry (MC-ICP-MS). Geochem. Geophys. Geosystems. 3 (8), 1-8.

De La Rocha, C. L., Brzezinski, M. A., DeNiro, M. J., 1997. Fractionation of silicon isotopes by marine diatoms during biogenic silica formation. Geochim. Cosmochim. Acta 61 (23), $5051-5056$.

De Souza, G. F., Reynolds, B. C., Rickli, J., Frank, M., Saito, M. A., Gerringa, L. J., Bourdon, B., 2012. Southern Ocean control of silicon stable isotope distribution in the deep Atlantic Ocean. Global Biogeochem. Cycles 26 (2), GB2035.

Delstanche, S., Opfergelt, S., Cardinal, D., Elsass, F., André, L., Delvaux, B., 2009. Silicon isotopic fractionation during adsorption of aqueous monosilicic acid onto iron oxide. Geochim. Cosmochim. Acta 73, 923-924. 
Demarest, M. S., Brzezinski, M. A., Beucher, C. P., 2009. Fractionation of silicon isotopes during biogenic silica dissolution. Geochim. Cosmochim. Acta 73, 5572-5583.

DeMaster, D., 1981. The supply and accumulation of silica in the marine environment. Geochim. Cosmochim. Acta 45 (10), 1715-1732.

DeMaster, D. J., 2019. The global marine silica budget: Sources and sinks. In: Encyclopedia of Ocean Sciences. Elsevier Ltd, pp. 473-483.

Dixit, S., Van Cappellen, P., 2003. Predicting benthic fluxes of silicic acid from deep-sea sediments. J. Geophys. Res.: Oceans 108 (C10).

Dixit, S., Van Cappellen, P., Van Bennekom, A. J., 2001. Processes controlling solubility of biogenic silica and pore water build-up of silicic acid in marine sediments. Mar. Chem. 73, $333-352$.

Docquier, D., Fuentes-Franco, R., Koenigk, T., Fichefet, T., 2020. Sea Ice-Ocean Interactions in the Barents Sea Modeled at Different Resolutions. Front. Earth Sci. 8 (172).

Downes, P. P., Goult, S. J., Woodward, E. M. S., Widdicombe, C. E., Tait, K., Dixon, J. L., 2021. Phosphorus dynamics in the Barents Sea. Limnol. Oceanogr. 66, S326-S342.

Dutkiewicz, A., Müller, R. D., O'Callaghan, S., Jónasson, H., 2015. Census of seafloor sediments in the world's ocean. Geology 43 (9), 795-798.

Dybwad, C., Assmy, P., Olsen, L. M., Peeken, I., Nikolopoulos, A., Krumpen, T., Randelhoff, A., Tatarek, A., Wiktor, J. M., Reigstad, M., 2021. Carbon Export in the Seasonal Sea Ice Zone North of Svalbard From Winter to Late Summer. Front. Mar. Sci. 7 (525800).

Egan, K. E., Rickaby, R. E., Leng, M. J., Hendry, K. R., Hermoso, M., Sloane, H. J., Bostock, H., Halliday, A. N., 2012. Diatom silicon isotopes as a proxy for silicic acid utilisation: A Southern Ocean core top calibration. Geochim. Cosmochim. Acta 96, 174-192. 
Ehlert, C., Doering, K., Wallmann, K., Scholz, F., Sommer, S., Grasse, P., Geilert, S., Frank, M., 2016a. Stable silicon isotope signatures of marine pore waters - Biogenic opal dissolution versus authigenic clay mineral formation. Geochim. Cosmochim. Acta 191, $102-117$.

Ehlert, C., Reckhardt, A., Greskowiak, J., Liguori, B. T., Böning, P., Paffrath, R., Brumsack, H. J., Pahnke, K., 2016b. Transformation of silicon in a sandy beach ecosystem: Insights from stable silicon isotopes from fresh and saline groundwaters. Chem. Geol. 440, 207-218.

Fabre, S., Jeandel, C., Zambardi, T., Roustan, M., Almar, R., 2019. An Overlooked Silica Source of the Modern Oceans: Are Sandy Beaches the Key? Front. Earth Sci. 7 (231).

Fahl, K., Stein, R., Gaye-Haake, B., Gebhardt, C., Kodina, L., Unger, D., Ittekkot, V., 2003. Biomarkers in surface sediments from the Ob and Yenisei estuaries and the southern Kara Sea: Evidence for particulate organic carbon sources, pathways, and degradation. In: Stein, R., Fahl, K., Fütterer, D., Galimov, E., Stepanets, O. (Eds.), Siberian River Run-off in the Kara Sea: Characterisation, Quantification, Variability, and Environmental Significance. Elsevier, Amsterdam, pp. 329-488.

Fanning, K. A., Schink, D. R., 1969. Interaction of Marine Sediments with Dissolved Silica. Limnol. Oceanogr. 14 (1), 59-68.

Faust, J. C., Stevenson, M., Abbott, G., Knies, J., 2020. Does Arctic warming reduce preservation of organic matter in Barents Sea sediments? Philos. Trans. Royal Soc. A 378 (2181).

Faust, J. C., Tessin, A., Fisher, B. J., Zindorf, M., Papadaki, S., Hendry, K. R., Doyle, K. A., März, C., 2021. Millennial scale persistence of organic carbon bound to iron in Arctic marine sediments. Nat. Commun. 12 (275).

Fetterer, F., Savoie, M., Helfrich, S., Clemente-Colón, P., 2010. Multisensor Analyzed Sea Ice Extent - Northern Hemisphere (MASIE-NH), Version 1. U.S. National Ice Center and National Snow and Ice Data Center, Boulder, Colorado USA. 
Freitas, F. S., Hendry, K. R., Henley, S. F., Faust, J. C., Tessin, A. C., Stevenson, M. A., Abbott, G. D., März, C., Arndt, S., 2020. Benthic-pelagic coupling in the Barents Sea: an integrated data-model framework. Philos. Trans. Royal Soc. A 378 (2181).

Frings, P., 2017. Revisiting the dissolution of biogenic Si in marine sediments: a key term in the ocean Si budget. Acta Geochim. 36, 429-432.

Frings, P. J., Clymans, W., Fontorbe, G., De La Rocha, C. L., Conley, D. J., 2016. The continental Si cycle and its impact on the ocean Si isotope budget. Chem. Geol. 425, $12-36$.

Gallinari, M., Ragueneau, O., Corrin, L., DeMaster, D. J., Tréguer, P., 2002. The importance of water column processes on the dissolution properties of biogenic silica in deep-sea sediments I. Solubility. Geochim. Cosmochim. Acta 66 (15), 2701-2717.

Gehlen, M., Malschaert, H., Van Raaphorst, W. R., 1995. Spatial and temporal variability of benthic silica fluxes in the southeastern North Sea. Cont. Shelf Res. 15 (13), 1675-1696.

Geilert, S., Grasse, P., Doering, K., Wallmann, K., Ehlert, C., Scholz, F., Frank, M., Schmidt, M., Hensen, C., 2020. Impact of ambient conditions on the Si isotope fractionation in marine pore fluids during early diagenesis. Biogeosciences 17, 1745-1763.

Georg, R. B., Reynolds, B. C., Frank, M., Halliday, A. N., 2006. New sample preparation techniques for the determination of Si isotopic compositions using MC-ICPMS. Chem. Geol. 235 (1-2), 95-104.

Giesbrecht, K. E., 2019. Biogenic Silica Dynamics of Arctic Marine Ecosystems. Ph.D. thesis, University of Victoria.

Giesbrecht, K. E., Varela, D. E., 2021. Summertime Biogenic Silica Production and Silicon Limitation in the Pacific Arctic Region From 2006 to 2016. Global Biogeochem. Cycles $35(1)$. 
Grasse, P., Brzezinski, M. A., Cardinal, D., De Souza, G. F., Andersson, P., Closset, I., Cao, Z., Dai, M., Ehlert, C., Estrade, N., François, R., Frank, M., Jiang, G., Jones, J. L., Kooijman, E., Liu, Q., Lu, D., Pahnke, K., Ponzevera, E., Schmitt, M., Sun, X., Sutton, J. N., Thil, F., Weis, D., Wetzel, F., Zhang, A., Zhang, J., Zhang, Z., 2017. GEOTRACES inter-calibration of the stable silicon isotope composition of dissolved silicic acid in seawater. J. Anal. At. Spectrom. 32 (3), 562-578.

Hammond, D. E., Cummins, K. M., Mcmanus, J., Berelson, W. M., Smith, G., Spagnoli, F., 2004. Methods for measuring benthic nutrient flux on the California Margin: Comparing shipboard core incubations to in situ lander results. Limnol. Oceanogr.: Methods 2 (6), $146-159$.

Hátún, H., Azetsu-Scott, K., Somavilla, R., Rey, F., Johnson, C., Mathis, M., Mikolajewicz, U., Coupel, P., Tremblay, J., Hartman, S., Pacariz, S. V., Salter, I., Ólafsson, J., 2017. The subpolar gyre regulates silicate concentrations in the North Atlantic. Sci. Rep. 7 (14576).

Haug, T., Bogstad, B., Chierici, M., Gjøsæter, H., Hallfredsson, E. H., Høines, Å. S., Hoel, A. H., Ingvaldsen, R. B., Jørgensen, L. L., Knutsen, T., Loeng, H., Naustvoll, L. J., Røttingen, I., Sunnanå, K., 2017. Future harvest of living resources in the Arctic Ocean north of the Nordic and Barents Seas: A review of possibilities and constraints. Fish. Res. $188,38-57$.

Hawkings, J. R., Wadham, J. L., Benning, L. G., Hendry, K. R., Tranter, M., Tedstone, A., Nienow, P., Raiswell, R., 2017. Ice sheets as a missing source of silica to the polar oceans. Nat. Commun. 8 (14198).

Hendry, K. R., Andersen, M. B., 2013. The zinc isotopic composition of siliceous marine sponges: Investigating nature's sediment traps. Chem. Geol. 354, 33-41.

Hendry, K. R., Huvenne, V. A., Robinson, L. F., Annett, A., Badger, M., Jacobel, A. W., Ng, H. C., Opher, J., Pickering, R. A., Taylor, M. L., Bates, S. L., Cooper, A., Cushman, G. G., Goodwin, C., Hoy, S., Rowland, G., Samperiz, A., Williams, J. A., Achterberg, 
E. P., Arrowsmith, C., Alexander Brearley, J., Henley, S. F., Krause, J. W., Leng, M. J., Li, T., McManus, J. F., Meredith, M. P., Perkins, R., Woodward, E. M. S., 2019. The biogeochemical impact of glacial meltwater from Southwest Greenland. Prog. Oceanogr. 176 (102126).

Hendry, K. R., Leng, M. J., Robinson, L. F., Sloane, H. J., Blusztjan, J., Rickaby, R. E., Georg, R. B., Halliday, A. N., 2011. Silicon isotopes in Antarctic sponges: An interlaboratory comparison. Antarct. Sci. 23, 34-42.

Hendry, K. R., Robinson, L. F., 2012. The relationship between silicon isotope fractionation in sponges and silicic acid concentration: Modern and core-top studies of biogenic opal. Geochim. Cosmochim. Acta 81, 1-12.

Holmes, R. M., McClelland, J. W., Peterson, B. J., Tank, S. E., Bulygina, E., Eglinton, T. I., Gordeev, V. V., Gurtovaya, T. Y., Raymond, P. A., Repeta, D. J., Staples, R., Striegl, R. G., Zhulidov, A. V., Zimov, S. A., 2012. Seasonal and Annual Fluxes of Nutrients and Organic Matter from Large Rivers to the Arctic Ocean and Surrounding Seas. Estuaries Coast 35 (2), 369-382.

Hopkins, J., 2018. The Changing Arctic Ocean Cruise JR16006, RRS James Clark Ross, Cruise Report No.51. Tech. rep.

Hou, Y., Hammond, D. E., Berelson, W. M., Kemnitz, N., Adkins, J. F., Lunstrum, A., 2019. Spatial patterns of benthic silica flux in the North Pacific reflect upper ocean production. Deep. Res. I 148, 25-33.

Hughes, H. J., Delvigne, C., Korntheuer, M., De Jong, J., André, L., Cardinal, D., 2011. Controlling the mass bias introduced by anionic and organic matrices in silicon isotopic measurements by MC-ICP-MS. J. Anal. At. Spectrom. 26 (9), 1892-1896.

Hughes, H. J., Sondag, F., Santos, R. V., André, L., Cardinal, D., 2013. The riverine silicon isotope composition of the Amazon Basin. Geochim. Cosmochim. Acta 121, 637-651. 
Hurd, D., 1983. Physical and chemical properties of siliceous skeletons. In: Aston, S. R. (Ed.), Silicon Geochemistry and Biogeochemistry. Academic Press, London, pp. 187-244.

Hurd, D. C., 1973. Interactions of biogenic opal, sediment and seawater in the Central Equatorial Pacific. Geochim. Cosmochim. Acta 37, 2257-2282.

Jakobsson, M., Grantz, A., Kristoffersen, Y., Macnab, R., 2003. Physiographic provinces of the Arctic Ocean seafloor. Geol. Soc. Am. Bull. 115 (12), 1443-1455.

Jakobsson, M., Mayer, L., Coakley, B., Dowdeswell, J. A., Forbes, S., Fridman, B., Hodnesdal, H., Noormets, R., Pedersen, R., Rebesco, M., Schenke, H. W., Zarayskaya, Y., Accettella, D., Armstrong, A., Anderson, R. M., Bienhoff, P., Camerlenghi, A., Church, I., Edwards, M., Gardner, J. V., Hall, J. K., Hell, B., Hestvik, O., Kristoffersen, Y., Marcussen, C., Mohammad, R., Mosher, D., Nghiem, S. V., Pedrosa, M. T., Travaglini, P. G., Weatherall, P., 2012. The International Bathymetric Chart of the Arctic Ocean (IBCAO) Version 3.0. Geophys. Res. Lett. 39 (12).

Jeandel, C., Peucker-Ehrenbrink, B., Jones, M. T., Pearce, C. R., Oelkers, E. H., Godderis, Y., Lacan, F., Aumont, O., Arsouze, T., 2011. Ocean margins: The missing term in oceanic element budgets? Eos 92 (26), 217-224.

Jones, M. T., Pearce, C. R., Oelkers, E. H., 2012. An experimental study of the interaction of basaltic riverine particulate material and seawater. Geochim. Cosmochim. Acta 77, $108-120$.

Kamatani, A., Oku, O., 2000. Measuring biogenic silica in marine sediments. Mar. Chem. $68(3), 219-229$.

Karl, D. M., Tien, G., 1992. MAGIC: A sensitive and precise method for measuring dissolved phosphorus in aquatic environments. Limnol. Oceanogr. 37 (1), 105-116.

Khalil, K., Rabouille, C., Gallinari, M., Soetaert, K., DeMaster, D. J., Ragueneau, O., 2007. Constraining biogenic silica dissolution in marine sediments: A comparison between diagenetic models and experimental dissolution rates. Mar. Chem. 106, 223-238. 
Kim, J., Dong, H., Seabaugh, J., Newell, S. W., Eberl, D. D., 2004. Role of Microbes in the Smectite-to-Illite Reaction. Science 303, 830-832.

King, S., Froelich, P., Jahnke, R., 2000. Early diagenesis of germanium in sediments of the Antarctic South Atlantic: In search of the missing Ge sink. Geochim. Cosmochim. Acta 64 (8), 1375-1390.

Koning, E., Epping, E., Van Raaphorst, W., 2002. Determining biogenic silica in marine samples by tracking silicate and aluminium concentrations in alkaline leaching solutions. Aquat. Geochem. 8, 37-67.

Krause, J. W., Duarte, C. M., Marquez, I. A., Assmy, P., Fernández-Méndez, M., Wiedmann, I., Wassmann, P., Kristiansen, S., Agustí, S., 2018. Biogenic silica production and diatom dynamics in the Svalbard region during spring. Biogeosciences 15 (21), 6503-6517.

Krause, J. W., Schulz, I. K., Rowe, K. A., Dobbins, W., Winding, M. H., Sejr, M. K., Duarte, C. M., Agustí, S., 2019. Silicic acid limitation drives bloom termination and potential carbon sequestration in an Arctic bloom. Sci. Rep. 9 (8149).

Krissansen-Totton, J., Catling, D. C., 2020. A coupled carbon-silicon cycle model over Earth history: Reverse weathering as a possible explanation of a warm mid-Proterozoic climate. Earth Planet. Sci. Lett. 537 (116181).

Kulikov, N., 2004. Amorphous silica contents in bottom sediments from the Kara Sea. PANGAEA.

Lalande, C., Bauerfeind, E., Nöthig, E. M., Beszczynska-Möller, A., 2013. Impact of a warm anomaly on export fluxes of biogenic matter in the eastern Fram Strait. Prog. Oceanogr. $109,70-77$.

Laruelle, G. G., Roubeix, V., Sferratore, A., Brodherr, B., Ciuffa, D., Conley, D. J., Dürr, H. H., Garnier, J., Lancelot, C., LeThiPhuong, Q., Meunier, J. D., Meybeck, M., Michalopoulos, P., Moriceau, B., Ni Longphuirt, S., Loucaides, S., Papush, L., Presti, M., 
Ragueneau, O., Regnier, P., Saccone, L., Slomp, C. P., Spiteri, C., Van Cappellen, P., 2009. Anthropogenic perturbations of the silicon cycle at the global scale: Key role of the land-ocean transition. Global Biogeochem. Cycles 23 (4).

Lawson, D. S., Hurd, D. C., Pankratz, H. S., 1978. Silica dissolution rates of decomposing phytoplankton assemblages at various temperatures. Am. J. Sci. 278, 1373-1393.

Lerman, A., Mackenzie, F. T., Bricker, O. P., 1975. Rates of dissolution of aluminosilicates in seawater. Earth Planet. Sci. Lett. 25 (1), 82-88.

Li, Y. H., Gregory, S., 1974. Diffusion of ions in seawater and in deep-sea sediments. Geochim. Cosmochim. Acta 38 (5), 703-714.

Lien, V. S., Vikebø, F. B., Skagseth, O., 2013. One mechanism contributing to co-variability of the Atlantic inflow branches to the Arctic. Nat. Commun. 4 (1488).

Liguori, B. T., Ehlert, C., Pahnke, K., 2020. The Influence of Water Mass Mixing and Particle Dissolution on the Silicon Cycle in the Central Arctic Ocean. Front. Earth Sci. $7(202)$.

Lind, S., Ingvaldsen, R. B., Furevik, T., 2018. Arctic warming hotspot in the northern Barents Sea linked to declining sea-ice import. Nature Climate Change 8, 634-639.

Loucaides, S., Koning, E., Van Cappellen, P., 2012. Effect of pressure on silica solubility of diatom frustules in the oceans: Results from long-term laboratory and field incubations. Mar. Chem. 136-137, 1-6.

Loucaides, S., Michalopoulos, P., Presti, M., Koning, E., Behrends, T., Van Cappellen, P., 2010. Seawater-mediated interactions between diatomaceous silica and terrigenous sediments: Results from long-term incubation experiments. Chem. Geol. 270, 68-79.

Mackenzie, F., Garrels, R., 1965. Silicates: Reactivity with Sea Water. Science 150 (3692), $57-58$. 
Mackenzie, F. T., Garrels, R. M., Bricker, O. P., Bickley, F., 1967. Silica in sea water: Control by silica minerals. Science 155 (3768), 1404-1405.

Maldonado, M., López-Acosta, M., Sitjà, C., García-Puig, M., Galobart, C., Ercilla, G., Leynaert, A., 2019. Sponge skeletons as an important sink of silicon in the global oceans. Nat. Geosci. 12, 815-822.

Martin, W., Bender, M., 1988. The variability of benthic fluxes and sedimentary remineralization rates in response to seasonally variable organic carbon rain rates in the deep sea; a modeling study. Am. J. Sci. 288 (6), 561-574.

März, C., Meinhardt, A. K., Schnetger, B., Brumsack, H. J., 2015. Silica diagenesis and benthic fluxes in the Arctic Ocean. Mar. Chem. 171, 1-9.

McManus, J., Hammond, D. E., Berelson, W. M., Kilgore, T. E., Demaster, D. J., Ragueneau, O. G., Collier, R. W., 1995. Early diagenesis of biogenic opal: Dissolution rates, kinetics, and paleoceanographic implications. Deep. Res. II 42 (2-3), 871-903.

Michalopoulos, P., Aller, R. C., 1995. Rapid clay mineral formation in Amazon delta sediments: Reverse weathering and oceanic elemental cycles. Science 270, 614-617.

Michalopoulos, P., Aller, R. C., 2004. Early diagenesis of biogenic silica in the Amazon delta: Alteration, authigenic clay formation, and storage. Geochim. Cosmochim. Acta 68 (5), 1061-1085.

Middag, R., de Baar, H. J., Laan, P., Bakker, K., 2009. Dissolved aluminium and the silicon cycle in the Arctic Ocean. Mar. Chem. 115 (3-4), 176-195.

Milligan, A. J., Varela, D. E., Brzezinski, M. A., Morel, F. M., 2004. Dynamics of silicon metabolism and silicon isotopic discrimination in a marine diatom as a function of pCO2. Limnol. Oceanogr. 49, 322-329.

Mortlock, R. A., Froelich, P. N., 1989. A simple method for the rapid determination of biogenic opal in pelagic marine sediments. Deep. Res. A 36 (9), 1415-1426. 
Neukermans, G., Oziel, L., Babin, M., 2018. Increased intrusion of warming Atlantic water leads to rapid expansion of temperate phytoplankton in the Arctic. Glob. Change Biol. $24(6), 2545-2553$.

Ng, H. C., Cassarino, L., Pickering, R. A., Woodward, E. M. S., Hammond, S. J., Hendry, K. R., 2020. Sediment efflux of silicon on the Greenland margin and implications for the marine silicon cycle. Earth Planet. Sci. Lett. 529 (115877).

Odin, G. S., Fröhlich, F., 1988. Chapter C3 Glaucony from the Kerguelen Plateau (Southern Indian Ocean). Dev. Sedimentol. 45, 277-294.

Olli, K., Wexels Riser, C., Wassmann, P., Ratkova, T., Arashkevich, E., Pasternak, A., 2002. Seasonal variation in vertical flux of biogenic matter in the marginal ice zone and the central Barents Sea. J. Mar. Syst. 38, 189 - 204.

Opfergelt, S., Delmelle, P., 2012. Silicon isotopes and continental weathering processes: Assessing controls on Si transfer to the ocean. C. R. - Geosci. 344 (11-12), 723-738.

Orkney, A., Platt, T., Narayanaswamy, B. E., Kostakis, I., Bouman, H. A., 2020. Bio-optical evidence for increasing Phaeocystis dominance in the Barents Sea: Increasing Phaeocystis in Barents Sea. Philos. Trans. Royal Soc. A 378 (2181).

Oziel, L., Neukermans, G., Ardyna, M., Lancelot, C., Tison, J. L., Wassmann, P., Sirven, J., Ruiz-Pino, D., Gascard, J. C., 2017. Role for Atlantic inflows and sea ice loss on shifting phytoplankton blooms in the Barents Sea. J. Geophys. Res.: Oceans 122 (6), 5121-5139.

Oziel, L., Sirven, J., Gascard, J. C., 2016. The Barents Sea frontal zones and water masses variability (1980-2011). Ocean Sci. 12, 169-184.

Pickering, R., Cassarino, L., Hendry, K., Wang, X., Maiti, K., Krause, J., 2020. Using Stable Isotopes to Disentangle Marine SedimentarySignals in Reactive Silicon Pools. Geophys. Res. Lett. 47 (15). 
Pirrung, M., Illner, P., Matthiessen, J., 2008. Biogenic barium in surface sediments of the European Nordic Seas. Mar. Geol. 250 (1-2), 89-103.

Rabouille, C., Gaillard, J. F., Tréguer, P., Vincendeau, M. A., 1997. Biogenic silica recycling in surficial sediments across the Polar Front of the Southern Ocean (Indian Sector). Deep. Res. II 44 (5), 1151-1176.

Ragueneau, O., Chauvaud, L., Leynaert, A., Thouzeau, G., Paulet, Y. M., Bonnet, S., Lorrain, A., Grall, J., Corvaisier, R., Le Hir, M., Jean, F., Clavier, J., 2002. Direct evidence of a biologically active coastal silicate pump: Ecological implications. Limnol. Oceanogr. 47 (6), 1849-1854.

Ragueneau, O., Gallinari, M., Corrin, L., Grandel, S., Hall, P., Hauvespre, A., Lampitt, R. S., Rickert, D., Stahl, H., Tengberg, A., Witbaard, R., 2001. The benthic silica cycle in the Northeast Atlantic: Annual mass balance, seasonality, and importance of non-steady-state processes for the early diagenesis of biogenic opal in deep-sea sediments. Prog. Oceanogr. $50(1-4), 171-200$.

Ragueneau, O., Savoye, N., Del Amo, Y., Cotten, J., Tardiveau, B., Leynaert, A., 2005. A new method for the measurement of biogenic silica in suspended matter of coastal waters: Using Si:Al ratios to correct for the mineral interference. Cont. Shelf Res. 25, 5-6.

Ragueneau, O., Tréguer, P., 1994. Determination of biogenic silica in coastal waters: applicability and limits of the alkaline digestion method. Mar. Chem. 45 (1-2), 43-51.

Ragueneau, O., Tréguer, P., Leynaert, A., Anderson, R. F., Brzezinski, M. A., DeMaster, D. J., Dugdale, R. C., Dymond, J., Fischer, G., François, R., Heinze, C., Maier-Reimer, E., Martin-Jézéquel, V., Nelson, D. M., Quéguiner, B., 2000. A review of the Si cycle in the modern ocean: Recent progress and missing gaps in the application of biogenic opal as a paleoproductivity proxy. Glob. Planet. Change 26 (4), 317-365.

Rahman, S., Aller, R. C., Cochran, J. K., 2016. Cosmogenic 32Si as a tracer of biogenic silica 
burial and diagenesis: Major deltaic sinks in the silica cycle. Geophys. Res. Lett. 43 (13), $7124-7132$.

Rahman, S., Aller, R. C., Cochran, J. K., 2017. The Missing Silica Sink: Revisiting the Marine Sedimentary Si Cycle Using Cosmogenic 32Si. Global Biogeochem. Cycles 31 (10), $1559-1578$.

Rahn, K. A., 1976. Silicon and aluminum in atmospheric aerosols: Crust-air fractionation? Atmos. Environ. 10, 597-601.

Rebreanu, L., Vanderborght, J. P., Chou, L., 2008. The diffusion coefficient of dissolved silica revisited. Mar. Chem. 112, 230-233.

Reigstad, M., Wassmann, P., Wexels Riser, C., Øygarden, S., Rey, F., 2002. Variations in hydrography, nutrients and chlorophyll a in the marginal ice-zone and the central Barents Sea. J. Mar. Syst. 38, 9-29.

Ren, H., Brunelle, B. G., Sigman, D. M., Robinson, R. S., 2013. Diagenetic aluminum uptake into diatom frustules and the preservation of diatom-bound organic nitrogen. Mar. Chem. $155,92-101$.

Rey, F., 2012. Declining silicate concentrations in the Norwegian and Barents Seas. ICES J. Mar. Sci. 69 (2), 208-212.

Reynolds, B. C., Aggarwal, J., André, L., Baxter, D., Beucher, C., Brzezinski, M. A., Engström, E., Georg, R. B., Land, M., Leng, M. J., Opfergelt, S., Rodushkin, I., Sloane, H. J., Van Den Boorn, S. H., Vroon, P. Z., Cardinal, D., 2007. An inter-laboratory comparison of Si isotope reference materials. J. Anal. At. Spectrom. 22 (5), 561-568.

Rickert, D., 2000. Dissolution kinetics of biogenic silica in marine environments. Ph.D. thesis, Christian-Albrecht University of Kiel.

Rickert, D., Schlüter, M., Wallmann, K., 2002. Dissolution kinetics of biogenic silica from the water column to the sediments. Geochim. Cosmochim. Acta 66 (3), 439-455. 
Sakshaug, E., 1997. Biomass and productivity distributions and their variability in the Barents Sea. ICES J. Mar. Sci. 54 (3), 341-350.

Sarmiento, J. L., Gruber, N., 2006. Ocean Biogeochemical Dynamics Sarmiento. Princeton University Press, Princeton, NJ.

Sayles, F. L., Deuser, W. G., Goudreau, J. E., Dickinson, W. H., Jickells, T. D., King, P., 1996. The benthic cycle of biogenic opal at the Bermuda Atlantic Time Series site. Deep. Res. I 43 (4), 383-409.

Sayles, F. L., Martin, W. R., Chase, Z., Anderson, R. F., 2001. Benthic remineralization and burial of biogenic $\mathrm{SiO} 2, \mathrm{CaCO} 3$, organic carbon, and detrital material in the Southern Ocean along a transect at $170^{\circ}$ West. Deep. Res. II 48 (19-20), 4323-4383.

Sayles, F. L., Martin, W. R., Deuser, W. G., 1994. Response of benthic oxygen demand to particulate organic carbon supply in the deep sea near Bermuda. Nature 371, 686-689.

Schink, D. R., Guinasso, N. L., Fanning, K. A., 1975. Processes affecting the concentration of silica at the sediment-water interface of the Atlantic Ocean. J. Geophys. Res. 80 (21), 3013-3031.

Schlüter, M., Sauter, E., 2000. Biogenic silica cycle in surface sediments of the Greenland Sea. J. Mar. Syst. 23 (4), 333-342.

Siever, R., 1968. Establishment of equilibrium between clays and sea water. Earth Planet. Sci. Lett. 5, 106-110.

Smedsrud, L. H., Esau, I., Ingvaldsen, R. B., Eldevik, T., Haugan, P. M., Li, C., Lien, V. S., Olsen, A., Omar, A. M., Risebrobakken, B., Sandø, A. B., Semenov, V. A., Sorokina, S. A., 2013. The role of the Barents Sea in the Arctic climate system. Rev. Geophys. $51(3), 415-449$.

Solan, M., 2018. The Changing Arctic Ocean: Cruise Report, RRS James Clark Ross JR17007. Tech. rep. 
Solan, M., Ward, E. R., Wood, C. L., Reed, A. J., Grange, L. J., Godbold, J. A., 2020. Climate-driven benthic invertebrate activity and biogeochemical functioning across the Barents Sea polar front: Climate driven benthic activity. Philos. Trans. Royal Soc. A $378(2181)$.

Srithongouthai, S., Sonoyama, Y. I., Tada, K., Montani, S., 2003. The influence of environmental variability on silicate exchange rates between sediment and water in a shallow-water coastal ecosystem, the Seto Inland Sea, Japan. Mar. Pollut. Bull. 47, 10-17.

Strickland, J., Parsons, T., 1972. A Practical Handbook of Seawater Analysis. Vol. 167. Fisheries Research Board of Canada, Ottawa.

Sun, X., Olofsson, M., Andersson, P. S., Fry, B., Legrand, C., Humborg, C., Mörth, C. M., 2014. Effects of growth and dissolution on the fractionation of silicon isotopes by estuarine diatoms. Geochim. Cosmochim. Acta 130, 156-166.

Sutton, J. N., André, L., Cardinal, D., Conley, D. J., De Souza, G. F., Dean, J., Dodd, J., Ehlert, C., Ellwood, M. J., Frings, P. J., Grasse, P., Hendry, K., Leng, M. J., Michalopoulos, P., Panizzo, V. N., Swann, G. E., 2018. A review of the stable isotope bio-geochemistry of the global silicon cycle and its associated trace elements. Front. Earth Sci. 5 (112).

Sutton, J. N., Varela, D. E., Brzezinski, M. A., Beucher, C. P., 2013. Species-dependent silicon isotope fractionation by marine diatoms. Geochim. Cosmochim. Acta 104, 300309.

Tréguer, P., Nelson, D. M., Van Bennekom, A. J., Demaster, D. J., Leynaert, A., Quéguiner, B., 1995. The silica balance in the world ocean: A reestimate. Science 268, 375-379.

Tréguer, P. J., De La Rocha, C. L., 2013. The World Ocean Silica Cycle. Ann. Rev. Marine Sci. 5, 477-501.

Tréguer, P. J., Sutton, J. N., Brzezinski, M., Charette, M. A., Devries, T., Dutkiewicz, S., Ehlert, C., Hawkings, J., Leynaert, A., Liu, S. M., Monferrer, N. L., López-Acosta, M., 
Maldonado, M., Rahman, S., Ran, L., Rouxel, O., 2021. Reviews and syntheses: The biogeochemical cycle of silicon in the modern ocean. Biogeosciences 18, 1269-1289.

Van Bennekom, A. J., Buma, A. G., Nolting, R. F., 1991. Dissolved aluminium in the Weddell-Scotia Confluence and effect of $\mathrm{Al}$ on the dissolution kinetics of biogenic silica. Mar. Chem. 35, 423-434.

van Bennekom, A. J., Fred Jansen, J. H., van der Gaast, S. J., van Iperen, J. M., Pieters, J., 1989. Aluminium-rich opal: an intermediate in the preservation of biogenic silica in the Zaire (Congo) deep-sea fan. Deep. Res. A 36 (2), 173-190.

Van Cappellen, P., Qiu, L., 1997. Biogenic silica dissolution in sediments of the Southern Ocean. I. Solubility. Deep. Res. II 44, 1109-1128.

Van Den Boorn, S. H., Vroon, P. Z., Van Bergen, M. J., 2009. Sulfur-induced offsets in MC-ICP-MS silicon-isotope measurements. J. Anal. At. Spectrom. 24 (8), 1111-1114.

Varela, D. E., Brzezinski, M. A., Beucher, C. P., Jones, J. L., Giesbrecht, K. E., Lansard, B., Mucci, A., 2016. Heavy silicon isotopic composition of silicic acid and biogenic silica in Arctic waters over the Beaufort shelf and the Canada Basin. Global Biogeochem. Cycles $30(6), 804-824$.

Wassmann, P., Olli, K., 2004. Central Barents Sea and Northern Spitsbergen. In: Stein, R., Macdonald, R. W. (Eds.), The Organic Carbon Cycle in the Arctic Ocean. Springer, Berlin, pp. 112-114.

Wassmann, P., Ratkova, T., Andreassen, I., Vernet, M., Pedersen, G., Rey, F., 1999. Spring bloom development in the marginal ice zone and the central Barents Sea. Mar. Ecol. $20(3-4), 321-346$.

Wassmann, P., Reigstad, M., Haug, T., Rudels, B., Carroll, M. L., Hop, H., Gabrielsen, G. W., Falk-Petersen, S., Denisenko, S. G., Arashkevich, E., Slagstad, D., Pavlova, O., 2006a. Food webs and carbon flux in the Barents Sea. Prog. Oceanogr. 71 (2-4), 232-287. 
Wassmann, P., Slagstad, D., Riser, C. W., Reigstad, M., 2006b. Modelling the ecosystem dynamics of the Barents Sea including the marginal ice zone: II. Carbon flux and interannual variability. J. Mar. Syst. 59 (1-2), 1-24.

Wetzel, F., de Souza, G. F., Reynolds, B. C., 2014. What controls silicon isotope fractionation during dissolution of diatom opal? Geochim. Cosmochim. Acta 131, 128-137.

Willey, J. D., 1978. Release and uptake of dissolved silica in seawater by marine sediments. Mar. Chem. 7, 53-65.

Wollast, R., 1974. The Silica Problem. In: Goldberg, E. (Ed.), The Sea, Volume 5: The Global Coastal Ocean. Harvard University Press, Ch. 11, pp. 359-392.

Zaborska, A., Carroll, J. L., Papucci, C., Torricelli, L., Carroll, M. L., Walkusz-Miotk, J., Pempkowiak, J., 2008. Recent sediment accumulation rates for the Western margin of the Barents Sea. Deep. Res. II 55 (20-21), 2352-2360.

Zheng, X. Y., Beard, B. L., Reddy, T. R., Roden, E. E., Johnson, C. M., 2016. Abiologic silicon isotope fractionation between aqueous $\mathrm{Si}$ and $\mathrm{Fe}(\mathrm{III})-\mathrm{Si}$ gel in simulated Archean seawater: Implications for Si isotope records in Precambrian sedimentary rocks. Geochim. Cosmochim. Acta 187, 102-122.

Figure 1: Map of ChAOS sampling stations and schematic of water mass circulation in the Barents Sea (PF- Polar Front (oceanic), AW-Atlantic Water, ArW-Arctic Water, NCCW- Norwegian Coastal Current Water, BSW- Barents Sea Water, BSO- Barents Sea Opening, BSX- Barents Sea Exit. Dotted current paths represent subducted water masses (Lien et al., 2013)). The Barents Sea has a mean water depth of $230 \mathrm{~m}$ and is the largest of seven shelf seas encircling the Arctic Ocean, covering $1.4 \times 10^{6} \mathrm{~km}^{2}$ (Sakshaug, 1997). NCCW and warm AW flow northwards through the BSO, while colder, relatively nutrient poor ArW flows southwards (Oziel et al., 2016; Årthun et al., 2012). The PF delineates the 
northern, ArW sector which is seasonally ice-covered (August-September minima, MarchApril maxima) and the AW dominated region to the south, which is kept perennially ice-free by the warmth of the AW. The bathymetry of the Barents Sea is characterised by the juxtaposition of deep troughs and shallow banks, which topographically constrain the PF in the western shelf, rendering it's position relatively stable (Oziel et al., 2016). This is in contrast to the eastern branch of the PF, which presents with significant positional variability on seasonal and interannual timescales (Smedsrud et al., 2013). The mixing of water masses, coupled with brine rejection from sea ice formation on the shallow banks forms denser BSW, which cascades to greater depths in a northeasterly direction, draining into the Arctic Ocean through the BSX (Smedsrud et al., 2013). BSW is thought to be critical for ventilation of the deep Arctic Ocean and for regional atmospheric $\mathrm{CO}_{2}$ sequestration (Oziel et al., 2016; Smedsrud et al., 2013). Bathymetry data is from the GEBCO 2014 dataset (Jakobsson et al., 2012).

Figure 2: Compilation of all [DSi] depth profiles analysed on board the three ChAOS cruises. Top row: southern, Atlantic water stations (B03, B13, B14 (PF)). Bottom row: northern, Arctic water stations (B15, B16, B17). Includes all three Multicorer deployments per station for each cruise year.

Figure 3: B13, B14 and B15 pore water $\delta^{30} \mathrm{Si}_{D S i-P W}$ and [DSi] depth profiles for the three ChAOS cruises, as well as representative pore water [Fe] (open symbols) (Faust et al., 2021) and $\mathrm{NO}_{3}^{-}$(closed symbols) concentrations (Freitas et al., 2020). The decrease in $\mathrm{NO}_{3}^{-}$ concentration with depth from the SWI reflects the shift from oxic to anoxic conditions in the pore waters, driving the increase in pore water Fe. Top row: B13 (black) and B15 (grey), bottom row: B14. Error bars represent $\pm 2 \sigma$ of the long term reproducibility of Diatomite standard, unless the same value for measurement replicates was greater. Vertical dashed lines show the core top water composition $\left(\delta^{30} \mathrm{Si}_{D S i-C T}\right)$ for the three stations from 2017. 
Figure 4: On-board core incubation experiment from 2019 (JR18006). Sampling was carried out every 3 hours over a 24 hour period. Top row: Core top water [DSi] against the ratio of sampling time (hours) to core top height $(\mathrm{cm})$. Gradient ('m') of the linear regressions represent the magnitude of the DSi benthic flux $\left(\mathrm{mmol} \mathrm{m}{ }^{-2}\right.$ day $^{-1}$, where $\mu \mathrm{M}$ is equivalent to $\mathrm{mmol} \mathrm{m} \mathrm{m}^{-3}$ ). Gradient uncertainty is represented by $95 \%$ confidence limits, dashed lines depict 95\% prediction bands. Bottom row: Si isotopic composition of the core top water $\left(\delta^{30} \mathrm{Si}_{D S i-I n c}\right)$. Error bars represent long term reproducibility of Si standards $(2 \sigma$ \pm 0.14 ), unless $2 \sigma$ of measurement replicates was greater.

Figure 5: A) BSi wt\% for B13, B14 and B15 samples from the 2019 cruise. Error bars denote $\pm 2 \sigma$ of sample triplicates. B) $\delta^{30} \mathrm{Si}$ compilation from this study, including all pore water and solid phase leachate measurements. $\delta^{30} \mathrm{Si}_{\mathrm{NaOH}}$ and $\delta^{30} \mathrm{Si}_{\mathrm{HCl}}$ values are grouped for the three stations (B13, B14, B15), as they are indistinguishable within long term reproducibility.

Figure 6: Pore water $\delta^{30} \mathrm{Si}_{D S i-P W}$ plotted against the inverse of the DSi concentration $(1 /[\mathrm{DSi}])$. The mixing line was calculated following equation 7, from Geilert et al. (2020). The $\delta^{30} \mathrm{Si}$ of the BSi solution for each station is equivalent to $\delta^{30} \mathrm{Si}_{A l k}$.

Figure 7: Comparison of sea ice conditions on the day of sampling at B14 (30th July 2017, 25th July 2018, 13th July 2019) compared to the sea ice extent on the 1st May of each cruise to demonstrate the disparity in ice melt across the three years. Left to right: JR16006 (summer 2017), JR17007 (2018), JR18006 (2019). Daily sea ice extent data from the U.S. National Ice Center and National Snow and Ice Data Center (NSIDC) (Fetterer et al., 2010). 


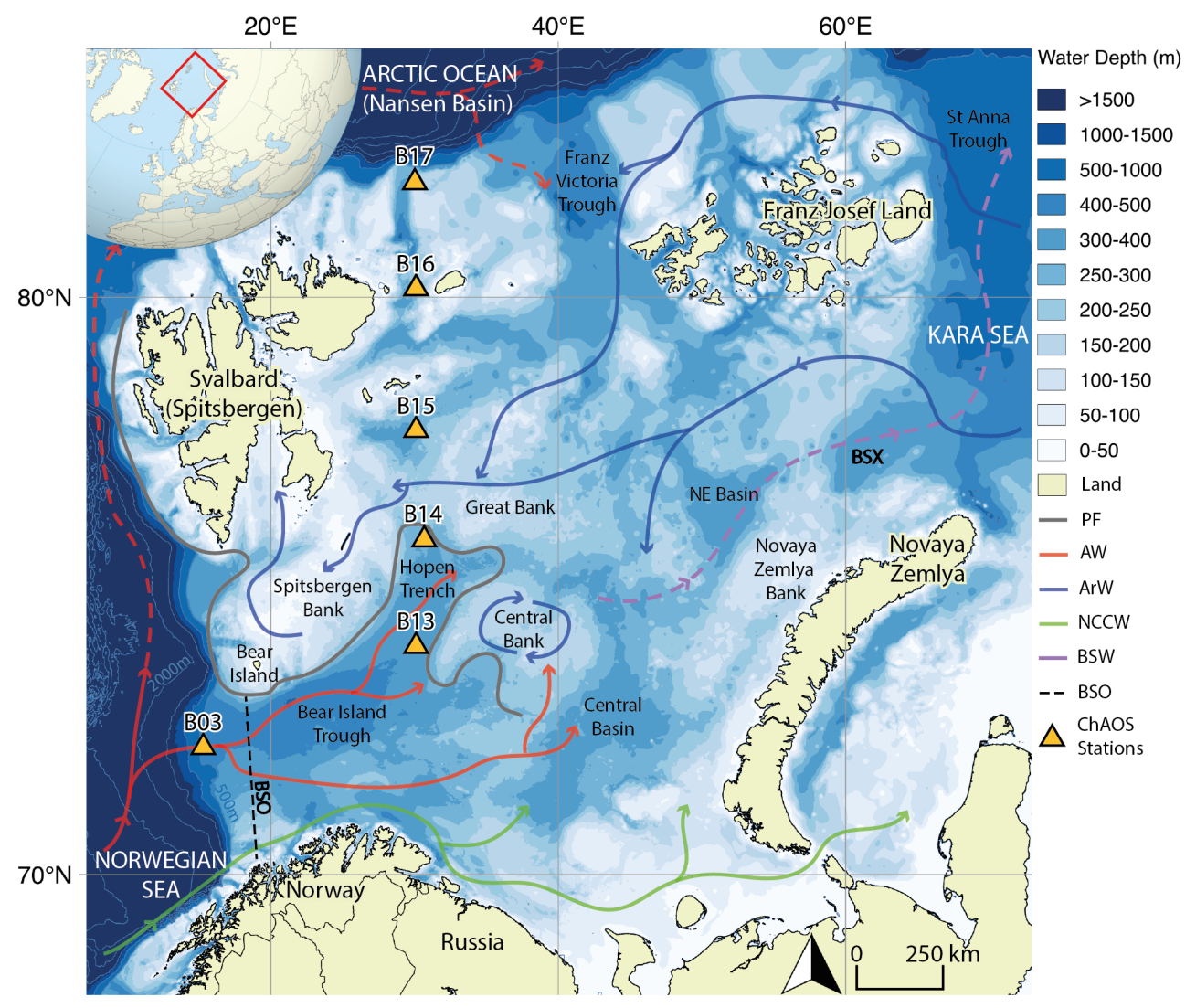

Figure 1: 

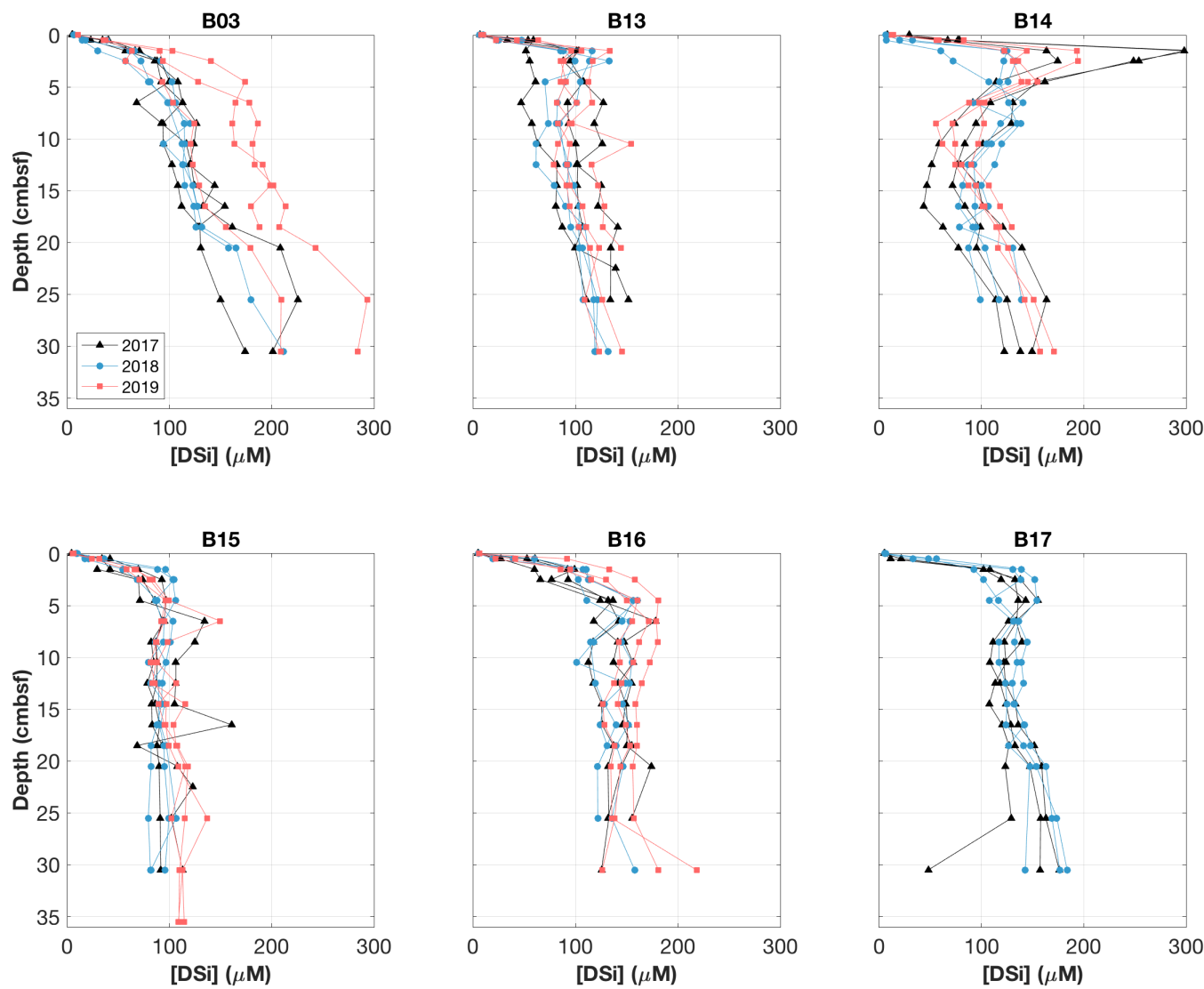

Figure 2: 

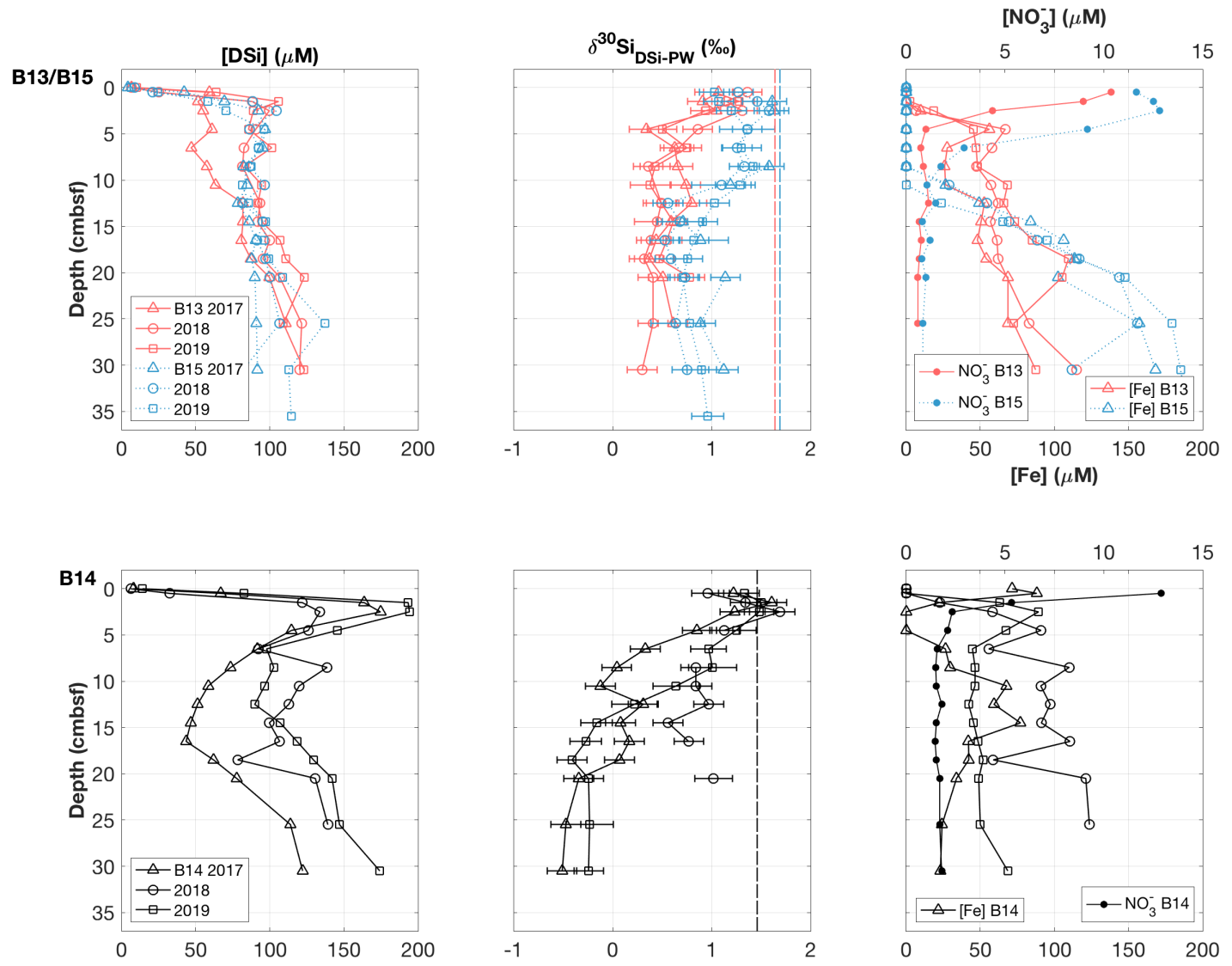

Figure 3: 

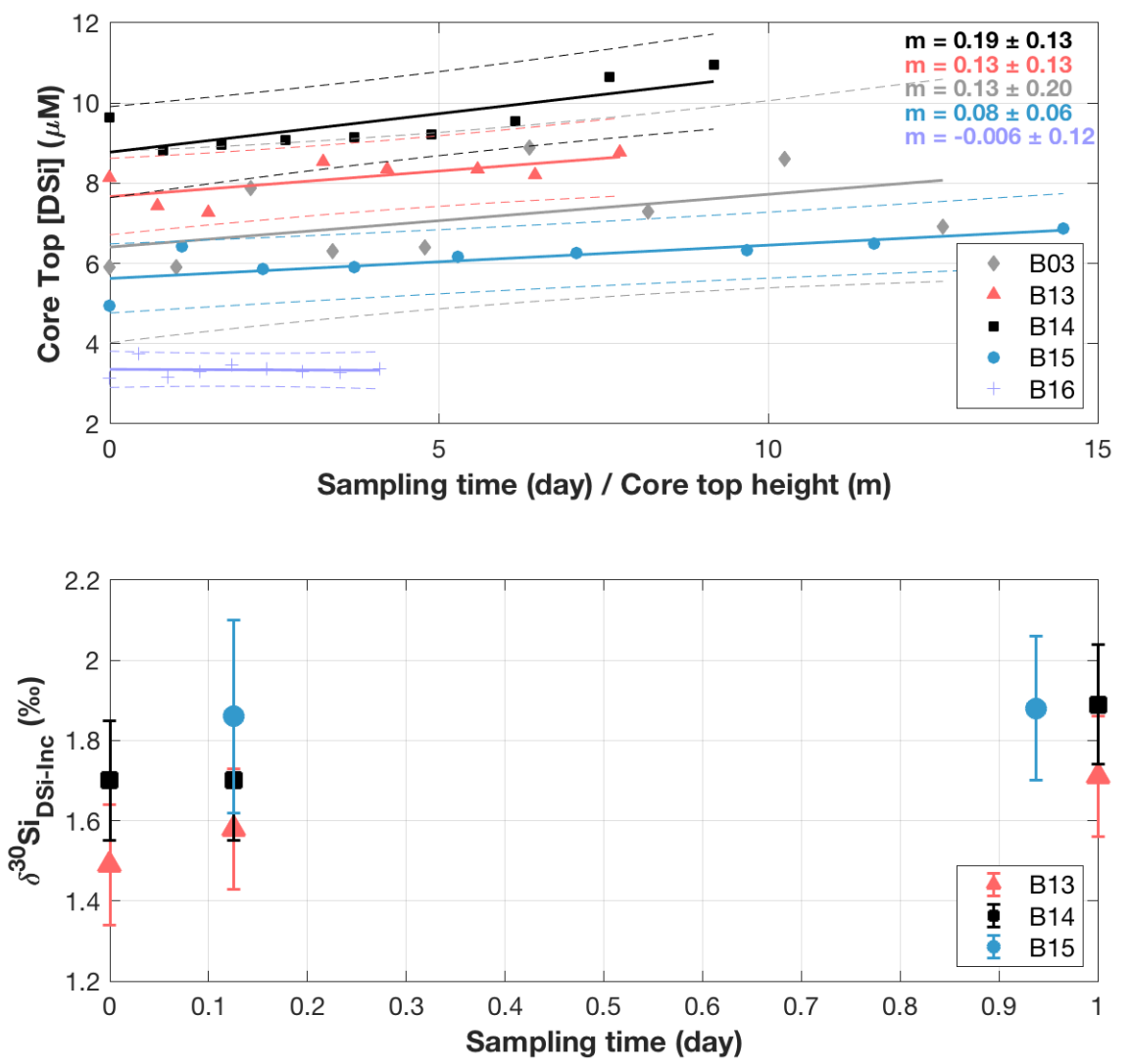

Figure 4: 

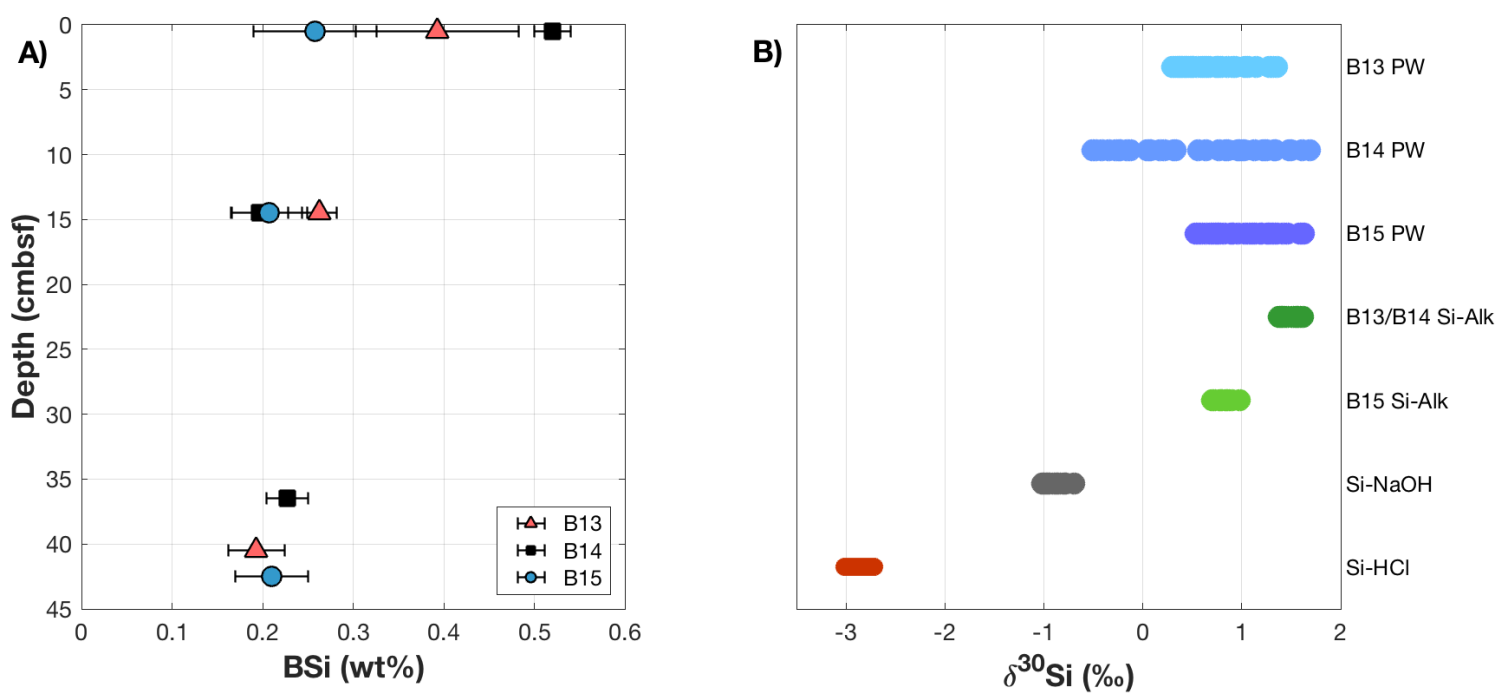

Figure 5:

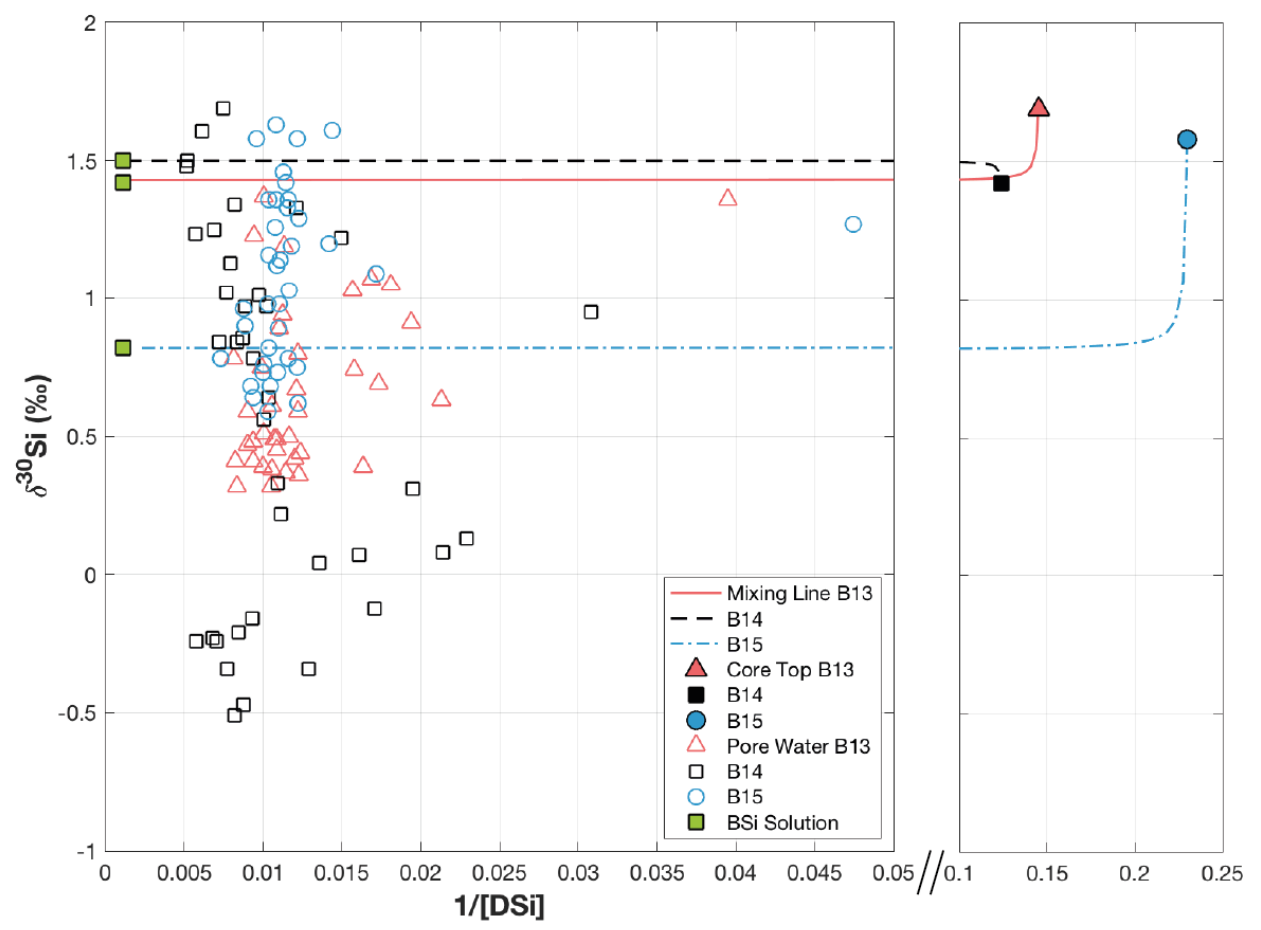

Figure 6: 

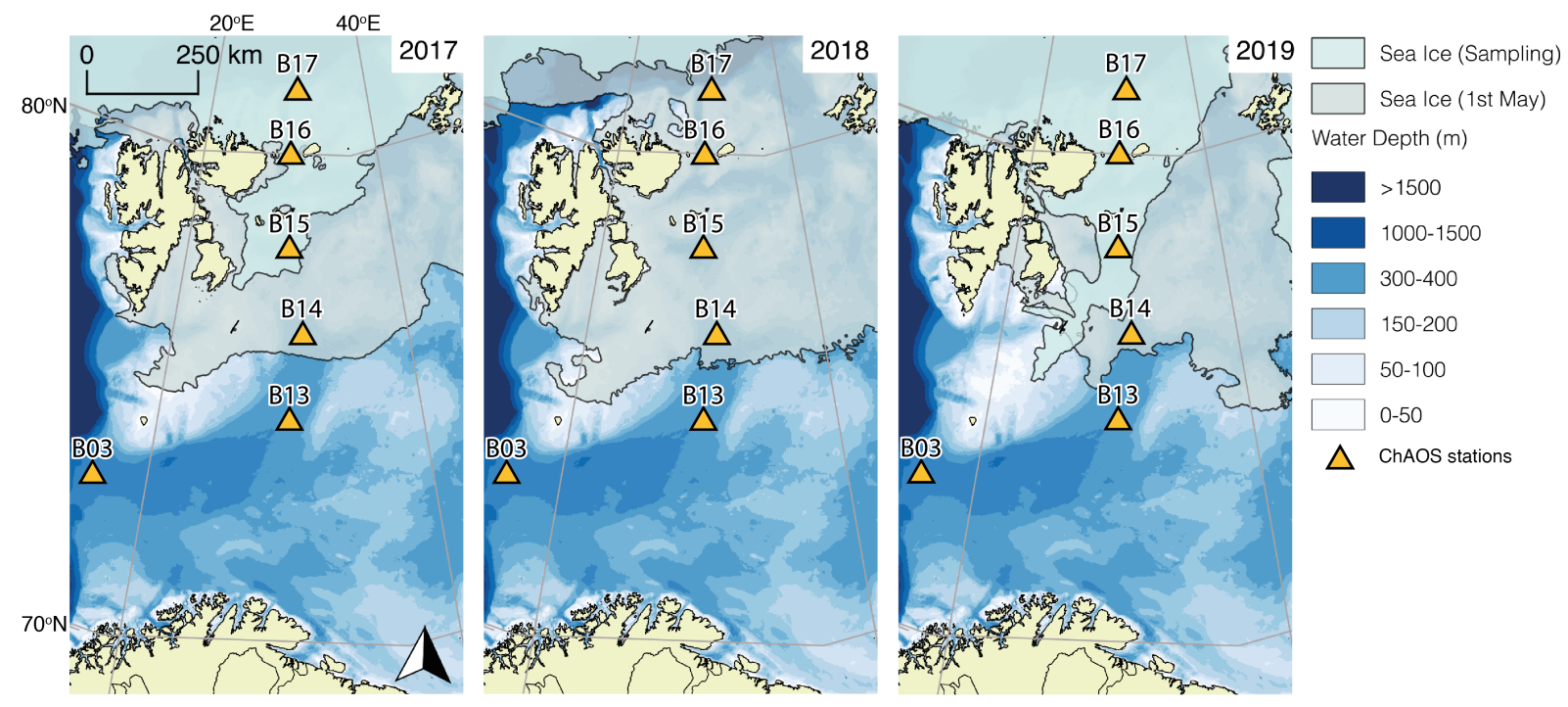

Figure 7: 


\title{
Supplementary Material: Stable Silicon Isotopes Uncover a Mineralogical Control on the Benthic Silicon Cycle in the Arctic Barents Sea
}

James P.J. Ward ${ }^{1,}$, Katharine R. Hendry ${ }^{1}$, Sandra Arndt ${ }^{2}$, Johan C. Faust ${ }^{3,7}$, Felipe S. Freitas $^{1}$, Sian F. Henley ${ }^{4}$, Jeffrey W. Krause ${ }^{5,6}$, Christian März ${ }^{7}$, Hong Chin Ng${ }^{1}$, Rebecca A. Pickering ${ }^{8}$, Allyson C. Tessin ${ }^{7}$

${ }^{1}$ School of Earth Sciences, University of Bristol, Bristol, BS8 1QE, UK

${ }^{2}$ BGeosys, Department of Geosciences, Université libre de Bruxelles, Brussels, CP160/03 1050, Belgium

${ }^{3}$ MARUM - Center for Marine Environmental Sciences, University of Bremen, Bremen, 28359, Germany

${ }^{4}$ School of GeoSciences, University of Edinburgh, Edinburgh, EH9 3FE, UK

${ }^{5}$ Dauphin Island Sea Lab, Dauphin Island, AL, USA

${ }^{6}$ School of Marine and Environmental Sciences, University of South Alabama, Mobile, AL, USA

${ }^{7}$ School of Earth and Environment, University of Leeds, Leeds, LS2 9JT, UK

${ }^{8}$ Department of Geology, Lund University, Sölvegatan 12223 62, Lund, Sweden

Author for correspondence: JamesPJ.Ward@bristol.ac.uk*

\begin{abstract}
This supplementary information comprises a detailed discussion on a series of sensitivity experiments carried out to determine the influence of solid phase sample preparation techniques on the isotopic composition of reactive pool leachates. Here we also present an explanation of the LSi correction calculations for the Si-Alk pool, as well as a description of the exponential curve-fitting methodology used to determine the magnitude of benthic DSi fluxes, complimentary to the linear (two-point) and incubation techniques.
\end{abstract}

\section{Contents}

- Section 2: What is the influence of different sample preparation and handling techniques on the BSi content and isotopic composition of operationally defined pools of reactive $\mathrm{Si}$ ? 
- Section 3: Correcting for LSi interference in the Si-Alk pool

- Section 4: Quantifying the DSi benthic flux magnitude by exponential curve-fitting

\section{Figures}

- Figure S1: Comparison of the isotopic composition of sediment leachates under contrasting sample preparation techniques.

- Figure S2: Concentration of metals analysed by ICP-OES in sediment leachates.

- Figure S3: Schematic of the 2019 on-board core incubation experiment.

- Figure S4: Example of the linear regression method used to measure BSi content and justification of the 20 minute extraction used to determine $\delta^{30} \mathrm{Si}_{A l k}$.

- Figure S5: Three $\mathrm{Si}$ isotope plot $\left(\delta^{29} \mathrm{Si}\right.$ vs $\left.\delta^{30} \mathrm{Si}\right)$ used to assess data quality.

- Figure S6: Isotopic composition of Si standards measured throughout this study.

- Figure S7: Map of a pan-Arctic DSi flux compilation.

- Figure S8: Map showing the distribution of lithologies across the Arctic seafloor.

- Figure S9: Rayleigh fractionation during DSi uptake by diatoms.

- Figure S10: Pore water major and trace element concentration data (Fe, Mn, Mg, K).

- Figure S11: Simulated rates of pore water dissolved Fe production at B13 and B15.

- Figure S12: Sediment solid phase Fe and Mn contents measured by XRF.

Tables

- Table S1: Summary of $\delta^{30} \mathrm{Si}_{\text {Alk }}$ values corrected for LSi interference.

- Table S2: Sediment pore water Mg and K concentrations measured by ICP-OES. 


\section{What is the influence of different sample preparation techniques on the BSi content and isotopic composition of operationally defined pools of reactive $\mathrm{Si}$ ?}

Contrasting sediment sample preparation techniques, for example oven drying and grinding, have been shown to significantly alter the estimated BSi content. Michalopoulos and Aller (2004) applied a correction factor of $-50 \%$, due to the effect of sample grinding/crushing, consistent with an artificial increase in sample reactivity through a decrease in surface crys-

tallinity (Pickering, 2020). Regardless, sediment drying and grinding remains a commonly used method of sample preparation. In this study we carried out sensitivity tests on a sequential digestion experiment protocol designed to access operationally defined pools of reactive Si (Pickering et al., 2020), so as to determine if the influence of these different sample preparation techniques could be traced isotopically.

The 0-0.5 cmbsf core slice collected in 2019 from station B15 was selected at random for this study. BSi content, as well as $\delta^{30} \mathrm{Si}$ and the concentration of a suite of metals was determined for all three leachates, each in sediment sample triplicate (50-70 mg dry weight) on three distinct groups consisting of different preparation techniques: 1) thawed from frozen, 2) dried/in-tact and 3) dried/ground. Half of the B15 frozen sediment core slice was oven dried for 24 hours at $60^{\circ} \mathrm{C}$ (for group 2), half of which was then thoroughly ground with a mortar and pestle (Cole-Parmer Agate) (for group 3). After grinding, the sample was allowed to re-equilibrate with the atmosphere for 24 hours before digestion.

We found that grinding the sediment (group 3, dried/ground) increased BSi content by $36.4 \%$ relative to the frozen sample (group 1), while drying the sediment (group 2, dried/in tact) decreased this value by $53.5 \%$ (Fig. S1). The difference between the BSi content of groups 3 and 1 is within 2 standard deviations $(2 \sigma)$, although is outside of 2 standard error of the mean (2SEM) (equation 1) and is statistically signifciant (ANOVA $\mathrm{p}=0.024$, group 1 $\mathrm{n}=5$, group $3 \mathrm{n}=4$ ). The mechanical effect of grinding the sediment on the BSi content is consistent with the findings of Michalopoulos and Aller (2004), in that sample surface area was increased and fresh BSi surfaces exposed, resulting in greater Si release when placed in 
to contact with the $\mathrm{Na}_{2} \mathrm{CO}_{3}$ leachate.

$$
2 S E M=2 \sigma / \sqrt{n}
$$

where $\sigma$ is the standard deviation and $\mathrm{n}$ the number of sample measurements.

Throughout the sequential digestions, group 2 sediments were more difficult to homogenise within the leachate. This finding is consistent with Mortlock and Froelich (1989), who suggested that clay-rich samples, such as those collected in 2019 from the Barents Sea, should not be dried to hardness as this can inhibit disaggregation of the sediment during BSi extraction. This lack of disaggregation will likely have limited contact of the sample with the leachate, resulting in the reduced estimate of $\mathrm{BSi}$ content relative to the other preparation techniques (Fig. S1A).

The influence of drying and grinding sediment samples not only has an impact on the estimated BSi content, but there is also a perceptible imprint on the isotopic composition of the leachates. $\delta^{30} \mathrm{Si}_{\mathrm{HCl}}$ in group $3(-2.56 \pm 0.14 \%$ ( $\left.\mathrm{n}=10)\right)$ was $0.28 \%$ o heavier than that measured in groups 1 or $2(-2.82 \pm 0.15 \%$ ( $\mathrm{n}=9)$ and $-2.85 \pm 0.14 \%$ ( $\mathrm{n}=9)$ respectively), which is outside of both 2SEM and $2 \sigma$ and is statistically significant (group 1 and 3 ANOVA $\mathrm{p}=7.0 E^{-8}$, group $1 \mathrm{n}=9$, group $3 \mathrm{n}=10$ ) (Fig. S1C). The Si-HCl operationally defined reactive pool of $\mathrm{Si}$ is associated with metal oxides (Pickering et al., 2020), however the increased surface area and reduced sediment grain size as a result of the grinding, in addition to the highly $\mathrm{Si}$ undersaturated nature of the pure $\mathrm{HCl}$ solution, could have allowed for the premature release/dissolution of an isotopically heavier phase from a different reactive pool (e.g. Si-NaOH or Si-Alk). This could explain why group 3 samples present with a ${ }^{30} \mathrm{Si}$ enriched $\delta^{30} \mathrm{Si}_{\mathrm{HCl}}$ relative to groups 1 and 2 and indicates that drying alone does not significantly influence the $\mathrm{Si}-\mathrm{HCl}$ pool. This is supported by the ICP-OES metal concentration data, which indicates elevated $\mathrm{Al}$ and $\mathrm{Ti}$ in the $\mathrm{Si}-\mathrm{HCl}$ of group 3 relative to groups 1 and 2 (Fig. S2). Al and Ti are typically considered to be lithogenic trace elements (Price et al., 1999), suggesting that grinding may have resulted in contamination of the Si-HCl pool from LSi minerals. It is possible that the difference in $\delta^{30} \mathrm{Si}_{H C l}$ observed between group 3 and 
groups $1 / 2$ is due to contamination of material from the agate mortar. However, there is no discernible influence of sample preparation techniques on $\delta^{30} \mathrm{Si}_{\mathrm{NaOH}}$ (Fig. S1D), nor between $\delta^{30} \mathrm{Si}_{\text {Alk }}$ of groups 2 and 3 (Fig. S1B), which we would expect if there had been significant contamination of the sample from agate particulates.

We also observe a shift in $\delta^{30} \mathrm{Si}_{A l k}$ induced by the distinct sample preparation methods. $\delta^{30} \mathrm{Si}_{\text {Alk }}$ of group $1(+0.82 \pm 0.16 \%(\mathrm{n}=14))$ is enriched in the lighter isotope, relative to groups $2(+0.95 \pm 0.14 \% 0(\mathrm{n}=9))$ and $3(+0.91 \pm 0.16 \%$ o $(\mathrm{n}=10))($ Fig. S1B). Oven drying (as opposed to freeze drying) sediment samples has been found to cause fragmentation of diatom frustules (Conley, 1998), with Flower (1993) finding diatom breakage in $100 \%$ of samples oven dried at $50^{\circ} \mathrm{C}$ overnight. This could explain why the $\mathrm{Si}-\mathrm{Alk}$ pool of sediment samples exposed to elevated temperatures present with a slightly heavier isotopic composition, as frustule breakage and thus exposure of fresh BSi surfaces could increase the ratio of BSi:LSi release during the $\mathrm{Na}_{2} \mathrm{CO}_{3}$ digestion. This is supported by our contamination correction calculations (Table S1), which suggest that the B15 frozen 20 minute $\mathrm{Na}_{2} \mathrm{CO}_{3}$ leachate has a higher proportion of LSi within its Si pool than the dried and ground counterpart (see supp. section 3).

As with the BSi content, the difference in $\delta^{30} \mathrm{Si}_{A l k}$ across the sample preparation techniques is within $2 \sigma$, but outside of $2 \mathrm{SEM}$ and the difference between groups 1 and 3 is statistically significant (ANOVA $\mathrm{p}=0.009$, group $1 \mathrm{n}=14$, group $3 \mathrm{n}=10$ ), as is that between groups 1 and 2 (ANOVA $\mathrm{p}=0.0001$, group $1 \mathrm{n}=14$, group $2 \mathrm{n}=9$ ).

There is very little influence of oven drying on $\delta^{30} \mathrm{Si}_{\mathrm{NaOH}}$, however this process does appear to enhance the release of $\mathrm{Al}, \mathrm{Fe}, \mathrm{Si}, \mathrm{Ti}, \mathrm{Mg}$ and $\mathrm{Mn}$ into the $4 \mathrm{M} \mathrm{NaOH}$ leachate, as well as $\mathrm{Mg}, \mathrm{Mn}$ and $\mathrm{Si}$ in the $\mathrm{Na}_{2} \mathrm{CO}_{3}$ leachate, with the dried and ground samples presenting with higher concentrations of the aforementioned elements (Fig. S2). This suggests that heating may enable other phases to release into a given leachate which are not activated in the thawed group. This influence is thought to be detectable within $\delta^{30} \mathrm{Si}_{A l k}$ due to the size of the Si pool, which is 7-10 times smaller in the $\mathrm{Na}_{2} \mathrm{CO}_{3}$ relative to the $\mathrm{NaOH}$ leachate (Fig. S2). The exact nature of the phase(s) is unclear, however isotopic analysis suggests 
that it is enriched in the ${ }^{30} \mathrm{Si}$ relative to $\delta^{30} \mathrm{Si}_{A l k}$ at $\mathrm{B} 15$.

To conclude, given the impact of oven drying on the measured BSi content (group 2) and the contamination observed in the sequential leach extractions brought about by grinding (group 3), we recommend that sediment samples are frozen after core recovery and gently thawed to room temperature prior to any extraction procedure following the group 1 protocol.

\section{Correcting for LSi interference in the Si-Alk pool}

Following Kamatani and Oku (2000) and Ragueneau et al. (2005), $\delta^{30} \mathrm{Si}_{\text {Alk }}$ values were corrected for LSi interference in the 20 minute $\mathrm{Na}_{2} \mathrm{CO}_{3}$ digestion leachate. Ragueneau and Tréguer (1994) estimate that this interference represents $~ 15 \%$ of the BSi content calculated from the intercept of the linear regression, slightly higher than that calculated in Mississippi River plume sediments $(7.4 \pm 4.5 \%)$ (Pickering et al., 2020). This correction is calculated using equation 2 :

$$
\left[\mathrm{Si}_{\mathrm{Cor}}\right]_{\mathrm{Na}_{2} \mathrm{CO}_{3}}=[\mathrm{Si}]_{\mathrm{Na}_{2} \mathrm{CO}_{3}}-[\mathrm{Al}]_{\mathrm{Na}_{2} \mathrm{CO}} \cdot \frac{1}{(\mathrm{Al}: \mathrm{Si})_{L S i}}
$$

, where $\left[\mathrm{Si}_{\mathrm{Cor}}\right]_{\mathrm{Na}_{2} \mathrm{CO}_{3}}$ is the LSi-corrected $\mathrm{Si}$ concentration in the $\mathrm{Na}_{2} \mathrm{CO}_{3}$ leachate. $\left[\mathrm{Si}_{\mathrm{Na}_{2} \mathrm{CO}_{3}}\right.$ is the total $\mathrm{Si}$ concentration initially measured in the 20 minute extraction, including the LSi and BSi components and $(S i: A l)_{L S i}$ is the inferred composition of the contaminating LSi phase.

To correct $\delta^{30} \mathrm{Si}_{A l k}$ we used the following equation (Pickering, 2020):

$$
\delta^{30} S i_{A l k C o r}=\frac{\left(\delta^{30} S i_{A l k} \cdot[S i]_{N_{2} C_{3}}\right)-\left(\delta^{30} S_{\mathrm{NaOH}_{3}} \cdot\left[S i_{L_{S i}}\right]_{\mathrm{Na}_{2} \mathrm{CO}_{3}}\right)}{\left[S i_{\mathrm{Cor}}\right]_{\mathrm{Na}_{2} \mathrm{CO}_{3}}}
$$

, where $\left[\mathrm{Si}_{\mathrm{LSi}}\right]_{\mathrm{Na}_{2} \mathrm{CO}_{3}}$ (LSi component in the Si-Alk pool) equates to $\left[\mathrm{Si}_{\mathrm{Na}_{2} \mathrm{CO}_{3}}-\left[\mathrm{Si}_{\mathrm{Cor}}\right]_{\mathrm{Na}_{2} \mathrm{CO}_{3}}\right.$.

Unfortunately, due to a lack of corresponding [Al] data, we were only able to apply this correction to three samples (B13, B15 and B15 ground). All three of these present with relatively low LSi interferences, suggesting that the majority of Si released into this phase from sediments of both the Atlantic and Arctic regions is due to the incorporation of the BSi pool. 
Table S1: Summary of ${ }^{30} \mathrm{Si}_{A l k}$ values corrected for LSi contamination using Al:Si ratios following Ragueneau etal. (2005) and Kamatani and Oku (2000). Comparison of calculated corrected $\delta^{30} \mathrm{Si}_{A l k}$ values when using an $A l: S i_{L S i}$ of the average continental crust $v s$ the second alkaline leach ( $\mathrm{Si}-\mathrm{NaOH}$ pool) carried out in this study. Units of $\delta^{30} \mathrm{Si}_{A l k}$ are in \%o, numbers in brackets represent the difference between the corrected and measured values for B13, B15 and B15 ground.

\begin{tabular}{lllllll}
\hline & $\mathrm{B} 13$ & & $\mathrm{~B} 15$ ground & \multicolumn{2}{c}{$\mathrm{B} 15$} \\
& $\delta^{30} S i_{\text {AlkCor }}$ & $\% \mathrm{LSi}$ & $\delta^{30} S i_{\text {AlkCor }}$ & $\% \mathrm{LSi}$ & $\delta^{30} S i_{\text {AlkCor }}$ & \%LSi \\
\hline Continental Crust & $1.59(+0.16)$ & 6.6 & $1.08(+0.17)$ & 8.7 & $1.36(+0.54)$ & 39.6 \\
$\mathrm{NaOH}$ supernatant & $1.47(+0.04)$ & 1.5 & $0.94(+0.03)$ & 1.8 & $0.89(+0.07)$ & 7.7 \\
\hline
\end{tabular}

We used two different $(A l: S i)_{L S i}$ ratios to correct $\delta^{30} \mathrm{Si}_{A l k}$. Our results demonstrate that the magnitude of the correction varies greatly depending on this ratio. If we use a lower $(A l: S i)_{L S i}$, such as that of the mean continental crust (0.131), as has been applied in similar calculations of a previous study (Pickering et al., 2020), the inferred contamination from LSi is much greater, espcially at B15 (Table S1). However, an alternative method is to use the $(A l: S i)$ of a second alkaline leach carried out on the sediment samples. Ragueneau et al. (2005) digested particulates collected from filtering seawater twice with $0.2 \mathrm{M} \mathrm{NaOH}$ for 40 minutes at $100^{\circ} \mathrm{C}$ and then assumed that the $(A l: S i)$ ratio measured in the supernatant of the second digestion (0.45) was reflective of the composition of the silicate minerals. Two alkaline leaches were carried out in this study, albeit using different reagents $\left(0.1 \mathrm{M} \mathrm{Na}_{2} \mathrm{CO}_{3}\right.$ followed by $4 \mathrm{M} \mathrm{NaOH}$ ). After applying the method of Ragueneau et al. (2005), assuming that the $(A l: S i)$ measured in the $\mathrm{NaOH}$ leachate $(0.57-0.67)$ is reflective of the Barents Sea sediment $(A l: S i)_{L S i}$, the corrections are significantly reduced and brought in-line with

previous values and estimates (Pickering et al., 2020; Ragueneau and Tréguer, 1994) (Table $\mathrm{S} 1)$.

\section{Quantifying the benthic flux magnitude by curve-fitting}

In addition to using a linear assumption of the DSi concentration gradient at the SWI (i.e. [DSi] in the core top water and at $0.5 \mathrm{cmbsf}$ ) for the flux calculations, here we also utilise 
an exponential function (equation 4) (Frings, 2017; McManus et al., 1995) to reproduce the sediment pore water [DSi] profiles, in order to determine which method is appropriate for the Barents Sea. Calculated fits of the profiles were obtained through adjustment of the asymptotic concentration $\left(C_{\text {asymp }}\right)$ and exponential constant $(\beta)$. Differentiation of equation 4 at the SWI (depth $(\mathrm{z})=0$ ) (equation 5) was carried out to determine the concentration gradient for Fick's first law of diffusion. Previous studies have employed both the linear assumption (Cassarino, 2018; März et al., 2015) and the full profile exponential fit methods (Ng et al., 2020; Frings, 2017).

$$
\begin{gathered}
{[D S i]_{z}=C_{a s y m p}-\left(C_{a s y m p}-C_{S W I}\right) \times e^{-\beta z}} \\
(d[D S i] / d z)_{z=0 c m}=\beta \times\left(C_{a s y m p}-C_{S W I}\right)
\end{gathered}
$$

Flux estimates for B15 are consistent across the two methodologies, indicating that a two point linear assumption of the gradient is adequate for estimating benthic flux magnitudes at this station (see main text Table 2). However, for B13 and B14 the flux magnitudes derived from the exponential fit method are significantly higher than the linear counterparts (see main text Table 2). An adequate representation of the asymptotic concentration at depth and the [DSi] gradient at the SWI are the two main sources of uncertainty in the curve fitting method (Rickert, 2000). The disparities observed across the two methods at $\mathrm{B} 13$ and B14 is therefore thought to be due to the deviations in the [DSi] profiles from a typical asymptotic increase (Cassarino et al., 2020) (Fig. 2), which precludes an accurate replication of the observational data in the modelled profiles. Unsurprisingly, this is reflected in the normalised RMSE between the calculated and measured [DSi] values, which are lowest for B15 profiles, indicating a better prediction of the measured data by the model at B15 relative to $\mathrm{B} 13$ and $\mathrm{B} 14$. 

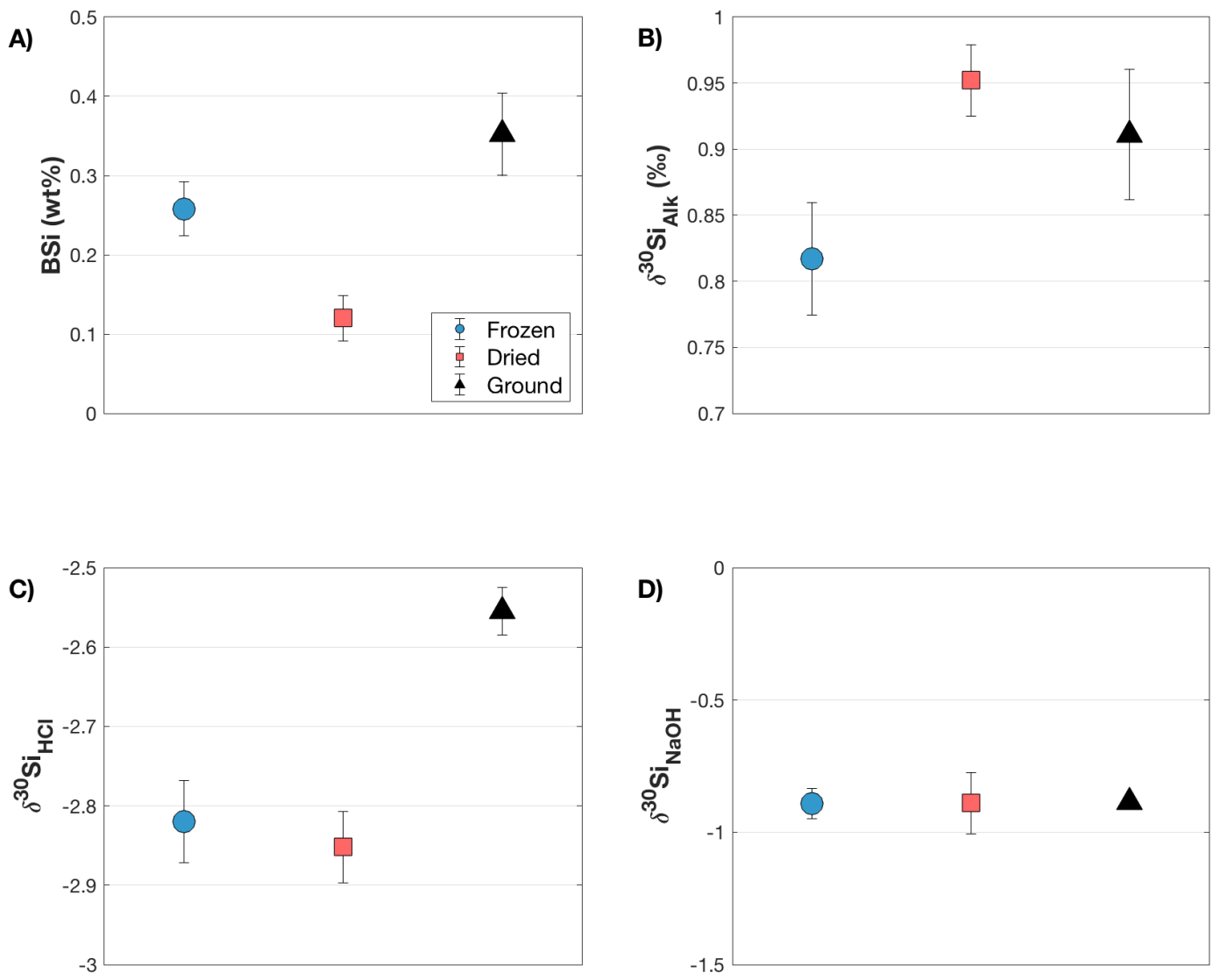

Figure S1: Sample preparation sensitivity experiment testing the influence of digesting thawed sediment (stored frozen), versus oven drying and subsequently grinding on the BSi content and Si isotopic compositions of the reactive pools. BSi content (wt\%) (A), Si-Alk (B), Si-HCl (C) and Si-NaOH (D). Error bars are $\pm 2 \mathrm{SEM}$ (equation 1). 

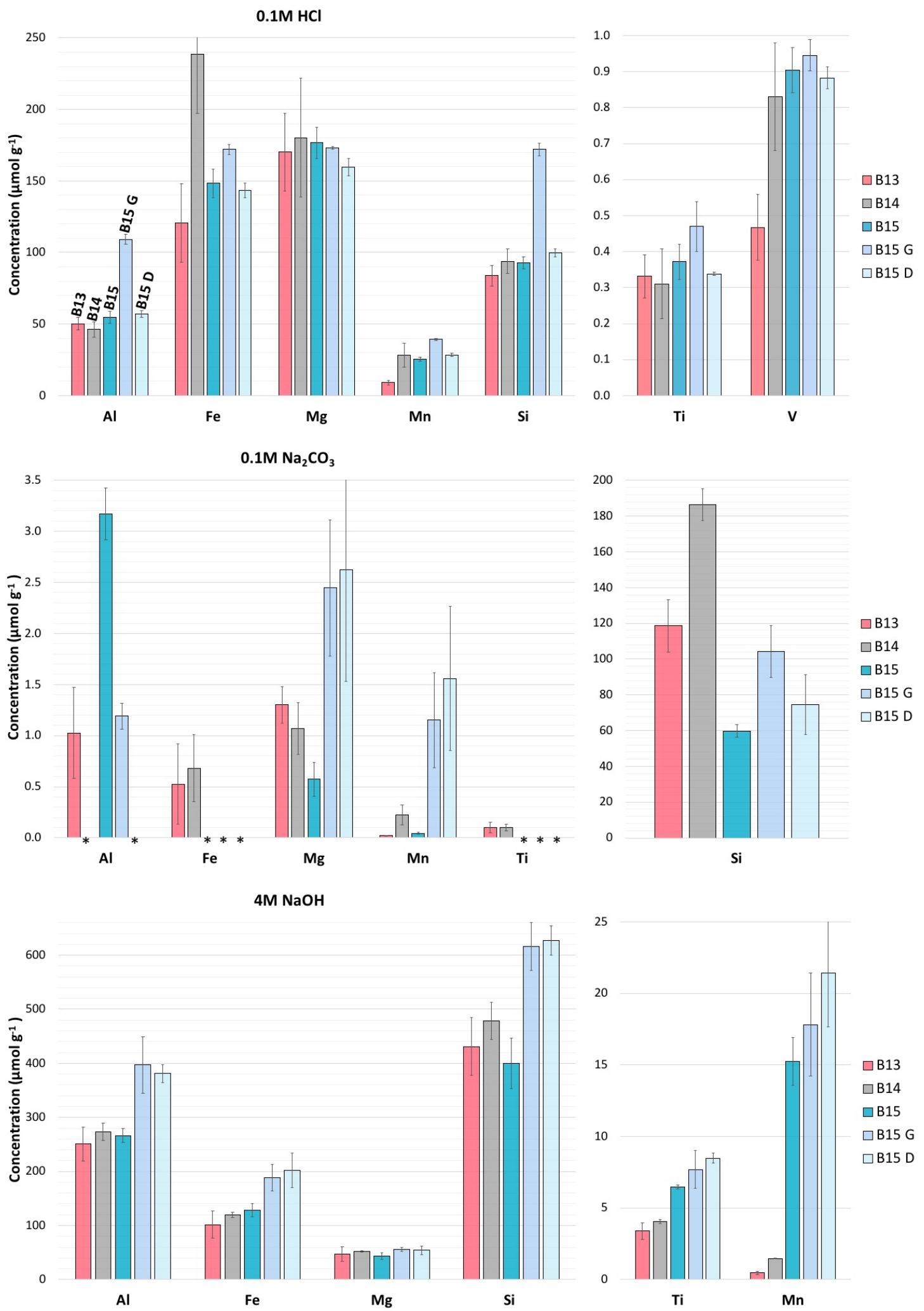

Figure S2: Concentration of metals ( $\mu \mathrm{mol}$ per dry weight $\mathrm{g}$ of sediment) measured by ICP-OES and Si by spectrophotometry in the sequential digestion experiment leachates for stations B13, B14 and B15, as well as in the B15 ground (B15 G) and dried (B15 D) samples. Top row: Si-HCl pool, middle row: Si-Alk, bottom row: $\mathrm{Si}-\mathrm{NaOH}$. Note the y axes scale changes. Error bars represent $\pm 2 \sigma$ of sample triplicates. ${ }^{*}$ signifies a concentration below the limit of quantification (LOQ) (average blank concentration $+8 \sigma$ ). 


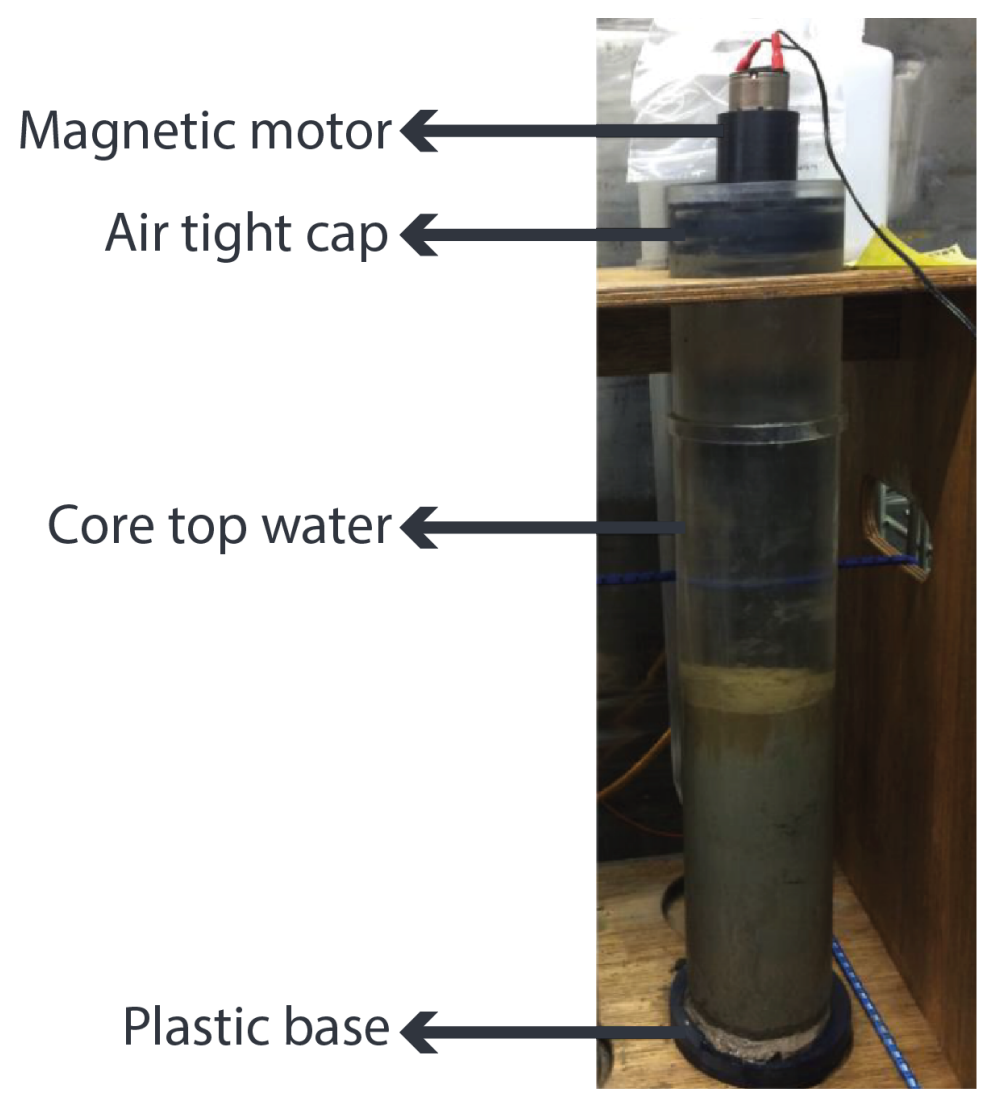

Figure S3: On-board (JR18006, 2019) core incubation experiment set-up. 


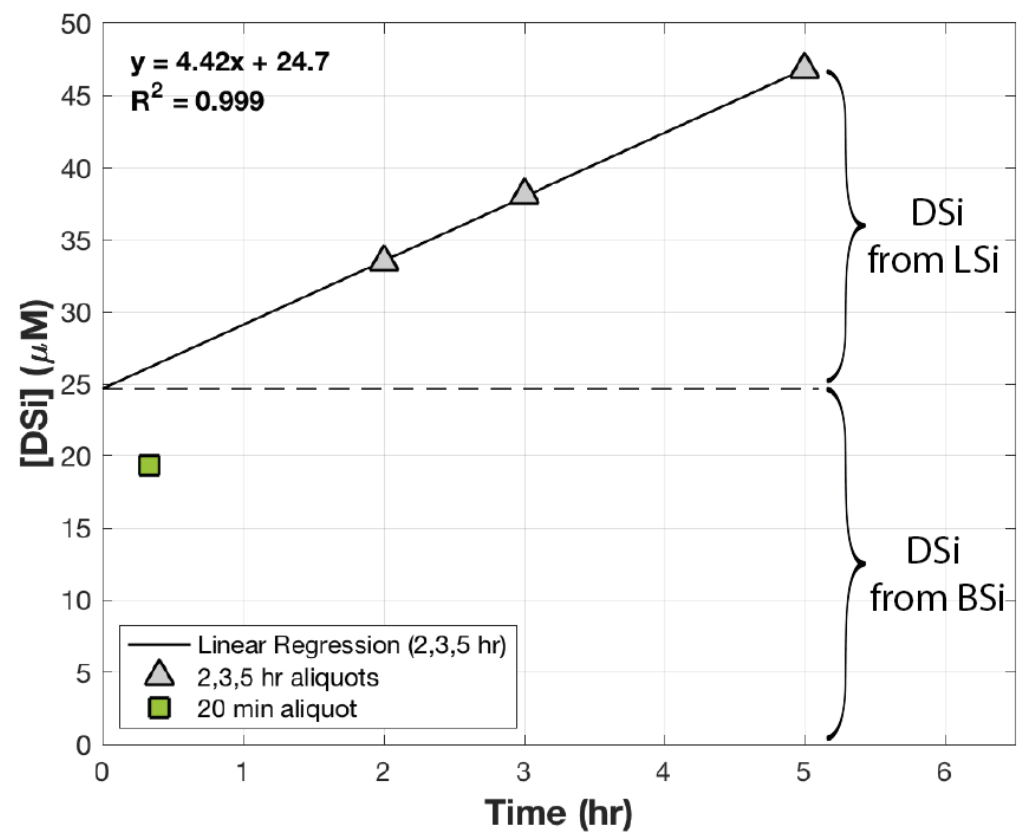

Figure S4: Example BSi extraction experiment from this study (B15 frozen, sample triplicate B, 2019). Intercept is extrapolated from the linear regression of the 2, 3 and 5 hour extractions (grey triangles). The green square depicts the [DSi] of the 20 minute extraction, which is below the regression intercept (used to calculate sample BSi content) and was used for Si isotopic analysis. Annotations illustrate the two stages of Si release. DSi released above the dashed line is sourced from the dissolution of clay minerals, while below is from BSi (DeMaster, 1981). 


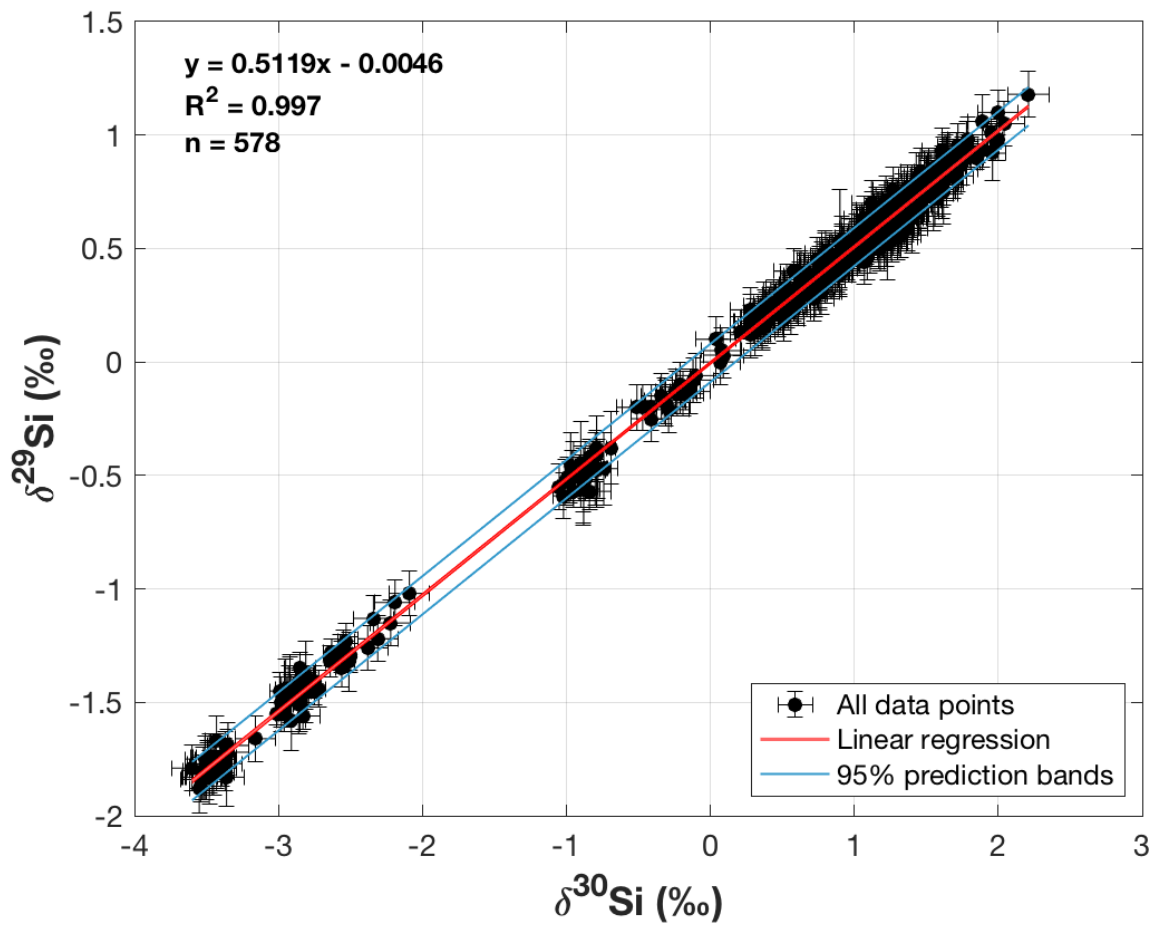

Figure S5: Three isotope plot of $\delta^{29} \mathrm{Si} v s \delta^{30} \mathrm{Si}$ for all samples and standards analysed throughout this study, to assess control of instrumental mass bias $(\mathrm{n}=578)$. Error bars denote long term reproducibility of standards (Diatomite) $\pm 2 \sigma\left( \pm 0.14 \delta^{30} \mathrm{Si}, \pm 0.09 \delta^{29} \mathrm{Si}\right)$. Linear regression (red line) has an $\mathrm{R}^{2}$ of 0.997 and gradient of 0.5119. Light blue lines depict the $95 \%$ prediction intervals of the linear regression. $95 \%$ confidence intervals fall within the line thickness of the linear regression. 

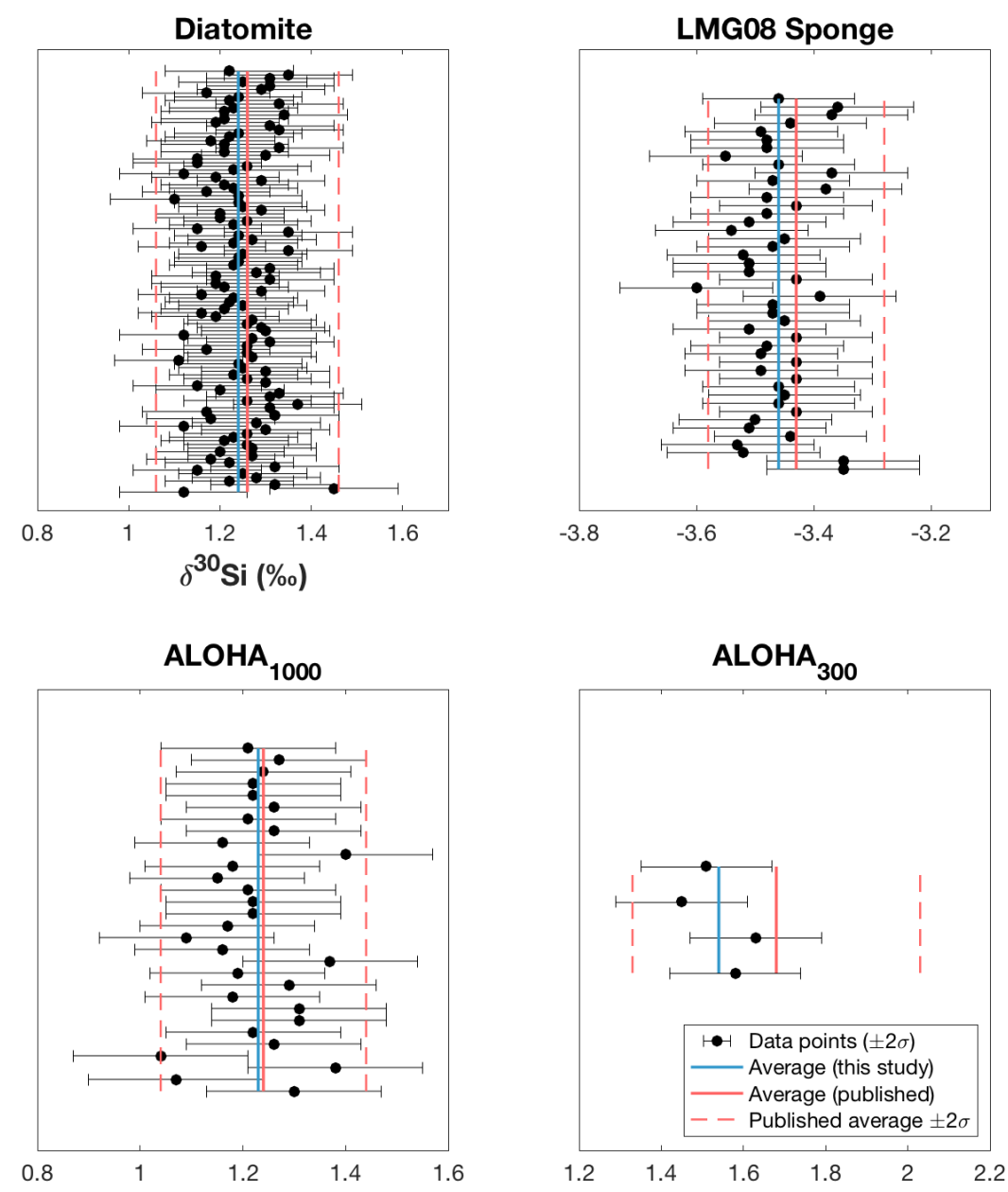

Figure S6: Long-term reproducibility of reference standards, including Diatomite, LMG08 sponge and GEOTRACES Station ALOHA seawater from $300 \mathrm{~m}$ and $1000 \mathrm{~m}$ depths. Blue lines represent the average value from this study, while the solid red lines depict the average published values. Error bars are $\pm 2 \sigma$ (Diatomite $\mathrm{n}=116, \mathrm{LMG}_{08} \mathrm{n}=46, \mathrm{ALOHA}_{1000} \mathrm{n}=30, \mathrm{ALOHA}_{300} \mathrm{n}=4$ ), as are the dotted red lines, but from the respective publications (Diatomite from Reynolds etal. (2007); LMG08 from Hendry and Robinson (2012); $\mathrm{ALOHA}_{1000}$ and $\mathrm{ALOHA}_{300}$ from Grasse etal. (2017)). 


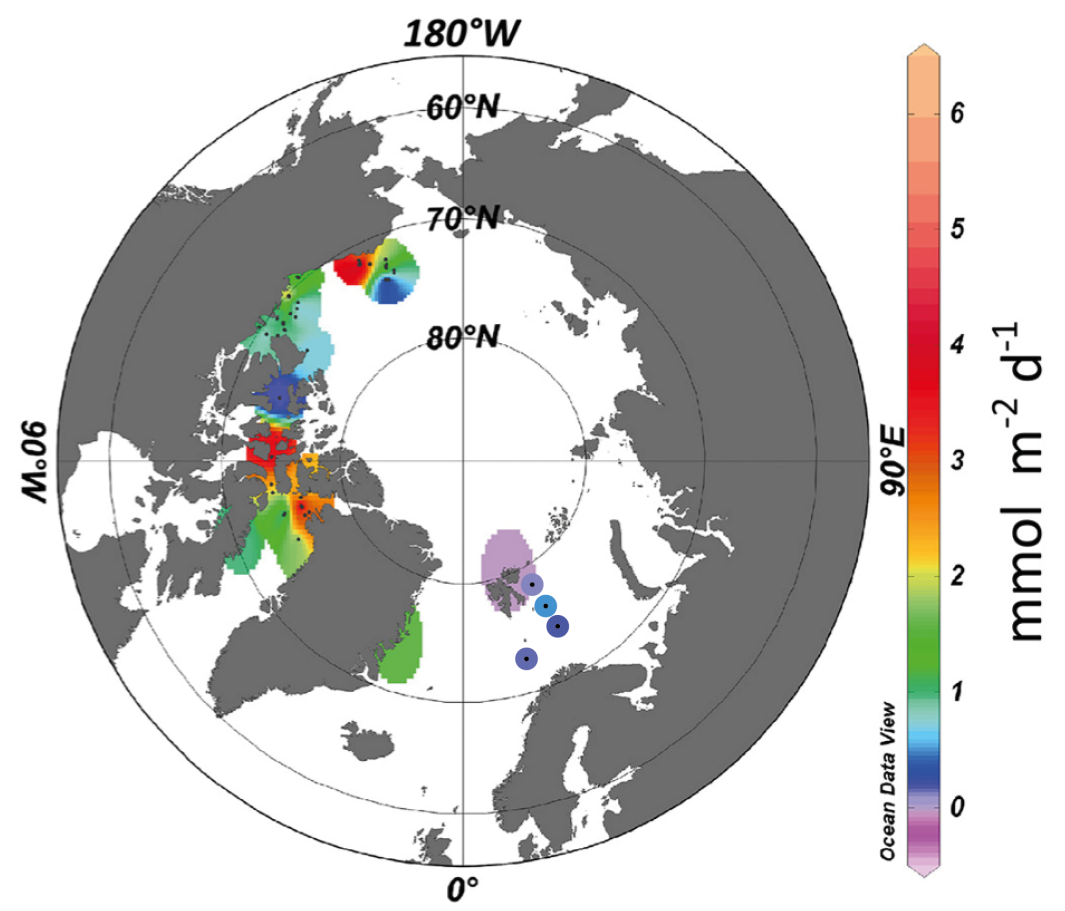

Figure S7: Pan-Arctic benthic DSi flux compilation modified from Bourgeois etal. (2017) (see references therein) to include data from this study (stations B03, B13, B14, B15). DSi fluxes $(\mathrm{n}=61)$ in mmol m $\mathrm{m}^{-2}$ day $^{-1}$. Note the density of data on shelves of the western Arctic relative to the scarcity of data from the European and Siberian Arctic Ocean sectors. 


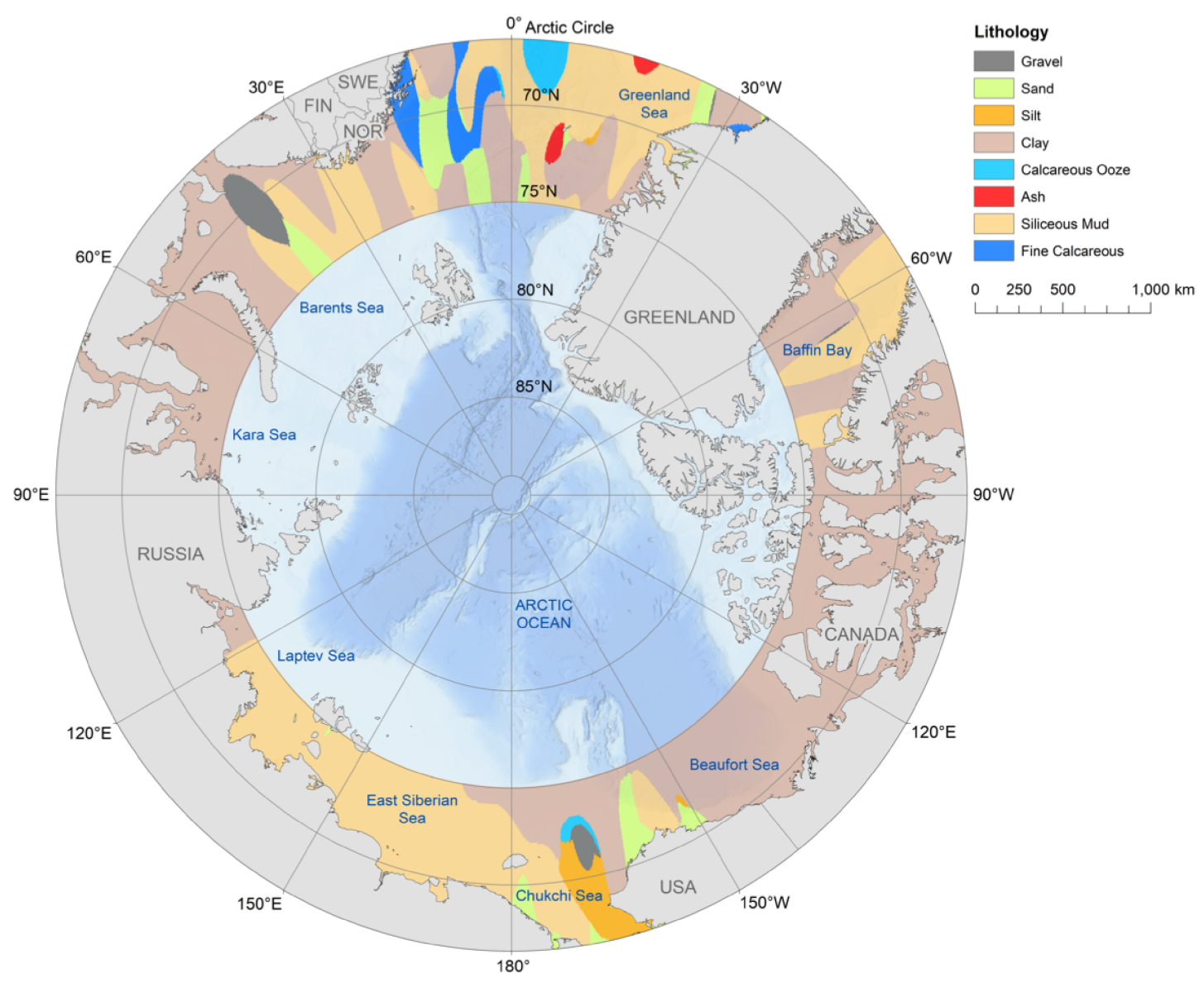

Figure S8: Seafloor lithological data for the Arctic Ocean taken from the Dutkiewicz etal. (2015) digital map. There is a paucity of data for the Central Arctic Ocean, but of the area with available data within the Arctic Circle (coastal and shelf sea regions) $52 \%$ is dominated by clay and $36 \%$ by siliceous mud. SWESweden, FIN- Finland, NOR- Norway. 


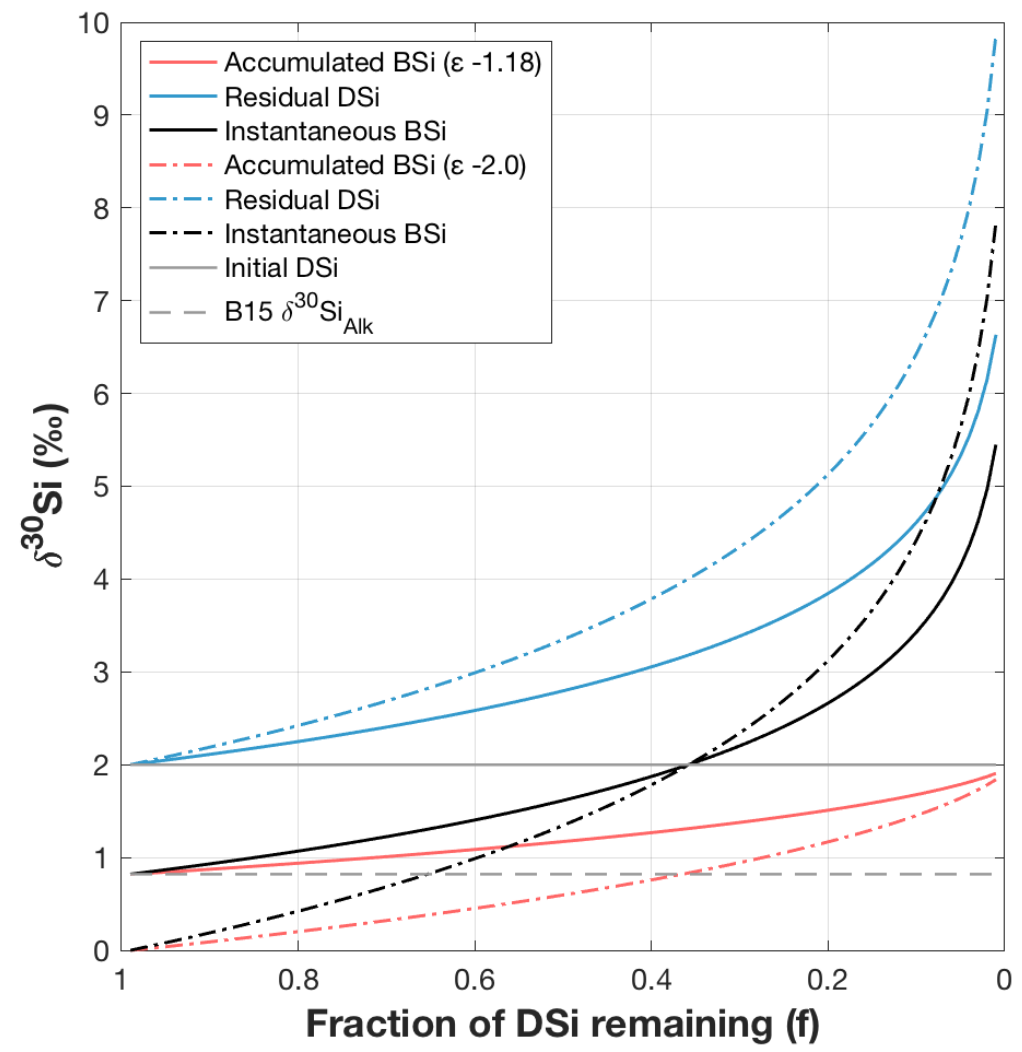

Figure S9: Simulating Rayleigh fractionation during the uptake of DSi by diatoms from seawater (De La Rocha etal., 1997). Lines depict changes in $\delta^{30} \mathrm{Si}$ of the DSi pool (blue) and the compositions of the instantaneously formed BSi (black) and accumulated BSi (red). A fractionation factor $\left({ }^{30} \epsilon\right.$ ) of $-1.18 \%$ (solid lines) represents the maximum value ${ }^{30} \epsilon$ can be, in order to generate an accumulated BSi composition of $+0.82 \%$, when assuming an initial surface water composition of $+2.0 \%$ (Liguori etal., 2020). We also model DSi uptake assuming a ${ }^{30} \epsilon$ of $-2.0 \%$ (dashed lines), representing the upper range of measured ${ }^{30} \epsilon$ values (Sutton etal., 2013). 

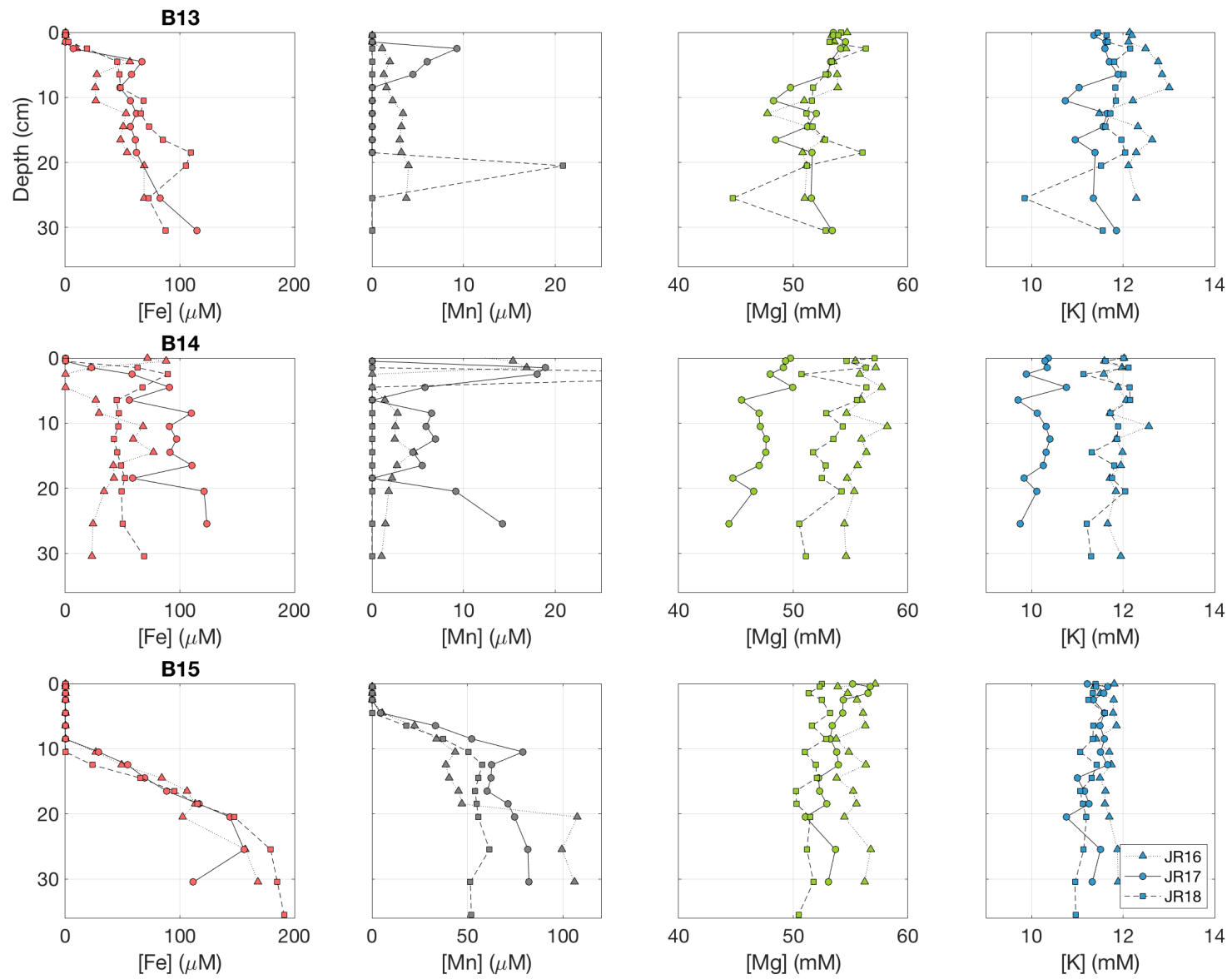

Figure S10: Pore water major $(\mathrm{Mg}, \mathrm{K})$ and trace element $(\mathrm{Fe}, \mathrm{Mn})$ concentrations for the three cruise years analysed by ICP-OES (top row station B13, middle row B14, bottom roe B15). Data presented correspond to the same coring events from which samples were collected for pore water $\mathrm{Si}$ isotope analysis. Note the change in scale of Mn concentrations between stations. Pore water trace and major element concentrations (Fe, Mn, Mg and K) were analysed at the University of Leeds using a Thermo Scientic iCAP 7400 Radial ICP-OES, uncertainty was $\pm 3.5 \%$ (Faust etal., 2021). Fe and Mn data are provided in the supplementary to Faust etal. (2021), Mg and K data can be found in Table S2 below. 
Table S 2: Sediment pore water Mg and K concentrations for stations B13, B14 and B15 across the three cruise years. Data corresponds to the same coring events from which samples were collected for pore water Si isotope analysis.

\begin{tabular}{|c|c|c|c|c|c|c|}
\hline & JR16 & & JR17 & & JR18 & \\
\hline $\begin{array}{l}\text { Depth } \\
\text { (cmbsf) }\end{array}$ & $\begin{array}{l}\mathrm{Mg} \\
(\mathrm{mM})\end{array}$ & $\begin{array}{l}\mathrm{K} \\
(\mathrm{mM})\end{array}$ & $\begin{array}{l}\mathrm{Mg} \\
(\mathrm{mM})\end{array}$ & $\begin{array}{l}\mathrm{K} \\
(\mathrm{mM})\end{array}$ & $\begin{array}{l}\mathrm{Mg} \\
(\mathrm{mM})\end{array}$ & $\begin{array}{l}\mathrm{K} \\
(\mathrm{mM})\end{array}$ \\
\hline \multicolumn{7}{|l|}{ B13 } \\
\hline 0.0 & 54.7 & 12.1 & 53.5 & 11.4 & 54.2 & 11.5 \\
\hline 0.5 & 53.3 & 12.2 & 53.5 & 11.4 & 53.9 & 11.6 \\
\hline 1.5 & 53.6 & 12.1 & 54.6 & 11.6 & 53.2 & 11.7 \\
\hline 2.5 & 54.6 & 12.5 & 54.1 & 11.6 & 56.3 & 12.2 \\
\hline 4.5 & 53.5 & 12.8 & 53.2 & 11.7 & 53.3 & 11.8 \\
\hline 6.5 & 53.8 & 12.9 & 53.0 & 11.9 & 52.8 & 12.0 \\
\hline 8.5 & 53.9 & 13.0 & 49.8 & 11.0 & 51.7 & 11.8 \\
\hline 10.5 & 51.0 & 12.2 & 48.3 & 10.7 & 51.6 & 11.8 \\
\hline 12.5 & 47.7 & 11.5 & 52.0 & 11.7 & 51.2 & 11.7 \\
\hline 14.5 & 51.3 & 12.3 & 51.2 & 11.6 & 51.7 & 11.6 \\
\hline 16.5 & 52.7 & 12.6 & 48.5 & 11.0 & 52.8 & 12.0 \\
\hline 18.5 & 50.8 & 12.3 & 51.7 & 11.4 & 56.1 & 12.0 \\
\hline 20.5 & 51.2 & 12.1 & & & 51.2 & 11.5 \\
\hline 25.5 & 51.0 & 12.3 & 51.6 & 11.3 & 44.7 & 9.8 \\
\hline 30.5 & & & 53.4 & 11.9 & 52.8 & 11.6 \\
\hline \multicolumn{7}{|l|}{ B14 } \\
\hline 0.0 & 57.2 & 12.0 & 49.8 & 10.4 & 57.1 & 12.0 \\
\hline 0.5 & 55.4 & 11.6 & 49.3 & 10.3 & 54.6 & 11.6 \\
\hline 1.5 & 57.2 & 12.0 & 49.1 & 10.3 & 56.3 & 12.1 \\
\hline 2.5 & 55.8 & 11.6 & 48.0 & 9.9 & 50.7 & 11.1 \\
\hline
\end{tabular}




\begin{tabular}{|c|c|c|c|c|c|c|}
\hline 4.5 & 57.7 & 11.9 & 50.0 & 10.8 & 56.4 & 12.1 \\
\hline 6.5 & 56.0 & 12.1 & 45.5 & 9.7 & 55.6 & 12.2 \\
\hline 8.5 & 54.6 & 11.7 & 47.0 & 10.1 & 52.9 & 11.7 \\
\hline 10.5 & 58.2 & 12.6 & 47.1 & 10.3 & 54.3 & 11.9 \\
\hline 12.5 & 56.0 & 11.9 & 47.6 & 10.4 & 53.5 & 11.9 \\
\hline 14.5 & 56.4 & 12.0 & 47.6 & 10.3 & 51.7 & 11.3 \\
\hline 16.5 & 55.6 & 12.0 & 47.0 & 10.3 & 52.8 & 11.8 \\
\hline 18.5 & 54.7 & 11.7 & 44.7 & 9.8 & 52.5 & 11.8 \\
\hline 20.5 & 55.3 & 11.8 & 46.5 & 10.1 & 54.2 & 12.0 \\
\hline 25.5 & 54.4 & 11.7 & 44.4 & 9.7 & 50.5 & 11.2 \\
\hline 30.5 & 54.6 & 12.0 & & & 51.1 & 11.3 \\
\hline \multicolumn{7}{|l|}{$B 15$} \\
\hline 0.0 & 57.2 & 11.8 & 55.2 & 11.2 & 52.5 & 11.4 \\
\hline 0.5 & 53.9 & 11.4 & 56.7 & 11.7 & 52.3 & 11.4 \\
\hline 1.5 & 54.8 & 11.5 & 56.5 & 11.6 & 51.3 & 11.3 \\
\hline 2.5 & 55.6 & 11.8 & 54.3 & 11.4 & 52.5 & 11.2 \\
\hline 4.5 & 56.1 & 11.8 & 54.3 & 11.6 & 53.2 & 11.6 \\
\hline 6.5 & 56.3 & 11.9 & 53.4 & 11.5 & 51.7 & 11.4 \\
\hline 8.5 & 53.8 & 11.4 & 53.2 & 11.6 & 52.9 & 11.3 \\
\hline 10.5 & 54.8 & 11.7 & 53.8 & 11.5 & 51.0 & 11.1 \\
\hline 12.5 & 56.3 & 11.7 & 54.0 & 11.7 & 52.0 & 11.4 \\
\hline 14.5 & 53.8 & 11.5 & 52.2 & 11.0 & 52.0 & 11.3 \\
\hline 16.5 & 55.2 & 11.6 & 52.3 & 11.2 & 50.2 & 11.1 \\
\hline 18.5 & 55.5 & 11.6 & 52.9 & 11.3 & 50.3 & 11.1 \\
\hline 20.5 & 54.5 & 11.7 & 51.1 & 10.8 & 51.5 & 11.2 \\
\hline 25.5 & 56.8 & 11.9 & 53.7 & 11.5 & 51.2 & 11.1 \\
\hline 30.5 & 56.2 & 11.9 & 53.1 & 11.3 & 51.8 & 10.9 \\
\hline 35.5 & & & & & 50.5 & 11.0 \\
\hline
\end{tabular}




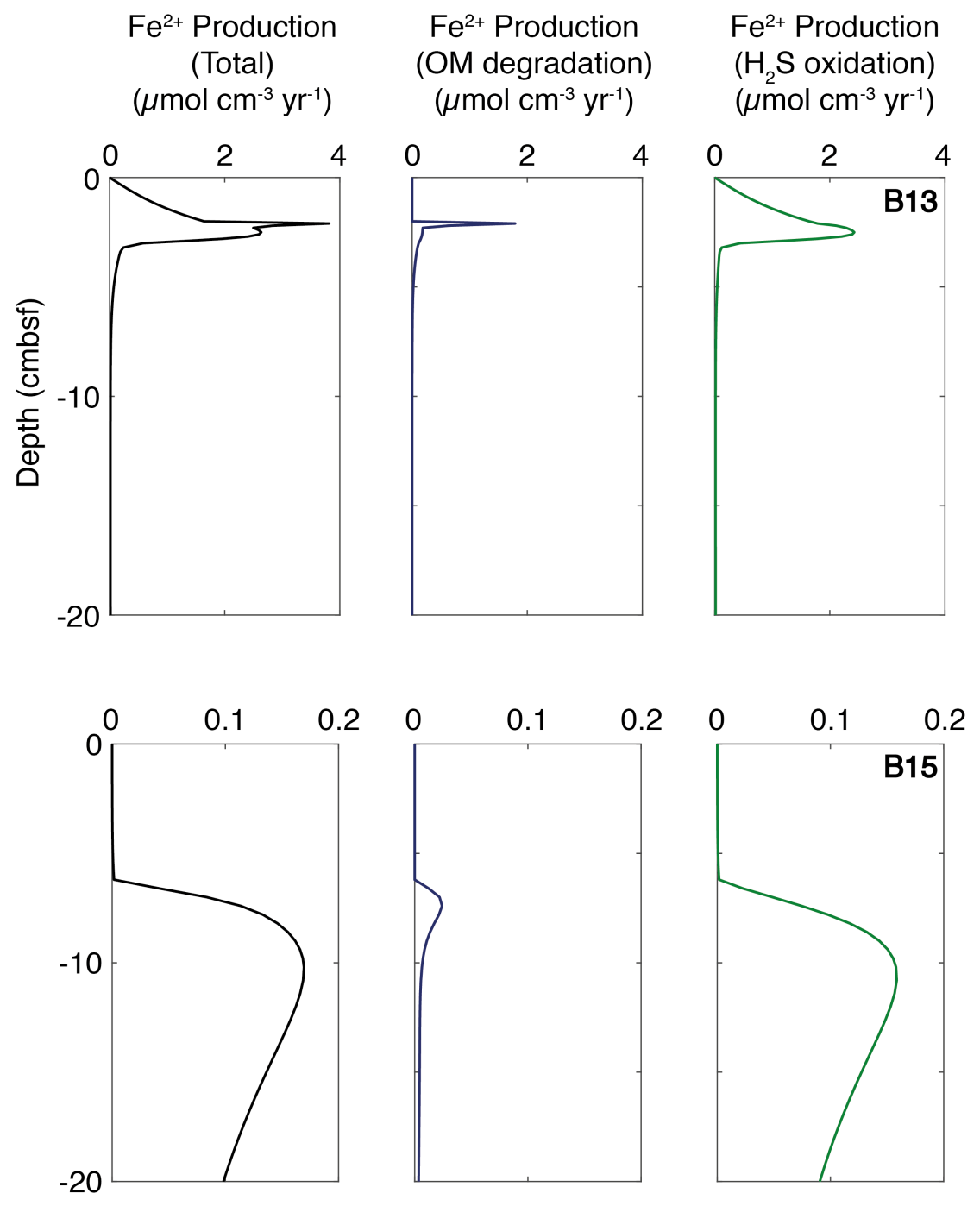

Figure S11: Simulated rates of dissolved Fe production in Barents Sea sediment cores, derived from steady state reaction-transport model simulations (Freitas etal., 2020). Note the change in $\mathrm{x}$ axis scale across the top (B13) and bottom (B15) rows. 

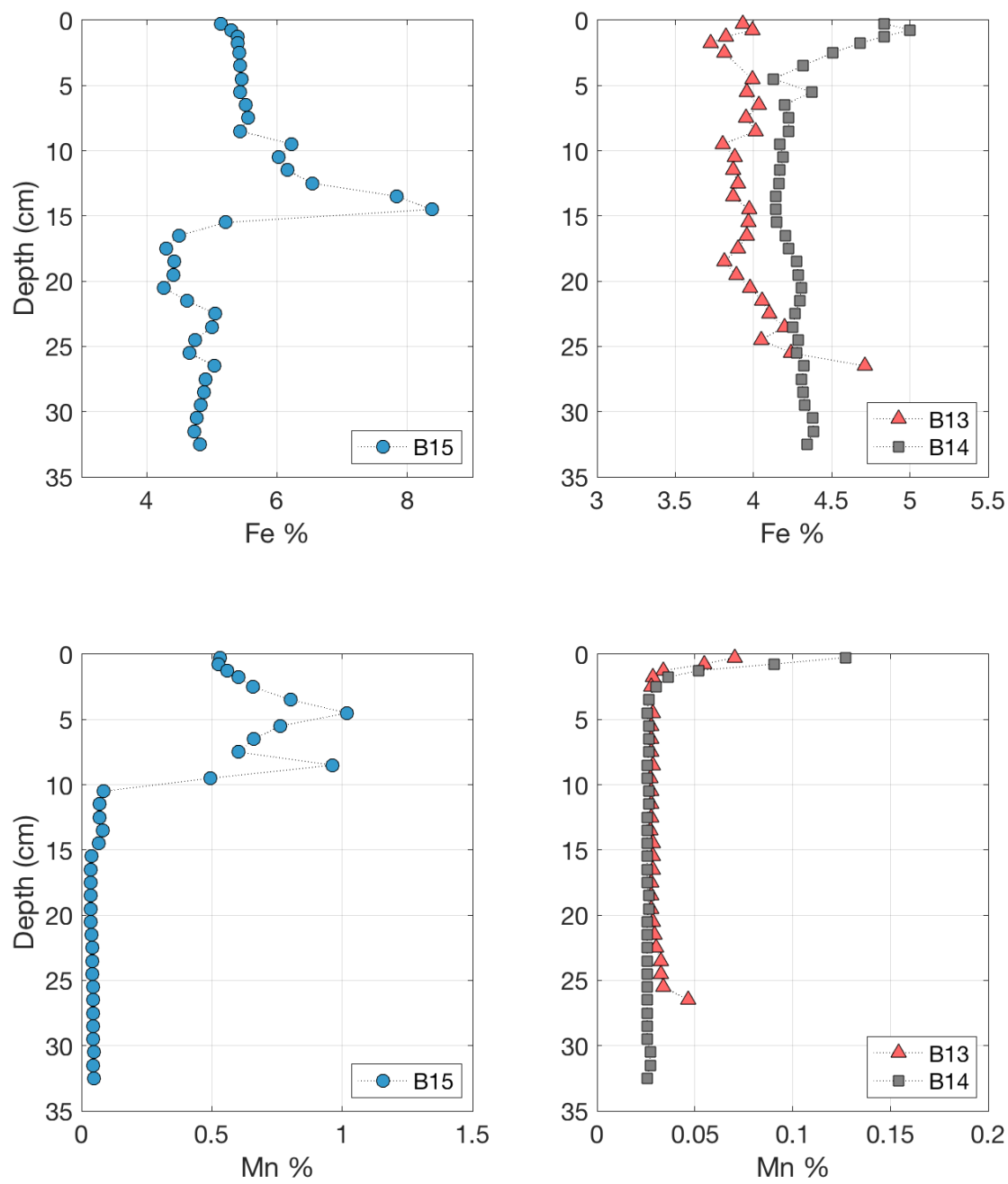

Figure S12: Solid phase Mn and Fe content measured by XRF. Note the scale change between the stations and elements. The increased Fe content between 12-15 cm at station B15 represents a pink, Fe-rich sediment band, hosting an increased content of crystalline Fe phases relative to the surrounding sediment layers. The sediments deposited within this pink band are thought to originate from Devonian sandstones in central Svalbard (Faust etal., 2021). XRF analysis was carried out using a Philips PW-2400 WD-X-ray fluorescence spectrometer at the University of Oldenburg. Analytical precision and accuracy were better than 5\%. Solid phase Fe and Mn data can be found in the main text and supplementary information respectively of Faust etal. (2021). 


\section{References}

Bourgeois, S., Archambault, P., Witte, U., 2017. Organic matter remineralization in marine sediments: A Pan-Arctic synthesis. Global Biogeochem. Cycles 31 (1), 190-213.

Cassarino, L., 2018. From micro to macro: silicon isotope fractionation during biogenic opal formation. Ph.D. thesis, University of Bristol.

Cassarino, L., Hendry, K. R., Henley, S. F., MacDonald, E., Arndt, S., Freitas, F. S., Pike, J., Firing, Y. L., 2020. Sedimentary Nutrient Supply in Productive Hot Spots off the West Antarctic Peninsula Revealed by Silicon Isotopes. Global Biogeochem. Cycles 34 (12).

Conley, D. J., 1998. An interlaboratory comparison for the measurement of biogenic silica in sediments. Mar. Chem. 63 (1-2), 39-48.

De La Rocha, C. L., Brzezinski, M. A., DeNiro, M. J., 1997. Fractionation of silicon isotopes by marine diatoms during biogenic silica formation. Geochim. Cosmochim. Acta 61 (23), $5051-5056$.

DeMaster, D., 1981. The supply and accumulation of silica in the marine environment. Geochim. Cosmochim. Acta 45 (10), 1715-1732.

Dutkiewicz, A., Müller, R. D., O’Callaghan, S., Jónasson, H., 2015. Census of seafloor sediments in the world's ocean. Geology 43 (9), 795-798.

Faust, J. C., Tessin, A., Fisher, B. J., Zindorf, M., Papadaki, S., Hendry, K. R., Doyle, K. A., März, C., 2021. Millennial scale persistence of organic carbon bound to iron in Arctic marine sediments. Nat. Commun. 12 (275).

Flower, R. J., 1993. Diatom preservation: experiments and observations on dissolution and breakage in modern and fossil material. Hydrobiologia 269, 473-484.

Freitas, F. S., Hendry, K. R., Henley, S. F., Faust, J. C., Tessin, A. C., Stevenson, M. A., Abbott, G. D., März, C., Arndt, S., 2020. Benthic-pelagic coupling in the Barents Sea: an integrated data-model framework. Philos. Trans. Royal Soc. A 378 (2181). 
Frings, P., 2017. Revisiting the dissolution of biogenic Si in marine sediments: a key term in the ocean Si budget. Acta Geochim. 36, 429-432.

Grasse, P., Brzezinski, M. A., Cardinal, D., De Souza, G. F., Andersson, P., Closset, I., Cao, Z., Dai, M., Ehlert, C., Estrade, N., François, R., Frank, M., Jiang, G., Jones, J. L., Kooijman, E., Liu, Q., Lu, D., Pahnke, K., Ponzevera, E., Schmitt, M., Sun, X., Sutton, J. N., Thil, F., Weis, D., Wetzel, F., Zhang, A., Zhang, J., Zhang, Z., 2017. GEOTRACES inter-calibration of the stable silicon isotope composition of dissolved silicic acid in seawater. J. Anal. At. Spectrom. 32 (3), 562-578.

Hendry, K. R., Robinson, L. F., 2012. The relationship between silicon isotope fractionation in sponges and silicic acid concentration: Modern and core-top studies of biogenic opal. Geochim. Cosmochim. Acta 81, 1-12.

Kamatani, A., Oku, O., 2000. Measuring biogenic silica in marine sediments. Mar. Chem. 68 (3), 219-229.

Liguori, B. T., Ehlert, C., Pahnke, K., 2020. The Influence of Water Mass Mixing and Particle Dissolution on the Silicon Cycle in the Central Arctic Ocean. Front. Earth Sci. 7 (202).

März, C., Meinhardt, A. K., Schnetger, B., Brumsack, H. J., 2015. Silica diagenesis and benthic fluxes in the Arctic Ocean. Mar. Chem. 171, 1-9.

McManus, J., Hammond, D. E., Berelson, W. M., Kilgore, T. E., Demaster, D. J., Ragueneau, O. G., Collier, R. W., 1995. Early diagenesis of biogenic opal: Dissolution rates, kinetics, and paleoceanographic implications. Deep. Res. II 42 (2-3), 871-903.

Michalopoulos, P., Aller, R. C., 2004. Early diagenesis of biogenic silica in the Amazon delta: Alteration, authigenic clay formation, and storage. Geochim. Cosmochim. Acta $68(5), 1061-1085$.

Mortlock, R. A., Froelich, P. N., 1989. A simple method for the rapid determination of biogenic opal in pelagic marine sediments. Deep. Res. A 36 (9), 1415-1426. 
Ng, H. C., Cassarino, L., Pickering, R. A., Woodward, E. M. S., Hammond, S. J., Hendry, K. R., 2020. Sediment efflux of silicon on the Greenland margin and implications for the marine silicon cycle. Earth Planet. Sci. Lett. 529 (115877).

Pickering, R., 2020. Silica Cycling at the Sediment Water Interface of Coastal Systems. Ph.D. thesis, The University of South Alabama College of Arts and Sciences.

Pickering, R., Cassarino, L., Hendry, K., Wang, X., Maiti, K., Krause, J., 2020. Using Stable Isotopes to Disentangle Marine SedimentarySignals in Reactive Silicon Pools. Geophys. Res. Lett. 47 (15).

Price, N. B., Brand, T., Pates, J. M., Mowbray, S., Theocharis, A., Civitarese, G., Miserocchi, S., Heussner, S., Lindsay, F., 1999. Horizontal distributions of biogenic and lithogenic elements of suspended particulate matter in the Mediterranean Sea. Prog. Oceanogr. 44 (13), 191-218.

Ragueneau, O., Savoye, N., Del Amo, Y., Cotten, J., Tardiveau, B., Leynaert, A., 2005. A new method for the measurement of biogenic silica in suspended matter of coastal waters: Using Si:Al ratios to correct for the mineral interference. Cont. Shelf Res. 25, 5-6.

Ragueneau, O., Tréguer, P., 1994. Determination of biogenic silica in coastal waters: applicability and limits of the alkaline digestion method. Mar. Chem. 45 (1-2), 43-51.

Reynolds, B. C., Aggarwal, J., André, L., Baxter, D., Beucher, C., Brzezinski, M. A., Engström, E., Georg, R. B., Land, M., Leng, M. J., Opfergelt, S., Rodushkin, I., Sloane, H. J., Van Den Boorn, S. H., Vroon, P. Z., Cardinal, D., 2007. An inter-laboratory comparison of Si isotope reference materials. J. Anal. At. Spectrom. 22 (5), 561-568.

Rickert, D., 2000. Dissolution kinetics of biogenic silica in marine environments. Ph.D. thesis, Christian-Albrecht University of Kiel.

Sutton, J. N., Varela, D. E., Brzezinski, M. A., Beucher, C. P., 2013. Species-dependent silicon isotope fractionation by marine diatoms. Geochim. Cosmochim. Acta 104, 300309. 